\title{
Percutaneous dilatational tracheotomy
}

Citation for published version (APA):

van Heurn, L. W. E. (1997). Percutaneous dilatational tracheotomy. [Doctoral Thesis, Maastricht University]. Universiteit Maastricht. https://doi.org/10.26481/dis.19970228lh

Document status and date:

Published: 01/01/1997

DOI:

10.26481/dis.19970228Ih

Document Version:

Publisher's PDF, also known as Version of record

\section{Please check the document version of this publication:}

- A submitted manuscript is the version of the article upon submission and before peer-review. There can be important differences between the submitted version and the official published version of record.

People interested in the research are advised to contact the author for the final version of the publication, or visit the DOI to the publisher's website.

- The final author version and the galley proof are versions of the publication after peer review.

- The final published version features the final layout of the paper including the volume, issue and page numbers.

Link to publication

\footnotetext{
General rights rights.

- You may freely distribute the URL identifying the publication in the public portal. please follow below link for the End User Agreement:

www.umlib.nl/taverne-license

Take down policy

If you believe that this document breaches copyright please contact us at:

repository@maastrichtuniversity.nl

providing details and we will investigate your claim.
}

Copyright and moral rights for the publications made accessible in the public portal are retained by the authors and/or other copyright owners and it is a condition of accessing publications that users recognise and abide by the legal requirements associated with these

- Users may download and print one copy of any publication from the public portal for the purpose of private study or research.

- You may not further distribute the material or use it for any profit-making activity or commercial gain

If the publication is distributed under the terms of Article $25 \mathrm{fa}$ of the Dutch Copyright Act, indicated by the "Taverne" license above, 


\title{
Percutaneous dilatational tracheotomy
}

\author{
PROEFSCHRIFT
}

ter verkrijging van de graad van doctor aan de Universiteit Maastricht,

op gezag van de Rector Magnificus, Prof. Mr. M.J. Cohen, volgens het besluit van het College van Decanen, in het openbaar te verdedigen op vrijdag 28 februari 1997 om 14.00 uur

door

Jonkheer Lodewijk Willem Ernest van Heurn

geboren op 30 mei 1961 te Haarlem 


\section{Promotor}

Prof. Dr. G. Kootstra

\section{Co-promotores \\ Dr . P.R.G. Brink \\ Dr. G. Ramsay}

\section{Beoordelingscommissie}

Prof. Dr. J.J. Manni (voorzitter)

Prof. Dr. J. Drukker

Prof. Dr. S. De Lange

Prof. Dr. C.J. van der Linden (Katholieke Universiteit Nijmegen)

Prof. Dr. A. Pesenti (Universita di Milano)

Part of the studies described and the publication of this thesis were supported financially by:

Stichting De Drie Lichten, Stichting Wetenschappelijk Onderzoek Assistenten Heelkundige Specialismen, Stichting Prof. Michaël-van Vloten Fonds, Cook BV, Laméris BV, Van Straten Medische Techniek BV, Glaxo BV, Sandoz BV, Sorin Biomedica Nederland NV, TD Medical, SmithKline Beecham Farma BV, and West Meditec BV. 
To my parents

For Lonneke 


\section{Contents}

1 Percutaneous dilatational tracheotomy: general overview 5

1.1 Introduction 6

1.2 Anatomy of the trachea 6

1.3 The indications for percutaneous dilatational tracheotomy 9

1.4 The technique of percutaneous dilatational tracheotomy 11

1.5 The complications of percutaneous dilatational tracheotomy 16

1.6 Percutaneous dilatational versus conventional open tracheotomy 25

$\begin{array}{lll}1.7 & \text { Percutaneous tracheotomy: other techniques } & 27\end{array}$

2 The history of tracheotomy 39

3 Clinical experience with percutaneous dilatational tracheotomy: report of 150 cases

4 Percutaneous subcricoid minitracheotomy: report of 50 procedures

5 Late complications of percutaneous dilatational tracheotomy

6 Pathologic changes of the trachea after percutaneous dilatational tracheotomy

7 Percutaneous dilatational versus conventional open tracheotomy in a growing animal: a study in goats

8 A complication of percutaneous dilatational tracheotomy: mediastinal emphysema

Summary and conclusions

Samenvatting en conclusie

Acknowledgements

Curriculum vitae 
Chapter 1

\section{Percutaneous dilatational tracheotomy}

General overview 


\subsection{Introduction}

Percutaneous dilatational tracheotomy (PDT) is a procedure for inserting a cannula into the tracheal lumen without a large incision, without extensive dissection of pretracheal tissue and without exposure of the trachea.

The objective of the thesis is to analyse the early results of this technique and of the smaller, but otherwise similar minitracheotomy. The late results of the operation as well as damage on the trachea are examined. The indications and contraindications of the technique are looked at, particularly its use in children. To make the thesis more useful for everyday practice a short overview is given of the relevant anatomy, the indications for tracheotomy, the technique of the percutaneous operation, its complications, and its comparison with conventional open tracheotomy and other percutaneous tracheotomy techniques.

\subsection{The anatomy of the trachea}

\section{Macroscopical anatomy}

The trachea is a tube that connects the larynx with the mainstem bronchi. It extends from the inferior border of the cricoid cartilage, the most narrow rigid part of the upper airways, to the origin of the two main bronchi.

In the adult it is 10 to $13 \mathrm{~cm}$ long (average $12 \mathrm{~cm}$ ). It is composed of 16 to 22 incomplete cartilaginous rings which are completed posteriorly by fibrous tissue and smooth muscle [1].

The coronal diameter of the lumen is 13 to $25 \mathrm{~mm}$ in the adult male and 10 to $21 \mathrm{~mm}$ in the adult female. The sagittal diameter measures 13 to $27 \mathrm{~mm}$ and 10 to $23 \mathrm{~mm}$, respectively $[2,3]$.

The cross-sectional area of the tracheal lumen measures an average of $2.8 \mathrm{~cm}^{2}$ in the third decade of life increasing up to $3.2 \mathrm{~cm}^{2}$ in the sixth decade due to age-dependent loss in elastic recoil of the tracheal wall $[4,5]$. The cross-sectional area of the average adult man is $40 \%$ greater than of the average adult female. Tracheal length, diameter and cross-sectional area all correlate with total body-height [6]. Both size and shape of particularly the extrathoracic portion of the trachea are responsive to moderate changes of intraluminal pressure, with a large increase of the cross-sectional area and a smaller increase of the tracheal length [7].

In the newborn the trachea measures 4 to $5 \mathrm{~cm}$ with an inside diameter of 3 to $4 \mathrm{~mm}$, in both boys and girls. Tracheal growth is proportionally greatest in infancy $[8,9]$. The adult tracheal diameters are usually reached at age 15 years 
in females, while the tracheal dimensions of some males probably not have reached their plateaus by age 20 years $[10,11]$. In children the trachea is soft and pliable. It becomes more rigid in adults and with increasing age the cartilaginous rings can calcify and even ossify.

\section{Histology}

The tracheal lumen is covered by ciliated pseudostratified columnar epithelium with approximately 200 cilia on each epithelial cell [12]. These beat continually at a rate of 10 to 20 times per second propelling mucus and foreign bodies towards the larynx. The epithelium contains numerous goblet cells that secrete mucus coating the entire tracheal surface [13]. The lamina propria lies under the epithelium separated by a thick basement lamina. It contains lymphatic tissue, an abundance of elastic fibres and up to 4000 serous and mucous glands, opening by short ducts on the surface of the epithelium. The glands are usually external to the elastic fibres [14]. Posteriorly, they extend through the muscular layer.

The supporting framework of the trachea consists of a hyaline cartilage with surrounding perichondrium that is mainly composed of collagen with some elastic fibres. These cartilages encircle the trachea on its ventral and lateral aspects. The posterior aspect consists of a layer of smooth muscle fibres, which mainly run transversely [15]. They are inserted into the elastic fibres surrounding the cartilage and into the mucous membrane by a layer of loose connective tissue.

Fibro-elastic tissue in the interspace between the cartilaginous rings makes the trachea more pliable and extensible. The outer surface of the trachea also consists of fibro-elastic tissue.

\section{Topography of the trachea and related structures}

The trachea runs in the midline, except distally where it deviates slightly to the right. In the adult it begins at the level of $\mathrm{C} 6$ and bifurcates at the upper level of T5 or more practically at the manubrio-sternal angle. It recedes from the surface as it passes downwards from the level of the cricoid cartilage, where it lies subcutaneously, to the carina. Approximately one third of the trachea (4 to 6 tracheal rings) is a cervical structure, lying above the incisura jugularis sterni. After hyperextension of the neck a part of the intrathoracic trachea moves into the neck, and with flexion of the neck most of the trachea becomes a mediastinal structure.

Both in the neck and in the thorax the trachea lies in close apposition to other structures. Anterolaterally, the cervical trachea lies between the thyroid gland with the isthmus overlying the second to fifth tracheal rings [16]. The 
thyroid gland is closely attached to the cricoid and the trachea by a band of dense connective tissue. Inferior to the thyroid gland, anterior to the trachea is a venous plexus, formed by the inferior thyroid veins, and occasionally a small thyroid ima artery. Intrathoracally the ascending aorta is anterior to the trachea. The brachiocephalic trunk (innominate artery) and the left common carotid artery, are anterior at first and then on the right and left side of the trachea, respectively.

Anterior to the cervical portion of the trachea and the thyroid gland are the superficial sternohyoid muscles and the deeper sternothyroid muscles. They are crossed by the jugular arch, a communicating branch of both anterior jugular veins and are in close relation with the cervical fascia, which can be divided into three parts [17-19]. The superficial layer of the cervical fascia lies under the platysma and encloses the sternocleidomastoid muscle. The pretracheal layer of the cervical fascia encloses the strap muscles, thyroid gland, trachea, pharynx and the large neck vessels. The prevertebral layer of the cervical fascia lies posterior to the oesophagus and the large neck vessels. The space it encloses has a direct connection with the posterior mediastinum. The space between the pretracheal layer and the prevertebral layer of the cervical fascia communicates freely with the anterior mediastinum as the space between the superficial layer and the pretracheal layer is closed inferiorly by the sternum.

Posterior to the trachea lies the oesophagus. The recurrent laryngeal nerve runs on each side near the trachea and the oesophagus, often in the tracheooesophageal groove. Its position, however, is variable. Lateral to both lobes of the thyroid gland, which enclose the trachea, lies on either side the carotid sheath enclosing the common carotid artery, the internal jugular vein and the vagal nerve.

The larynx is the part of the airways between the pharynx and the trachea. It consists of hyaline cartilages, the thyroid, the cricoid and the arytenoid cartilages, and a fibrous cartilage, the epiglottis [16]. The hyaline cartilages ossify during life starting with the thyroid cartilage at the time of puberty. The cricoid and arytenoid cartilages calcify somewhat later. The ossification of the male larynx is considerably earlier than the female larynx. For clinical purposes the larynx is divided in the supraglottis, the glottis and the subglottis. The supraglottis consists of the epilarynx, the laryngeal surface of the epiglottis, the aryepiglottic fold and the arytenoid, and the vestibule, the petiolus of the epiglottis, the vestibular folds and the upper part of the ventricle. The glottis consists of the vocal cords and the area $1 \mathrm{~cm}$ inferior to it; the subglottic space goes down to the lower border of the cricoid cartilage, the top end of the trachea. 


\section{Vascularisation of the trachea}

The cervical trachea is supplied with blood mainly by the inferior thyroid arteries $[20,21]$. Proximally, they anastomose with superior thyroid arteries which themselves have no direct branches to the trachea. In the thorax the trachea is vascularised by branches of the supreme intercostal arteries, the subclavian arteries, the right internal thoracic artery and the superior and middle bronchial arteries [20]. Branches of the main arteries, the tracheooesophageal arteries, divide in a tracheal branch and a oesophageal branch. The tracheal branches pass directly to the lateral tracheal wall where they anastomose to form the lateral longitudinal anastomosis.

From the lateral longitudinal anastomosis segmental intercartilaginous arteries segmentally vascularise the trachea [22]. They divide in a large anterior branch, the anterior transverse intercartilaginous artery, and a smaller posterior branch, the posterior transverse intercartilaginous artery. In the anterior midline the anterior branch anastomoses with the artery of the opposite side. By this time the arteries have become a submucosal capillary plexus. The smaller posterior intercartilaginous branches end at the junction of the cartilaginous and membranous part of the trachea. The vascularisation of the posterior membranous portion of the trachea stems from the primary oesophageal branches of the tracheo-oesophageal arteries with well developed longitudinal anastomoses between the various levels [22].

The lateral and anterior submucosal capillary plexus, fed by the transverse intercartilaginous arteries, is related to the endotracheal surface of the cartilaginous rings [22]. There is no important capillary plexus on the outer side of the rings. Posteriorly, the submucosal capillary plexus is fed by the oesophageal branches.

\subsection{Indications for percutaneous dilatational tracheotomy}

The main indications for tracheotomy are prolonged ventilation, weaning from ventilatory support, bronchial toilet, and upper airway obstruction $[23,24]$.

There is no common opinion when a tracheotomy should be done in ventilated patients $[25,26]$. Some authors prefer prolonged translaryngeal intubation because of the high complication rate of tracheotomy and because of the high incidence of bacterial colonisation of the tracheobronchial tree with tracheobronchial or pulmonary infection [27-33].

A prospective study of El-Naggar et al. showed more frequent and severe airway lesions and a greater incidence of contamination of the airway by new organisms after tracheal cannulation three days after oral intubation than after 
tracheotomy on the tenth day in patients with acute respiratory failure [34]. Dunham and LaMonica found no differences between early and late tracheotomy in a similar group of patients [35]. More recently Rodriguez et al. found a shorter duration of ventilatory support and a shorter hospital stay after early tracheotomy in trauma patients who required mechanical ventilation [36]. They also reported a significantly lower incidence of pneumonia in patients with a tracheotomy within two days after oral intubation than on the third day or later.

Others, who claim a low complication rate of (conventional) tracheotomy, also advocate early tracheotomy because an early tracheal cannula protects against further laryngeal injury from the translaryngeal tube, facilitates mouth care, improves comfort, facilitates oral nourishment and provides psychological benefit [37-42]. Also, ventilator-dependent patients may tolerate weaning attempts better when spontaneously breathing through a tracheal cannula because of a lower airway resistance than a translaryngeal tube and a tracheal cannula gives a reduction of the ventilatory dead space $[43,44]$.

In 1986 the American College of Chest Physician's Council on Critical Care recommended translaryngeal intubation for patients requiring assisted ventilation for less than 7 days, but a tracheotomy if on the seventh day extubation could not be foreseen in the next few days [45]. Three years later a consensus meeting on artificial airways in patients receiving mechanical ventilation recommended the translaryngeal route of intubation for anticipated need of the artificial airway up to ten days and a tracheotomy if an artificial airway for more than 21 days was anticipated [46]. In 1991 Heffner advised in a review article about the timing of tracheotomy a tracheotomy in ventilator-dependent patients if the anticipated duration of intubation exceeded two to three weeks. The patients undergo daily evaluation starting on the first day after intubation to avoid unnecessary delay of an inevitable tracheotomy [26].

A tracheotomy can be used to evacuate bronchial secretions in patients who are not able to cough up their own sputum. These secretions are generally aspirated with the help of a minitracheotomy cannula [47-50]. This cannula with an inner diameter of four $\mathrm{mm}$ is usually introduced through the cricothyroid membrane either as an open procedure or percutaneously with the help of a guide wire, but can be inserted into the trachea in the subcricoid position [5153]. If this mini-cannula is too small to evacuate viscid bronchial secretions a full sized cannula with an inside diameter of six mm or more can be introduced $[53,54]$.

Tracheotomy can be necessary if there is an upper airway obstruction caused by facial trauma, infection or malignancy of the pharynx or the larynx, laryngeal or subcricoid stenosis, or bilateral recurrent laryngeal nerve paralysis. If there is an acute complete supraglottic airway obstruction and transla- 
ryngeal intubation is not possible cricothyroidotomy is recommended [55-60]. The complications of emergency conventional tracheotomy are high and emergency is one of the contraindications for percutaneous dilatational tracheotomy [61-63].

Young age is one of the generally accepted contraindications for percutaneous tracheotomy. However, it has been used successfully in teenagers and adolescents $[64,65]$. In baby goats percutaneous dilatational tracheotomy gave significantly less tracheal stenosis after than conventional tracheotomy [66]. However, the available instruments on the commercially available set are too large for safe use in infants and toddlers.

Morbid obesity, a short thick neck and goitre were initially contraindications for percutaneous tracheotomy because the anatomic landmarks were obscured. When surgeons became familiar with the technique these factors became less of a contraindication and percutaneous dilatational tracheotomy became the preferred method of tracheotomy in patients with difficult anatomy at many institutions $[65,67]$. In these patients endoscopy and ultrasound may be helpful to puncture the tracheal lumen and to avoid guidewire dislodgement and false passage $[68,69]$.

Other, relative, contraindications for percutaneous tracheotomy include bleeding and clotting disorders and cardiopulmonary instability $[62,63,65]$.

\subsection{The technique of percutaneous dilatational tracheotomy}

\section{Equipment}

The disposable percutaneous introducer kit, as supplied by $\mathrm{Cook}^{\infty}$ (Cook Medical Company, Son, The Netherlands) consists of a disposable scalpel (No15 blade), a Teflon ${ }^{\star}$ introducer needle, a translucent syringe, a J-tipped 0.052 inch coated stainless steel guide wire, a Teflon ${ }^{\star}$ introducing dilatator, a Teflon guiding catheter, seven tapered dilatators (12-, 18-, 21-, 24-, 28-, 32- and 36French) and lubricating gelly (Figure 1).

Further equipment for the procedure includes a tracheotomy cannula (In adults we almost always used a No.8, $12 \mathrm{~mm}$ outside diameter, Shiley cannula (Laméris, Veenendaal, The Netherlands) and, if the procedure is not carried out under general anaesthesia, a syringe with lidocaine 1\%. Reintubation equipment, a laryngoscope and an endotracheal tube should be available.

The procedure is carried out by a surgeon inserting the tracheotomy cannula and an anaesthetist to monitor the patients bloodpressure and percutaneous oxygen saturation, to withdraw the endotracheal tube and to control the patients upper airway. 


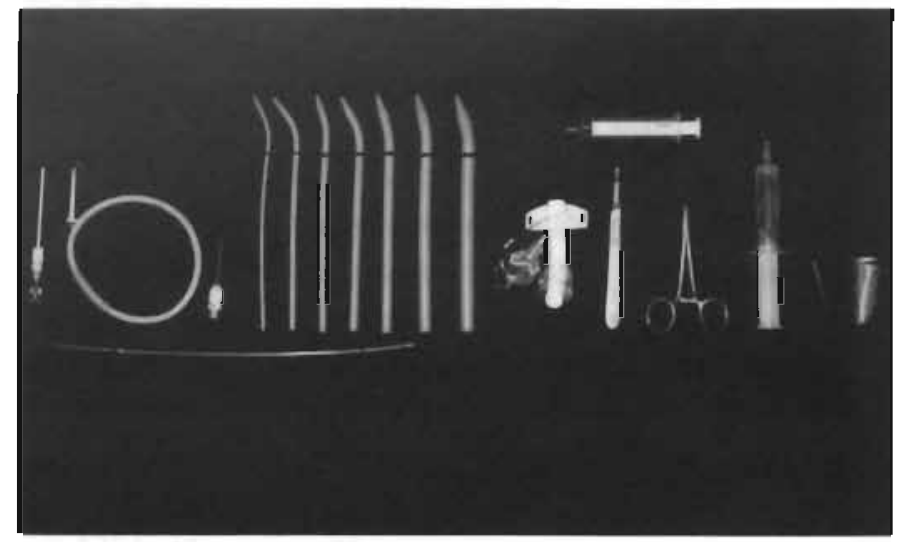

Figure 1. The equipment used for percutaneous dilatational tracheotomy

\section{Preparation}

The position of the trachea on the chest X-ray is assessed and the patient's coagulation profile is checked. The stomach should be empty for the procedure.

The patient is placed with moderate hyperextension of the neck, so that the thyroid cartilage, the cricoid cartilage, and the upper tracheal rings are palpable or can be palpated after dissection of the pretracheal fascia. The patient is prepared with antiseptic solution and draped, after he has been anaesthetised. In ventilated patients the inspiratory oxygen fraction $\left(\mathrm{FiO}_{2}\right)$ is increased to 1.0 . The cuff of the tracheal cannula is checked by the inflation and deflation of air. If the procedure is carried out under local anaesthesia the skin is infiltrated with lidocaine $1 \%$.

\section{Technique [62,63,70-72]}

A $2 \mathrm{~cm}$ longitudinal skin incision is made one $\mathrm{cm}$ below the lower edge of the cricoid cartilage, the landmark for the localisation of the procedure. After the removal of secretions from the mouth and the pharynx with a suction catheter, the cuff of the orotracheal tube, if present, is deflated and the tube is withdrawn with its tip just below the vocal cords, approximately at a distance of approximately $18 \mathrm{~cm}$ from the teeth. The cuff is inflated again so that the air leak can be minimised by pushing the cuff against the vocal cords.

The trachea is punctured with a cannulated needle and an attached syringe when the level of the puncture site between the first and second, or preferably between the second and third tracheal ring can be palpated with the index finger. If the anatomic structures are obscure the pretracheal fascia is bluntly dissected in the midline with a curved mosquito clamp. Possible bleeding is tamponaded with gauzes. The cannulated needle is directed at an almost right 
angle to the skin and thus only slightly caudally in relation to the trachea. As the needle is advanced into the tracheal lumen, air is aspirated with the syringe (Figure 2).

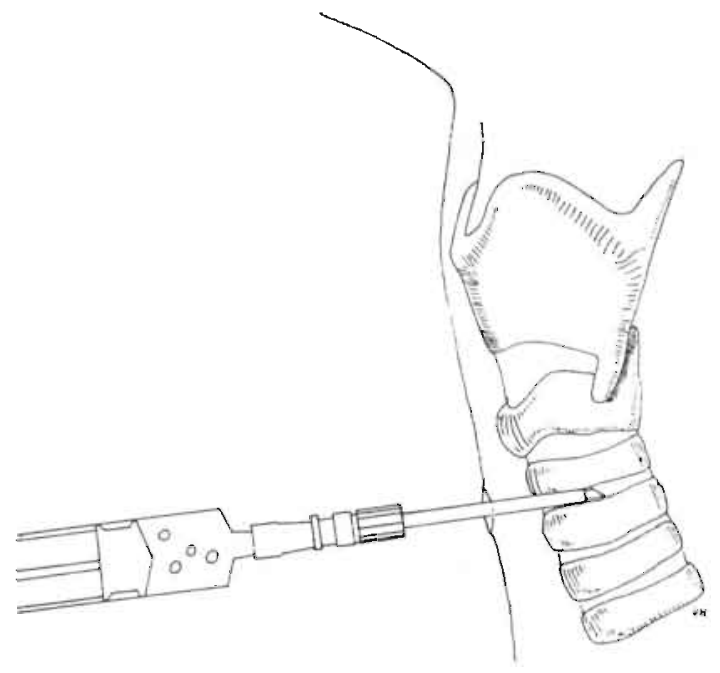

Figure 2. The trachea is punctured with a cannulated needle

The endotracheal tube is gently rotated and oscillated to ensure that the needle has not impaled the tube. The needle is pulled back and the catheter advanced into the tracheal lumen. Its intraluminal position is confirmed again by the suction of air into the newly attached syringe. Then, the guide wire is introduced through the catheter, which is removed (Figure 3).

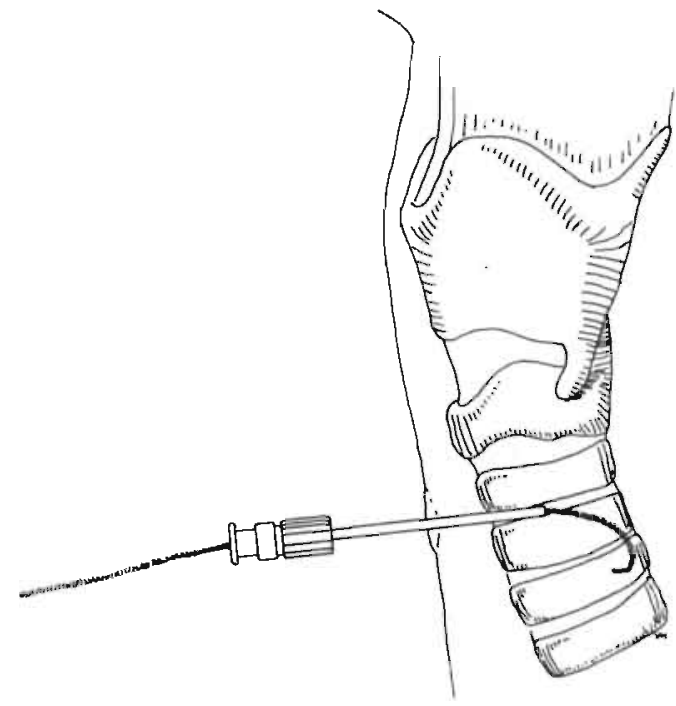

Figure 3. A guide wire is introduced into the tracheal lumen 
The snaall Teflon dilatator is placed over the guide wire and removed again. This makes placement of the Teflon ${ }^{\star}$ guiding catheter possible: the double black marks and the small ridge of the guiding catheter are nearest to the tracheal opening. It is advanced over the wire until the end of the guiding catheter is at the same level as the soldermark on the guide wire and it has to be kept at this level.

The tapered dilatators are lubricated and sequently placed over the guide wire-catheter complex and advanced to the ridge on the catheter (Figure 4).

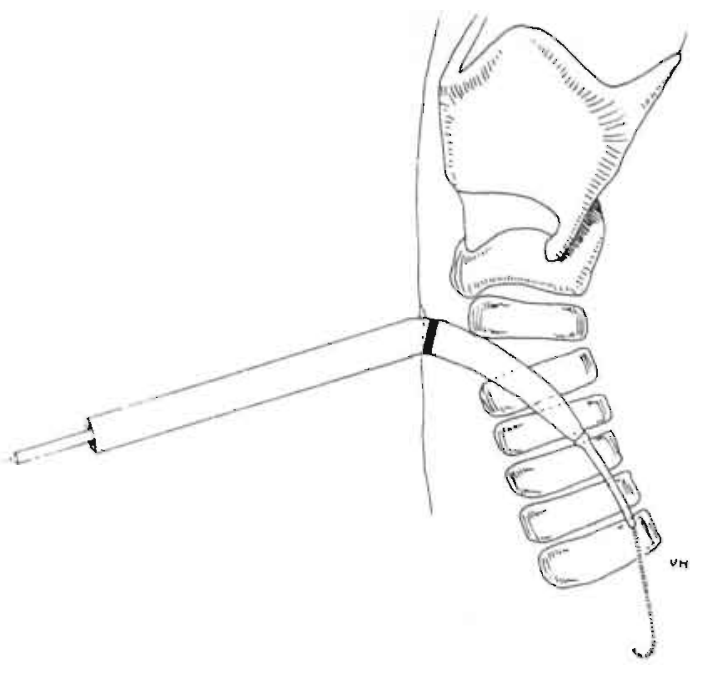

Figure 4. The opening into the trachea is dilated over the guide wire

The whole system (wire-catheter-dilatator) is pushed into the trachea with a rocking motion for two or three times, until its resistance diminishes. The black marks on the dilatators should not be advanced beyond the skin level. After each dilatational step the dilatator is replaced by a larger one and the trachea is dilated with a semi circular rocking movement of the hand which has to follow the shape of the dilatators. When the dilatation has been completed the largest dilatator remains in situ so that the patient can be ventilated without airleak and without the possibility of blood running down into the tracheal lumen, while the tracheal cannula is loaded on the appropriately sized dilatator (for a No.8 cannula, a 28-French dilatator is needed). Care is taken not to damage the tip of the dilatator with the holes of the cannula if a fenestrated cannula is used. The lubricated dilatator-cannula complex is positioned over the guide wire-catheter complex when the largest dilatator has been removed from the tract. It is pushed into the trachea with firm pressure (Figure 5). 


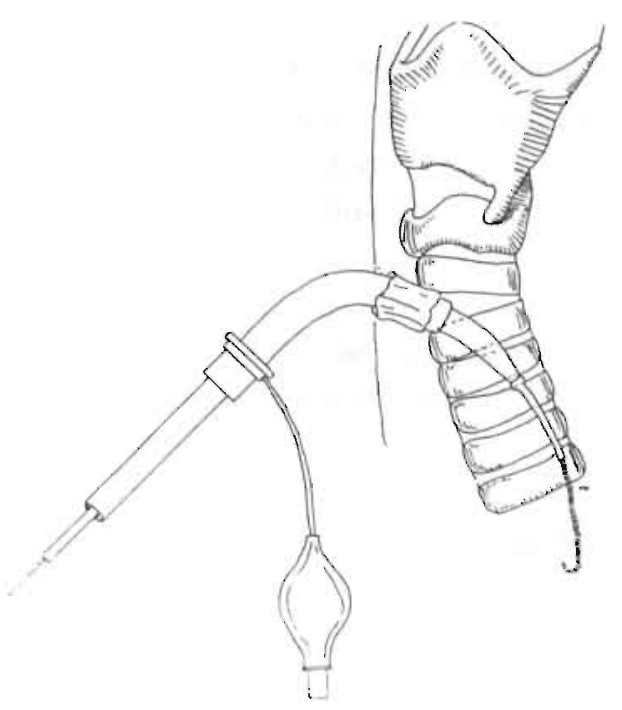

Figure 5. A tracheal cannula is introduced over the guide wire and an appropriately sized dilatator

This pressure should not be used too far downwards, because this can result in kinking of the guide wire-catheter complex with a pretracheal placement of the cannula. Some rotational movements make introduction more easy. There may be a small ridge between the cannula and the dilatator that prevents smooth introduction between two tracheal rings. The latest dilatational step may be repeated and it should be checked if the introduction of the cannula is not hindered by the pretracheal fascia. If so, this fascia may be incised. If it remains impossible to insert a full sized cannula, a smaller cannula should be tried. After insertion of the cannula into the tracheal lumen, the wire, catheter and dilatator are removed. The inner cannula of the tracheotomy is placed inside the outer cannula and the cuff of the cannula is inflated to prevent airleak and the leakage of blood from the wound into the bronchi and the lungs.

The trachea and bronchi are cleared from blood and secretions with bronchial suction. The ventilator is attached to the cannula. The tracheotomy ties are applied, the breath sounds are checked and a chest X-ray is taken.

Endoscopic assistance can be used to verify correct placement of the needle into the tracheal lumen, guide wire insertion, dilatation and cannulation during the procedure $[68,69]$.

\section{Minitracheotomy [53]}

Commercially available kits as supplied by $\mathrm{Cook}^{\otimes}$ and Portex ${ }^{\otimes}$ contain a disposable scalpel, an cannulated needle, a J-tipped guidewire, a dilatator, and a reclosable flanged minitracheotomy cannula with an inside diameter of $4 \mathrm{~mm}$.

The technique is similar to the percutaneous dilatational tracheotomy technique and the procedure is usually carried out with local anaesthesia. A 
small vertical skin incision is made and the trachea is punctured preferably below the first tracheal ring with a (cannulated) needle attached to a syringe. The intratracheal position of the needle is confirmed by the aspiration of air into the syringe. A guide wire is placed inside the trachea. The minitracheotomy cannula, loaded over the dilatator, is passed over the guide wire into the tracheal lumen using firm pressure. The guide wire and dilatator are removed and the tracheotomy ties applied. To facilitate the introduction of the cannula, we currently use a second larger dilatator that has been added to the set.

\subsection{The complications of percutaneous dilatational tracheotomy}

The complications of percutaneous dilatational tracheotomy (PDT) can be separated into three groups: firstly, complications of the operative procedure itself and complications that are directly attributed to the procedure, secondly, complications during cannulation and thirdly, complications after decannulation (late complications).

There are several other techniques to insert a tracheal cannula percutaneously [73-84]. This chapter discusses the most common complications of PDT only. The pros and cons of other percutaneous tracheotomy techniques are reported in chapter 1.6 .

\section{Mortality}

The mortality of percutaneous dilatational tracheotomy is below $1 \%$. Until now three operative deaths have been reported in more than 1000 procedures $[65,67,69,85-96]$. Reported causes of operative death after percutaneous dilatational tracheotomy are: cardiac arrhythmia, bronchospasm and acute cardiac failure $[67,69,92]$. Many patients have died during the period of cannulation, but deaths were not attributable to the procedure or to the tracheal cannula. Two patients are reporteơ who died of a massive tracheal bleeding after tracheotomy presumably due to a tracheo-innominate artery fistula, and the cause of death was tracheotomy related $[91,97]$.

\section{Operative complications}

\section{CONVERSION}

Conversion from percutaneous dilatational to conventional open tracheotomy is rare. Two cases have been reported and comprise one patient with extensive ossification of his tracheal rings and one patient with a major venous bleeding 
that could not be controlled with local compression $[65,86]$.

Ciaglia described the inability to insert a size- 8 Shiley cannula with an outside diameter of $12 \mathrm{~mm}$ into the tracheal lumen, before the largest (36French) dilatator had been added to the set [89]. Particularly in young males it is sometimes difficult to push a size- 8 cannula into the trachea even after maximal dilatation of the tract with a 36 -French dilatator. Since the cannula usually does not fit tightly on the appropriately sized dilatator, there is a small ridge of the cannula that prevents smooth introduction of the cannula beyond the cartilaginous rings $[98,99]$. If introduction of a (size-8 Shiley) cannula proves to be impossible, it is helpful to insert a smaller cannula that can be replaced if required after two or three days for a larger (size-8) one. Also, a more flexible cannula can be used [84].

\section{HAEMORRHAGE}

Operative haemorrhage is the most common complication of percutaneous dilatational tracheotomy $[65,67,89,92]$. The incidence of significant bleeding of percutaneous dilatational tracheotomy is between $0 \%$ and $6 \%$. However, studies are difficult to compare because there are no consistent definitions of bleeding [65]. In the majority of the registered cases of bleeding it was considered minor and did not require therapy other than compression with gauzes.

Operative haemorrhage is often venous in origin. There are large veins in front of the trachea that are damaged easily and using percutaneous dilatational tracheotomy, primary haemostasis is not possible. High central venous pressure with congested veins may give an increased risk of procedural bleeding. Also, introduction below the second tracheal ring has the potential to cause bleeding from the thyroid isthmus [101]. Extensive blunt dissection of pretracheal tissue with a mosquito clamp may cause an additional risk of bleeding [102]. Other causes of bleeding include coagulation and bleeding disorders, attributable to medication (e.g. coumarin and non steroidal anti-inflammatory drugs), congenital diseases, kidney function disturbances with uraemia, liver function disturbances or sepsis with diffuse intravascular coagulation $[63,102,103]$.

No special measurements are necessary to avoid procedural bleeding other than correction of coagulation and clotting dysfunction. In patients with operative bleeding local compression with gauzes is usually sufficient to stop the bleeding. Any residual bleeding may be tamponaded when the cannula is installed into the tracheal lumen by compression of the pretracheal tissue on the cannula [91]. Suture ligation of large vessels and surgical exploration are seldom necessary.

One of the most dangerous complications of procedural bleeding is blood running down from the stoma into the bronchi [94]. Obstruction of one of the 
main bronchi or even the distal trachea by clots gives pulmonary atelectasis [104]. Severe hypoxia and even death may occur $[105,106]$. If there is a substantial operative bleeding it is advisable to put the patient in Trendelenburg (head down) position during dilatation of the stoma. Immediately after the procedure has finished, careful bronchial toilet is necessary to evacuate blood and clots from the respiratory tract.

\section{TRANSFIXATION OF THE TRANSLARYNGEAL TUBE}

Transfixation of the translaryngeal tube is a new complication of tracheotomy that is presented in case reports. During surgery the airway has to be shared between the operator and the anaesthetist. Because percutaneous tracheotomy is a blind procedure the cuff or the translaryngeal tube itself can be punctured with the introducer needle when its position is below the vocal cords $[107,108]$. This complication can become serious if there is a prolonged decrease of respiratory flow in patients with maximal oxygen requirements and if the cuff of the translaryngeal tube is torn and fragments are left in the trachea and bronchi [109].

Transfixation of the tube can be diagnosed in an early stage of the procedure by a twisting motion of the translaryngeal tube. This is impossible when the tube has been punctured with the needle. Other ways to prevent this complication are withdrawal of the tube under direct vision or with endoscopic guidance to confirm its position above the vocal cords and the use of a laryngeal mask $[104,108,110-113]$.

\section{MALPLACEMENT OF THE CANNULA}

The incidence of insertion of the cannula outside the tracheal lumen is below $1 \%$, while the incidence of a 'false route' during dilatational steps is slightly higher $[65,67,92]$.

Malplacement of the cannula is avoided by the use of a guide wire and a guiding catheter $[70,114]$. During dilatation of the tract it should be possible to move the guide wire freely [115]. If the intraluminal position of the guide wire is questionable, the Teflon sheath of the cannula needle is reintroduced over the wire [67]. When the wire has been removed the intraluminal position of the sheath is confirmed by the aspiration of air into the syringe. If its position is correct, the procedure can be continued, but if there is fear for a paratracheal tract, the trachea should be punctured again.

The trachea does not run in a horizontal plane, but particularly when the head is hyperextended it recedes from the surface as it passes downwards. If the cannula-dilatator complex is pointed too far distally, it may slide off on the anterior aspect of the trachea kinking the guide wire and the guiding catheter 
with as result a paratracheally located cannula.

Endoscopy is helpful to avoid incorrect placenent of the needle, dilatation outside the tracheal lumen and malplacement of the cannula $[68,69 \mid$. However, it is claimed that it makes ventilation more difficult because of tlow limitation through the translaryngeal tube by the presence of the fibreoptic scope 198,104,116]. Temporary hypoventilation and hypercarbia seem well tolerated by most patients. The effect of transient hypercarbia should be considered before performing endoscopic guided percutaneous tracheotomy on patients with evidence of elevated intracranial pressure [117]. Especially in the hands of inexperienced operators percutaneous tracheotomy under direct vision may avoid malplacement of the cannula and other rare but sometimes serious complications $[118,119]$.

\section{SUBCUTANEOUS AND MEDIASTINAL EMPHYSEMA}

The incidence of subcutaneous emphysema is below $2 \%$. Only one patient with mediastinal emphysema after percutaneous dilatational tracheotomy has been described until now [120].

There are four possible risk factors in the genesis of this complication. Multiple puncture sites and torn intercartilaginous tissue next to the cannula or laceration of the posterior tracheal wall may cause leakage of air which progression is stopped by the inflation of the tracheal cannula cuff $[84,121]$. The third etiological factor, lesions of the distal trachea and bronchi, is avoided by the use of a J-tip guide wire and tapered dilatators in the Cook ${ }^{*}$ kit (Cook Medical Company, Son, The Netherlands). Subcutaneous and mediastinal emphysema may develop during the cannulation procedure or afterwards during ventilation. Air is trapped by pretracheal tissue that fits snugly around the tracheotomy cannula, or subcutaneously when air dissects around the cannula and is trapped below the skin.

Subcutaneous emphysema is a self-limiting process that resolves spontaneously by the reabsorption of the trapped air. Its progression is stopped by inflating the cannula cuff if the tracheal lesion is above it. A small amount of air in the mediastinum requires no treatment, whereas large amounts may induce hemodynamic instability and require chest tube drainage [122].

\section{PNEUMOTHORAX}

The incidence of pneumothorax after PDT is between $0 \%$ and $2 \%$ in adults $[67,88]$. Direct damage to the pleura is rare although the dome of the pleura may be punctured and the cannula may even be installed into the pleural space [123]. To prevent this complication the trachea should be punctured in the midline and the needle should not be inserted too far downwards. 
Too deep an insertion of the guide wire into the smaller bronchi with the risk of pulmonary damage is avoided by soldermarks on the guide wire. If the guiding catheter is put between those marks, the position of the wire and the catheter in relation to the skin can be maintained easily. The risk of direct pulmonary damage is further decreased by the J-tip of the guide wire.

Extreme changes in transpleural pressures as a result of positive-pressure ventilation in patients with an intermittent air leak through an opening into the trachea that is opened and closed during dilatation, may lead to rupture of a bulla and unilateral or bilateral pneumothorax [124]. High ventilatory pressures due to an increase of the tidal volume to accommodating air leak through the tracheal opening and around the translaryngeal tube that is withdrawn, should be avoided $[107,114,125]$.

Malplacement of the cannula followed by positive pressure ventilation can lead to disastrous results $[121,126]$. Dissection of paratracheal tissue and bilateral tension pneumothorax may occur. If high ventilatory pressures are required immediately after insertion of a tracheal cannula its intraluminal position has to be confirmed by introducing a suction catheter or a guide wire. Tracheobronchoscopy may be helpful to check the position of the cannula and to evacuate bloodclots which may occlude one of the bronchi and may be also responsible for high ventilatory pressures $[68,69,104]$.

\section{Complications during cannulation}

\section{HAEMORRHAGE}

Haemorrhage that cannot be attributed to the operative procedure itself is particularly seen in patients with a haemostatic defect. Arterial or venous bleeding from vascular erosion by continuous movements of the cannula is rare because the cannula fits snugly in the surrounding tissue.

Secondary haemorrhage is treated by correction of the underlying defect. Seldom, suture ligation of the bleeding vessel is required.

\section{TRACHEO-INNOMINATE ARTERY FISTULA}

A tracheo-innominate artery fistula is a rare and devastating complication after tracheotomy causing massive haemorrhage [127]. After percutaneous dilatational tracheotomy it was the presumed cause of death in two patients with a massive haemorrhage after tracheotomy and it has occurred in an unreported case of a 13-year old child [92,98, Walz-personal communication].

The mechanism of injury is related to erosion of the innominate artery as result of pressure from the bend, the cuff or the tip of the cannula against the artery [127-129]. It is more common in patients with a low tracheotomy, below 
the third or fourth tracheal ring, or in patients with a high-lying innominate artery, particularly children [128-130].

If there is suspicion of a tracheo-innominate artery fistula, the tracheal cannula should be removed and a tracheoscopy done. Apart from major haemorrhage, a pulsating cannula may be a pathognomonic warning sign [131]. Replacement of the cannula by a translaryngeal tube with its cuff below the level of the innominate artery may be lifesaving [132]. Hyperinflation of the cuff may provide temporary control. The bleeding is further controlled by digital compression through the tract of the tracheotomy after extension of the incision into the jugular notch $[130,132,133]$. Pressure is applied between the anterior trachea and the posterior aspect of the manubrium sterni to compress the artery. The patient is taken to the operating theatre for median sternotomy, vessel ligation and excision of the damaged part of the artery [132]. Reconstruction of the damaged trachea is best deferred to later.

\section{TRACHEO-OESOPHAGEAL FISTULA}

A tracheo-oesophageal fistula is a rare complication after tracheotomy and has not yet been reported after percutaneous dilatational tracheotomy. Most fistulas appear to be the result of pressure necrosis of the trachea and the oesophagus by the tracheal cannula cuff and a nasogastric tube or the vertebral column. Its incidence has been greatly reduced by the introduction of high-volume lowpressure cuffs [134-136]. The influence of procedural damage to posterior wall of the trachea and the oesophagus is unknown. After percutaneous dilatational tracheotomy direct puncture of the oesophagus, dilatation or even cannulation may cause tracheo-oesophageal fistulas.

The diagnosis is suspected when there is a marked increase in tracheal secretions, abdominal distention and air leak around the cuff if a patient is ventilated [137]. If the patient is taking oral feeding, coughing following swallowing with feedings in the tracheal aspirate and recurrent pulmonary infection may occur. The diagnosis is confirmed with tracheoscopy with or without methylene blue into the oesophagus that appears in the tracheal lumen [138]. A barium swallow usually demonstrates the fistula clearly [137].

In most patients surgical repair of the fistula is necessary $[137,139]$. Reconstruction is best deferred as long as the patient is still ventilated [140141].

\section{DISLODGEMENT OF THE CANNULA}

Dislodgement of a tracheal cannula is more likely to cause problems during the first days after cannulation than afterwards [94]. The incidence of this complication after percutaneous dilatational tracheotomy is low, less than $1 \%$. The 
dilatation procedure produces a stoma tissue tract that fits snugly around the cannula. The close fit improves cannula anchoring and lessens the risk of accidental decannulation. The incidence of tube dislodgement is higher in patients with a fat neck or goitre if a standard tracheal cannula (Shiley-8) is used. Such patients may benefit from an adjustable neckplate. The tapes to lasten the cannula should be tied around the neck so that only one finger can be placed between the tape and the neck and only a small dressing should be applied. After a few days a tracheocutaneous tract has formed diminishing the consequences of displacement of the cannula.

Signs of dislodgement include an obstructed airway with high ventilatory pressures if a patient is mechanically ventilated, the ability of the patient to produce speech or the inability to pass a suction catheter through the cannula into the tracheal lumen.

When dislodgement of the cannula occurs the patient is translaryngeally intubated or an emergency cricothyroidotomy is performed. With the use of a percutaneous technique there are no stay sutures in the tracheal wall next to the cannula that facilitate re-entry of a dislodged cannula into the tracheal lumen [142].

\section{WOUND INFECTION}

The definition of stomal infection, redness and swelling of the stomal edges of more than one $\mathrm{cm}$ with a swab from which grew pathogenic organisms, is arbitrary [65]. The incidence, which depends on the physical condition of the patient, the mean duration of cannulation and the antibiotic regime, is below $2 \%[69,71]$. The low infection rate is credited to minimal dissection that is necessary to install a tracheal cannula with a percutaneous technique and the surrounding tissue that is snugged around the cannula preventing the formation of haematoma with a subsequent risk of infection [143-144].

Stomal infection generally responds well to local treatment, incision of a subcutaneous abscess, removal of the tracheal cannula and translaryngeal intubation, or to antibiotic therapy. Deeper infection with paratracheal abscesses has not been reported after percutaneous dilatational tracheotomy, although one patient with a wound infection and concomitant systemic sepsis 22 days after tracheotomy has been described [92].

\section{GRANULATION TISSUE}

The incidence of granulation tissue in the tracheal lumen after percutaneous dilatational tracheotomy mainly depends on the duration of cannulation and varies between $0 \%$ and $5 \%$. The vast majority of granuloma formation occurs at the stomal site, at the site of the windows of a fenestrated tracheal cannula, 
or at its tip. It can result in suprastomal stenosis, hinder decannulation or make breathing and speaking impossible when a fenestrated cannula is occluded and the inner cannula removed [143]. High ventilatory pressure during ventilatory support may be caused by partial occlusion of the end of the cannula by granulation tissue or a submucosal fold caused by off-centre placement of the cannula $[119,146]$. Tracheal haemorrhage during the period of cannulation can be the result of granulation tissue and is usually self-limited [147]. The diagnosis is easily made with tracheoscopy.

Unlike tracheal stenosis due to a stricture or protrusion of the anterior wall into the tracheal lumen, granulation tissue is removed by coring out with an endoscopy or laser resection [148].

\section{Late complications}

\section{TRACHEAL STENOSIS}

The incidence of tracheal stenosis after percutaneous dilatational tracheotomy is reported to be low. However, only a limited number of prospective studies have been done to assess the late complications of percutaneous dilatational tracheotomy and these comprise only limited numbers of patients $[88,97]$. The incidence of symptomatic tracheal stenosis is probably low, between $0 \%$ and $2 \%$.

The majority of patients with symptomatic tracheal stenosis become symptomatic between two and 12 weeks after decannulation [149]. Occasionally, obstructive symptoms develop with the cannula in situ or immediately after decannulation. Obstructive symptoms such as dyspnea on exertion or at rest, stridor, cough and the inability to clear bronchial secretions are highly aspecific $[30,149]$.

Tracheal stenosis is caused by granulation tissue at the stoma site or at the tip of the cannula, by protrusion of the anterior tracheal wall by an obliquely inserted cannula or by tracheomalacia and fibrosis of the trachea at the stoma or the cuff site [101,148-152]. The use of high-volume low-pressure cuffs has reduced the incidence of tracheal stenosis significantly $[134-136,155,156]$. Presently, the majority of lesions occur at the stoma site and have a symmetric configuration reducing the coronal diameter of the tracheal lumen. Etiologic factors are an obliquely inserted cannula, chondritis by large cannulas, rigid connecting systems with a continuous friction of the cannula and tracheal infection $[34,138,155,157,158]$.

Symptoms of tracheal stenosis should be evaluated by tomography of the trachea $[138,159]$. Fluoroscopy may be useful in the diagnosis of tracheamalacia. Contrast tracheography, computed tomography (CT) and magnetic resonance imaging (MRI) scans offer little additional information in benign 
stenosis $[138,160,161]$. Tracheoscopy should be performed in all patients prior to corrective surgery to evaluate the stenosis [162].

The treatment of a stenosis due to granulation tissue is endoscopic removal of the granuloma or laser resection [148]. If a larger circumferential stricture is present, less than $1 \mathrm{~cm}$ in length, serial dilatation or laser therapy may be tried. However, most procedures fail within months. Usually symptomatic stenoses are best treated by resection and end-to-end anastomosis [163-165].

\section{SUBGLOTTIC STENOSIS}

Subglottic stenosis after percutaneous dilatational tracheotomy has been reported twice [101]. It is related to the surgical technique and the risk of this complication may be increased with percutaneous tracheotomy because it is a blind procedure. High insertion of the cannula between the cricoid cartilage and the first tracheal ring, and oblique insertion with the possibility of erosion and fracture of the cricoid ring are risk factors $[101,154,158,160]$. Other risk factors include damage of the cricoid ring by prolonged translaryngeal intubation before the tracheal cannula has been installed or infection $[150,157,166]$.

The symptoms of subglottic stenosis are similar to those of tracheal stenosis. Both patients reported after percutaneous dilatational tracheotomy failed to be extubated [101].

The usual treatment of symptomatic subglottic stenosis is surgery [165,$167,168]$.

\section{VOICE CHANGES}

The incidence of voice changes after percutaneous dilatational tracheotomy is unknown. Authors evaluating the long-term results of this technique report a low incidence $[90,97]$.

Voice changes after tracheotomy are usually caused by translaryngeal tube and tracheal cannula related damage to the vocal cords [38]. When extubated, the regular movements of the cords prevent their fusion. If a tracheotomy cannula is inserted, the vocal cords can lie in apposition from the physiological loss of vocal cord abduction. Scarring of the damaged cords can lead to fusion [169]. Also, a high tracheotomy between the cricoid cartilage and the first tracheal ring can cause damage of the cricoid and laryngitis, which may result in voice changes. Blind puncture of the trachea as done with percutaneous tracheotomy may cause damage of the recurrent laryngeal nerve with vocal cord paralysis. This complication has been reported once [144]. Stridor, dyspnea and voice changes are common symptoms of recurrent nerve damage. From the low incidence of these symptoms after percutaneous dilatational tracheotomy it can be concluded that recurrent nerve damage is rare. 


\section{TRACHEOCUTANEOUS FISTULA}

A tracheocutaneous fistula develops when a tracheal stoma fails to close spontaneously after decannulation. Prolonged cannulation has allowed epithelialisation of the tissue tract between the skin and the trachea. Its incidence depends on the number of patients having a tracheal cannula for a long period $[65,96]$.

Closure of a tracheocutaneous fistula is a relatively simple surgical procedure that is usually postponed until the patient has recovered from prolonged ventilatory support [170].

\subsection{Percutaneous dilatational versus conventional open tracheotomy}

Since Jackson in 1909 described the technique, indications and instruments for tracheotomy, many operative techniques have been used $[171,172]$. Tracheal incisions include vertical and horizontal incisions, excision of a window of the anterior tracheal wall and an inferior based, U-shaped flap [173-177]. To decrease the risk of failure to reinsert the tracheal cannula into the tracheal lumen after accidental decannulation, Björk and modified Björk flaps have been advocated, which are presently the most commonly used techniques of conventional tracheotomy $[173,178,179]$.

There is a wide variety in reported complications after conventional tracheotomy. The comparison of the early complication rate of nine large series of conventional tracheotomy is listed in Table 1 .

Table 1. The characteristics of nine major studies of conventional open tracheotomy. a: unknown

\begin{tabular}{|c|c|c|c|c|c|c|c|c|}
\hline First Author & Dale & $\begin{array}{l}\text { Total pro- } \\
\text { cedures }\end{array}$ & Mortality & $\begin{array}{l}\text { Major hae- } \\
\text { morrhage }\end{array}$ & $\begin{array}{l}\text { Pyeuno- } \\
\text { thorax }\end{array}$ & $\begin{array}{l}\text { Subcutaneous } \\
\text { emplyysema }\end{array}$ & $\begin{array}{l}\text { Caunula dis- } \\
\text { lougement }\end{array}$ & $\begin{array}{l}\text { Siomal } \\
\text { infection }\end{array}$ \\
\hline$\overline{\text { Rogers [180] }}$ & 1969 & 688 & $1.2 \%$ & $2.0 \%$ & $0.1 \%$ & $0 \%$ & $1.3 \%$ & $0.6 \%$ \\
\hline Dugan [181] & 1963 & 461 & $1.1 \%$ & $3.0 \%$ & $1.3 \%$ & $1.5 \%$ & $0.4 \%$ & $0.7 \%$ \\
\hline Mulder [182] & 1969 & 428 & $5.1 \%$ & $5.3 \%$ & $1.6 \%$ & a & $0.7 \%$ & $20.5 \%$ \\
\hline Yarington [183] & 1965 & 240 & $0.8 \%$ & $1.3 \%$ & $1.7 \%$ & $1.7 \%$ & $0.8 \%$ & $0 \%$ \\
\hline Meade [184] & 1961 & 212 & 2.85 & $3.3 \%$ & $0.9 \%$ & $1.4 \%$ & $2.8 \%$ & $3.3 \%$ \\
\hline Watts [185] & 1963 & 212 & $1.4 \%$ & $0.9 \%$ & $0.9 \%$ & $2.4 \%$ & $\mathbf{a}$ & a \\
\hline Goldstein [186] & 1987 & 124 & $0 \%$ & $0 \%$ & $1.6 \%$ & $1.6 \%$ & a & a \\
\hline Chew [187] & 1972 & 100 & $0 \%$ & $1.0 \%$ & $1.0 \%$ & $0 \%$ & $7.0 \%$ & $0 \%$ \\
\hline Allen [89] & 1992 & 100 & $0 \%$ & $6.0 \%$ & $1.0 \%$ & $0 \%$ & $0 \%$ & $5.0 \%$ \\
\hline
\end{tabular}


Table 2 shows the early conaplication rate of the largest studies of percutaneous dilatational tracheotomy. The late complications of this technique, however, have not yet been assessed in large studies using airway imaging techniques.

\section{Table 2. The characteristics of nine major studies of percutaneous dilatational tracheotomy}

\begin{tabular}{lccllllll}
\hline First Author & Date & $\begin{array}{l}\text { Total pro- } \\
\text { cedures }\end{array}$ & Mortality & $\begin{array}{l}\text { Major hat- Pneumo- } \\
\text { roorhage } \\
\text { thorax }\end{array}$ & $\begin{array}{l}\text { Subcutaneous } \\
\text { emphysema }\end{array}$ & $\begin{array}{l}\text { Cannula dis- } \\
\text { lodgement }\end{array}$ & $\begin{array}{l}\text { Stomal } \\
\text { infection }\end{array}$ \\
\hline Ciaglia [90] & 1992 & 170 & $0 \%$ & $0 \%$ & $0 \%$ & $1.2 \%$ & $0.6 \%$ & $0.6 \%$ \\
Van Heurn [65] & 1996 & 150 & $0 \%$ & $3.3 \%$ & $0 \%$ & $1.3 \%$ & $0 \%$ & $0 \%$ \\
Toursarkissian [67] 1994 & 144 & $0.7 \%$ & $3.5 \%$ & $1.4 \%$ & $0 \%$ & $0 \%$ & $1.4 \%$ \\
Friedman [92] & 1993 & 100 & $1.0 \%$ & $4.0 \%$ & $0 \%$ & $2.0 \%$ & $0 \%$ & $3.0 \%$ \\
Allen [89] & 1992 & 100 & $0 \%$ & $6.0 \%$ & $0 \%$ & $0 \%$ & $0 \%$ & $0 \%$ \\
Manara [95] & 1994 & 77 & $0 \%$ & $2.6 \%$ & $0 \%$ & $0 \%$ & $0 \%$ & $2.6 \%$ \\
Winkler [96] & 1994 & 71 & $0 \%$ & $0 \%$ & $0 \%$ & $0 \%$ & $0 \%$ & $1.4 \%$ \\
Marelli [69] & 1990 & 61 & $1.6 \%$ & $0 \%$ & $0 \%$ & $0 \%$ & $0 \%$ & $3.3 \%$ \\
Hayard [85] & 1988 & 55 & $0 \%$ & $1.8 \%$ & $1.8 \%$ & $3.6 \%$ & $0 \%$ & $1.8 \%$ \\
\hline
\end{tabular}

Table 1 and Table 2 are difficult to compare. The majority of studies of conventional procedures were done twenty years before the percutaneous procedures and the complication rate of conventional tracheotomy has decreased since then [188]. There are also great differences in indications, patients and definitions of complications [189]. Conventional tracheotomy has been used in emergency situations with a higher complication rate whereas almost all percutaneous dilatational tracheotomies were done electively $[61,190]$. Although percutaneous dilatational tracheotomy is used in children $[64,65]$, the large contribution of this age group in the results of some studies of conventional tracheotomy gives the false impression of a high complication rate of this technique $[182,183]$. Particularly tracheotomy related mortality and the incidence of pneumothorax, interstitial air and cannula dislodgement are higher in children [191-195]. On the other hand the mean duration of cannulation is longer in the percutaneous studies.

The general lack of definitions of complications in most studies makes it difficult to compare. Suture ligation to stop procedural haemorrhage, a normal part of the conventional operation, is considered to be a complication of percutaneous tracheotomy. Minor cervical subcutaneous emphysema is registered as a complication in percutaneous tracheotomy, but many studies of conventional tracheotomy report it as a complication only when its progression is beyond the cervical region or when stitches have to be removed.

There are studies comparing percutaneous dilatational tracheotomy with conventional open tracheotomy $[88,89,91,118,196]$. Allen found in a partially 
prospective, partially retrospective study between two groups of 100 patients no significant differences between the early complication rate of the two techniques, although there was a stomal infection rate of $1 \%$ in the percutaneous group and of $5 \%$ in the conventional group [89]. A prospective analysis of Leinhardt et al. showed a favourable, but not significantly different, complication rate for percutaneous dilatational tracheotomy compared with that for the conventional procedure reporting a stomal infection rate of $0 \%$ and $13 \%$, respectively [91].

There are three prospective randomised trials of conventional and percutaneous dilatational tracheotomy. Friedman et al. and Barba et al. found no significant differences between the two techniques with respect to early complications $[118,196]$. Hazard et al. showed significantly less early complications in patients undergoing percutaneous tracheotomy which was mainly due to a difference in the infection rate of $4 \%$ in the percutaneous group versus $33 \%$ in the conventional group [88].

The operating times of both techniques were assessed in all four prospective studies showing a consistent and significant shorter duration of operation for percutaneous tracheotomy $[88,91,118,196]$. Barba et al. confirmed the impression of others that percutaneous tracheotomy is cheaper than conventional tracheotomy reporting lower hospital charges after percutaneous tracheotomy in the ICU than after conventional tracheotomy in the operating theatre [118].

\subsection{Percutaneous tracheotomy: other techniques}

Percutaneous tracheotomy was first described in the Renaissance [197]. The straight tracheal cannula was introduced into the tracheal lumen with a trocar. Its use was infrequent and the results of this technique are unknown [198-201].

In 1955 Shelden described a percutaneous technique for inserting a tracheal cannula [73]. A slot-needle was introduced into the tracheal lumen. He loaded a tracheal cannula onto a ball-tipped cutting trocar and slid it along the slot into the trachea. Once the trocar was within the tracheal lumen, the needle was removed and the tracheal cannula was pushed into the lumen with the trocar, which was then removed. Two years after his first publication Shelden reported "no morbidity, complications or unfavourable sequelae" of this technique [74]. There are no further studies of this technique and its results are unknown.

In 1969 Toye and Weinstein first used a guide wire for inserting a cannula into the trachea [75]. The tracheal lumen was punctured with a cannulated splitting needle. They passed a dilatator with a flexible leader at its tip into the tracheal lumen after the needle was split. A six $\mathrm{mm}$ inner diameter tracheal 
cannula loaded over the dilatator was advanced into the lumen and the dilatator was removed. It was claimed that the procedure was done in 30 seconds to two minutes and that the technique could be used in emergency situations. In a series of 100 patients there was one death due to dislodgement of the cannula and an early complication rate of $14 \%$, of whom $6 \%$ had a paratracheal placement of the cannula [76]. There are no other reports on this technique.

In 1989, four years after Ciaglia's report of percutaneous dilatational tracheotomy, Schachner et al. reported a new technique [77]. The trachea was punctured and a flexible metal guide wire introduced into the tracheal lumen. They enlarged the intercartilaginous space with a tipped spreader that slid over the wire into the trachea. The guide wire was removed and the tracheal cannula was introduced between the legs of the spreader.

This technique, used in elective and emergency cases, requires less operating time than dilatational tracheotomy $[91,202]$. The complication rate, however, is higher. Failure to insert the cannula, cannula misplacement and perforation of the cannula cuff on the legs of the spreader are the most common complications $[78,91,142,202-4]$. Also, more serious complications have been reported. Mediastinal emphysema or pneumothorax caused by a misplaced tracheal cannula or caused by the sharp dilatating tool damaging the posterior tracheal wall, are life-threatening $[91,121,205]$.

A modification on Ciaglia's dilatational technique was used by Griggs et al. [79]. They punctured the trachea with a cannulated needle, introduced a guide wire and advanced a dilatator forceps along the wire into the tracheal lumen. Instead of several dilatational steps as used with Ciaglia's technique, the opening in the trachea was enlarged with a forceps. The tracheal cannula loaded over a dilatator was inserted over the guide wire and inserted into the trachea.

This procedure that can be completed within 30 seconds of the skin incision is suitable for emergency tracheotomy [206]. Its complication rate is low and comparable with the percutaneous dilatational technique [80,207-209].

\section{References}

1. Bannister LH. Respiratory system. In Williams PL (ed). Gray's anatomy. 28th ed. NewYork: Churchill Livingstone, 1995:1627-82.

2. Breatnach E, Abbott GC, Fraser RG. Dimensions of the normal human trachea. AJR. 1984;141:903-6.

3. Jesseph JE, Merendino KA. The dimensional interrelationships of the major components of the tracheobronchial tree. Surg Gynecol Obstet 1957;105:210-4.

4. Hartung W, Düweling A. Histomechanische Messungen an Menschlichen Leichentracheen. Med Thorac 1964;21:257-64.

5. Gibellino F. Osmanliev DP, Watson A. Pride NB. Increase in tracheal size with age. 
Implications for maximal expiratory flow. Am Rev Respir Dis 1985;132:784-7.

6. Griscom NT, Wohl MEB. Dimensions of the growing trachea related to body height. Am Rev Respir Dis 1985;131:840-4.

7. Griscom NT. Wohl MEB. Tracheal size and shape: effects of change in intraluminal pressure. Radiology 1983;149:27-30.

8. Butz RO. Length and cross-section growth patterns in the human trachea. Pediatrics 1968;42:336-41.

9. Wailoo MP. Emery JL. Normal growth and development of the trachea, Thorax 1982;37:584-7.

10. Griscom NT. Wohl MEB. Dimensions of the growing trachea related to age and gender. AJR 1986;146:233-7.

11. Griscom NT. CT measurements of the tracheal lumen in children and adolescents. AJR $1991 ; 156: 371-2$.

12. Rhodin JAG. The ciliated cell. Ultrastructure and function of the human tracheal mucosa. Am Rev Respir Dis 1966;93:suppl:1-15.

13. Ellefsen P, Tos M. Goblet cells in the human trachea. Quantitative studies of a pathological biopsy material. Arch Otolaryngol 1972;95:547-55.

14. Tos M. Anatomy of the tracheal mucous glands in man. Arch Otolaryngol 1970;92:1327.

15. Hakansson CH, Toremalm NG. Studies on the physiology of the human trachea. V. Electrical and mechanical activity of the smooth muscles. Ann Otol Rhinol Laryngol 1967;77:255-63.

16. Proctor DF. The upper airways. The larynx and the trachea. Am Rev Respir Dis $1977 ; 1] 5: 315-42$.

17. Coller FA, Yglesias S. The relations of the spread of infection to fascial planes in the neck and thorax. Surgery 1937;1:323-37.

18. Grodinsky M, Holyoke EA. The fasciae and fascial spaces of the head, neck and adjacent regions. American Journal of Anatomy 1938;63:367-408.

19. Carlson GW. Surgical anatomy of the neck. Surg Clin North Am 1993;73:837-52.

20. Swigart LL, Siekert RG, Hambley WC, Anson BJ. The esophageal arteries; anatomic study of 150 specimens. Surg Gynecol Obstet 1950;90:234-43.

21. Miura T, Grillo HC. The contribution of the inferior thyroid artery to the blood supply of the human trachea. Surg Gynecol Obstet 1966;123:99-102.

22. Salassa JR, Pearson BW, Payne WS. Gross and microscopical blood supply of the trachea. Ann Thorac Surg 1977;24:100-7.

23. Galloway TC. Tracheotomy in bulbar poliomyelitis. JAMA 1943;123:1096-8.

24. Lassen HCA. Preliminary report on 1952 epidemic of poliomyelitis in Copenhagen with special reference to treatment of acute respiratory insufficiency. Lancet 1953;1:37-43.

25. Berlauk JF. Prolonged endotracheal intubation vs. tracheostomy. Crit Care Med $1986 ; 14: 742-5$.

26. Heffner JE. Timing of tracheotomy in ventilator-dependent patients. Clin Chest Med 1991:12:611-25.

27. Bryant LR, Trinkle JK, Mobin-Uddin K, Baker J, Griffen WO. Bacterial colonization profile with tracheal intubation and mechanical ventilation. Arch Surg 1972;104:64751 .

28. Dane TEB, King EG. A prospective study of complications after tracheostomy for assisted ventilation. Chest 1975;67:398-404.

29. Bartlett JG, Faling LJ, Willey S. Quantitative tracheal bacteriologic and cytologic studies in patients with long-term tracheostomies. Chest 1978;74:635-9. 
30. Stauffer JL, Olson DE, Petty: TL. Complications and consequences of endotracheal intubation and tracheostomy. Aum J Med 1981;70:65-76.

31. Cross AS, Roup B. Role of respiratory assistance devices in endemic nosocomial pneumonia. Am J Med 1981;70:681-5.

32. Niederman MS, Ferranti RD, Zeigler A, Merrill WW, Reynolds HY. Respiratory infection complicating long-term tracheostomy. The implication of persistent gramnegative tracheobronchial colonization. Chest 1984;85:39-44.

33. Niederman MS, Merrill WW, Ferranti RD, Pagano KM, Palmer LB, Reynolds HY. Nutritional status and bacterial binding in the lower respiratory tract in patients with chronic tracheostomy. Ann Intern Med 1984;100:795-800.

34. El-Naggar M, Sadagopan S, Levine H, Kantor H, Collins VJ. Factors influencing choice between tracheostomy and prolonged translaryngeal intubation in acute respiratory failure: a prospective study. Anesth Analg 1976;55:195-201.

35. Dunham $\mathrm{CM}$, LaMonica $C$. Prolonged tracheal intubation in the trauma patient. $J$ Trauma 1984;24:120-4.

36. Rodriguez JL, Steinhery SM, Luchetti FA, Gibbons KJ, Taheri PA, Flint LM. Early tracheostomy for primary airway management in the surgical critical care setting. Surgery 1990; 108:655-9.

37. Astrachan DI, Kirchner JC, Goodwin WJ. Prolonged intubation vs. tracheotomy: complications, practical and psychological considerations. Laryngoscope 1988;98:116569.

38. Whited RE. Posterior commissure stenosis post long-term intubation. Laryngoscope 1983;93:1314-8.

39. Whited RE. A prospective study of laryngotracheal sequelae in long-term intubation. Laryngoscupe 1984;94:367-77.

40. Gaynor EB, Greenberg SB. Untoward sequelate of prolonged intubation. Laryngoscope 1985;95:1461-7.

41. Dayal VS, El Masri W. Tracheostomy in intensive care setting. Laryngoscope 1986;96:58-60.

42. Stock MC, Woodward CG, Shapiro BA, Cane RD, Lewis V, Pecaro B. Perioperative complications of elective tracheostomy in critically ill patients. Crit Care Med 1986;14:861-3.

43. Yung MW, Snowdon SL. Respiratory resistance of tracheostomy tubes. Arch Otolaryngol 1984;110:591-5.

44. Godwin JE, Heffner JE. Special critical care considerations in tracheostomy management. Clin Chest Med 1991;12:573-83.

45. Heffner JE, Miller KS, Sahn SA. Tracheostomy in the intensive care unit. Part 1: indications, technique, management. Chest 1986;90:269-74.

46. Plummer AL, Gracey DR. Consensus Conference on Artificial Airways in Patients Receiving Mechanical Ventilation. Chest 1989;96:178-80.

47. Matthews HR, Hopkinson RB. Treatment of sputum retention by minitracheotomy. Br J Surg 1984;71:147-50.

48. Gupta A, McClelland MR, Evans A, el Masri WS. Minitracheotomy in the early respiratory management of patients with spinal injuries. Paraplegia 1989;27:269-77.

49. Issa MM, Healy DM, Maghur HA, Luke DA. Prophylactic minitracheotomy in lung resections. A randomized controlled study. J Thorac Cardiovasc Surg 1991;101:895900.

50. Pedersen J, Schurizek BA, Melsen NC, Juhl B. Is minitracheotomy a simple and safe procedure? A prospective investigation in the intensive care unit. Intensive Care Med 
$1991 ; 17: 333-5$.

51. Corke C, Cranswick P. A Seldinger technique for minitracheostomy insertion. Anaesth Intensive Care 1988;16:206-7.

52. Jackson IJB, Choudhry AK, Ryan DW, Matthews HR, Corike CF. Minitracheotomy. Seldinger-assessment of a new technique. Anaesthesia 1991;46:475-7.

53. Heurn LWE van, Geffen GJ van, Brink PRG. Percutaneous subcricoid minitracheostomy: report of 50 procedures. Ann Thorac Surg 1995;59:707-9.

54. Au J, Walker WS, Inglis D, Cameron EWJ. Percutaneous cricothyroidostomy (minitracheostomy) for bronchial toilet: results of therapeutic and prophylactic use. Ann Thorac Surg 1989;48:850-2.

55. Safar P, Penninckx J. Cricothyroid membrane puncture with a special cannula. Anesthesiology 1967;28:943-8.

56. Brantigan $\mathrm{CO}$, Grow JB. Cricothyroidotomy: elective use in respiratory problems requiring tracheotomy. J Thorac Cardiovasc Surg 1976;71:72-80.

57. Esses BA, Jafek BW. Cricothyroidotomy: a decade of experience in Denver. Ann Otol Rhinol Laryngol 1987;96:519-24.

58. Erlandson MJ, Clinton JE, Ruiz E, Cohen J. Cricothyrotomy in the emergency department revisited. J Emerg Med 1989;7:115-8.

59. Spaite DW, Joseph M. Prehospital cricothyrotomy: an investigation of indications, technique, complications, and patient outcome. Ann Emerg Med 1990;19:279-85.

60. Burkey B, Esclamado R, Morganroth $M$. The role of cricothyroidotomy in airway management. Clin Chest Med 1991;12:561-71.

61. Skaggs JA, Cogbill CL. Tracheostomy: Management, mortality, complications. Am Surg 1969;35:393-6.

62. Anderson HL, Bartlett RH. Elective tracheotomy for mechanical ventilation by the percutaneous technique. Clin Chest Med 1991;12:555-60.

63. Friedman Y, Franklin C. The technique of percutaneous tracheostomy. J Crit Illness 1993;8:289-97.

64. Toursarkissian B, Fowler CL, Zweng TN, Kearney PA. Percutaneous dilational tracheostomy in children and teenagers. J Ped Surg 1994;29:1421-4.

65. Heurn LWE van, Getfen GJ van, Brink PRG. Clinical experience with percutaneous dilatational tracheostomy: report of 150 cases. Eur J Surg 1996;162:531-5.

66. Heurn LWE van, Bogaard AEJM, Kootstra G, Brink PRG. Percutaneous dilatational versus open tracheotomy in a growing animal: a study in goats. J Ped Surg 1996;31:1512-5.

67. Toursarkissian B, Zweng TN, Kearney PA, Pofahl WE, Johnson SB, Barker DE. Percutaneous dilational tracheostomy: report of 141 cases. Ann Thorac Surg 1994;57:862-7.

68. Paul A, Marelli D, Chiu RCJ, Vestweber KH, Mulder DS. Percutaneous endoscopic tracheostomy. Ann Thorac Surg 1989;47:314-5.

69. Marelli D, Paul A, Manolidis S, et al. Endoscopic guided percutaneous tracheostomy: early results of a consecutive trial. J Trauma 1990;30:433-5.

70. Ciaglia P, Firsching R, Syniec C. Elective percutaneous dilatational tracheostomy. Chest 1985;87:715-9.

71. Worthley LIG, Holt A. Percutaneous tracheostomy. Intensive Care World 1992;9:18792.

72. Earl PD, Lowry JC. The percutaneous dilatational subcricoid tracheostomy. Br J Oral Maxillofac Surg 1994;32:24-5.

73. Shelden CH, Pudenz RH, Freshwater DB, Crue BL. A new method for tracheostumy. J 
74. Shelden CH, Pudenz RH, Tichy FY. Percutaneous tracheotomy. JAMA 1957;165:206870.

75. Toye FJ, Weinstein JD. A percutaneous tracheostomy device. Surgery 1969;65:384-9.

76. Toye FJ, Weinstein JD. Clinical experience with percutaneous tracheostomy and cricothyroidotomy in 100 patients. J Trauma 1986;26:1034-40.

77. Schachner A, Ovil Y, Sidi J, Rogev M, Heilbronn Y, Levi MJ. Percutaneous tracheostomy - a new method. Crit Care Med 1989;17:1052-6.

78. Schachner A, Ovil J, Sidi J, Avram A, Levy MJ. Rapid percutaneous tracheostomy. Chest 1990;98:1266-70.

79. Griggs WM, Worthley LIG, Gilligan JE. Thomas PD, Myburg JA. A simple percutaneous tracheostomy technique. Surg Gynecol Obstet 1990;170:543-5.

80. Griggs WM, Myburgh JA, Worthley LIG. A prospective comparison of a percutaneous tracheosomy technique with standard surgical tracheostomy. Intensive Care Med 1991;$17: 261-3$.

81. Ciaglia $\mathrm{P}$, Graniero KD. Life-threatening complications from percutaneous dilatational tracheostomy. Crit Care Med 1992;20:907.

82. Ciaglia P. Percutaneous tracheotomy. Laryngoscope 1992;102:954-5.

83. Friedman Y. Percutaneous tracheotomy. Laryngoscope 1992;102:955.

84. Ciaglia P. Defining percutaneous dilational tracheostomy. Chest 1994;106:983.

85. Hazard PB, Garrett HE, Adams JW, Robbins ET, Aguillard RN. Bedside percutaneous tracheostomy: experience with 55 elective procedures. Ann Thorac Surg 1988;46:63-7.

86. Cook PD, Callanan VI. Percutaneous dilational tracheostomy technique and experience. Anaesth Intensive Care 1989;17:456-7.

87. Bodenham A, Diament R, Cohen A, Webster N. Percutaneous dilational tracheostomy. A bedside procedure on the intensive care unit. Anaesthesia 1991;46:570-2.

88. Hazard P, Jones $C$, Benitone J. Comparative clinical trial of standard operative tracheostomy with percutaneous tracheostomy. Crit Care Med 1991;19:1018-24.

89. Allen LH. Percutaneous tracheostomy in the intensive care unit. Aust J Otolaryngol 1992; $1: 130-3$.

90. Ciaglia P, Graniero KD. Percutaneous dilatational tracheostomy. Results and long-term follow-up. Chest 1992;101:464-7.

91. Leinhardt DJ, Mughal M, Bowles B, et al. Appraisal of percutaneous tracheostomy. Br J Surg 1992;79:255-8.

92. Friedman $Y$, Mayer AD. Bedside percutaneous tracheostomy in critically ill patients. Chest 1993; 104:532-5.

93. Walz MK, Thürauf N, Eigler FW. Die punktionstracheostomie beim intensivpatienten. Technik und ergebnisse einer minimal-invasiven methode. Zentralbl Chir 1993;118:406-11.

94. Gaukroger MC. Allt-Graham J. Percutaneous dilatational tracheostomy. Br J Oral Maxillofac Surg 1994;32:375-9.

95. Manara AR. Experience with percutaneous tracheostomy in intensive care: the techoique of choice? Br J Oral Maxillotac Surg 1994;32:155-60.

96. Winkler WB, Karnik R, Seelmann O, Havlicek J, Slany J. Bedside percutaneous dilational tracheostomy with endoscopic guidance: experience with 71 ICU patients. Intensive Care Med 1994;20:476-9.

97. Fischler MP, Kubn M, Cantieni R, Frutiger A. Late outcome of percutaneous dilatational tracheostomy in intensive care patients. Intensive Care Med 1995:21:475-81.

98. Imami E, Hogans L, Komer K, Martin M. Percutaneous dilational tracheostomy. Risks 
and benefits of brochoscopy. A prospective randomized study. Crit Care Med 1994;22: A67.

99. Cooper AE. Percutaneous tracheostomy insertion can be difficult. Anaesthesia 1991;46: 1091.

100. Sun KO. Laryngotracheal stenosis following percutaneous tracheostomy. Anaesthesia 1995;50:182-3.

101. McFarlane C, Denholm SW, Sudlow CLM, Moralee SJ, Grant IS, Lee A. Laryngotracheal stenosis: a serious complication of percutaneous tracheostomy. Anaesthesia $1994 ; 49: 38-40$.

102. Skowronski GA, Bersten AD, Vedig AE. Bleeding risk with percutaneous tracheostomy. Anaesth Intensive Care 1990;18:273.

103. McAuley FT, Lawler PG. Percutaneous dilational tracheostomy. Completing the anaesthetist's range of airway techniques. Anaesthesia 1993;48:736.

104. Brimacombe J, Clarke G. Rigid bronchoscope; a possible new option for percutaneous dilational tracheostomy. Asaesthesiology;83:646-7.

105. Stemmer EA, Oliver C, Carey JP, Connolly JE. Fatal complications of tracheotomy. Am J Surg 1976;131:288-90.

106. Bernard SA, Jones BM, Shearer WA. Percutaneous dilatational tracheostomy complicated by delayed life-threatening haemorrhage. Aust N Z J Surg 1992;62:152-3.

107. Masterson GR, Smurthwaite GJ. A complication of percutaneous tracheostomy. Anaesthesia 1994;49:452-3.

108. Hill SA. An unusual complication of percutaneous tracheostomy. Anaesthesia 1995;50:469-70.

109. Day C, Rankin N. Laceration of the cuff of an endotracheal tube during percutaneous dilatational tracheostomy. Chest 1994;105:644.

110. Cook TM. Percutaneous dilational tracheostomy. Anaesthesia 1993;48:735.

111. Dexter TJ. The laryngeal mask airway: a method to improve visualisation of the trachea and larynx during fibreoptic assisted percutaneous tracheostomy. Anaesth Intensive Care 1994;22:35-9.

112. Lyons BJ, Flynn CGM. The laryngeal mask simplities airway management during percutaneous dilational tracheostomy. Acta Anaesthesiol Scand 1995;39:414-5.

113. Mahon SV. Fibreoptic tracheal tube placement prior to percutaneous dilatational tracheostomy. Anaesthesia 1995;50:92-3.

114. Wang MB, Berke GS, Ward PH, Calcaterra TC, Watts D. Early experience with percutaneous tracheotomy. Laryngoscope 1992;102:157-62.

115. Holtzman RB. Percutaneous approach to tracheostomy. Crit Care Med 1989;17:595.

116. Deblieux P. Wadell C. McClarity Z, deBoisblanc BP. Facilitation of percutaneous dilational tracheostomy by use of a perforated endotracheal tube exchanger. Chest 1995;108:572-4.

117. Reilly PM, Anderson HL, Sing RF, Schwab CW, Bartett RH. Occult hypercarbia. An unrecognized pheneomenon during percutaneous endoscopic tracheostomy. Chest 1995;107:1760-3.

118. Barba CA, Angood PB, Kauder DR, et al. Endoscopically guided percutaneous dilatational tracheostomy: a safe, easy and cost-saving procedure. Crit Care Med 1993;21:S251.

119. Hazard PB. Further retinement of percutaneous tracheostomy technique. Intensive Care Med 1994;20:466-7.

120. Heurn LWE van, Welten RJTJ, Brink PRG. A complication of percutaneous dilatational tracheostomy: mediastinal emphysema. Anaesthesia 1996;51:605. 
121. Hutchinson RC, Mitchell RD. Life-threatening complications from percutaneous dilational tracheostomy. Crit Care Med 1991;19:118-20

122. Heffner JE, Miller KS, Sahn SA. Tracheostomy in the intensive care unit. Part 2: complications. Chest 1986;90:430-6.

123. Noden JB, Kirkpatrick T. Intrapleural percutaneous tracheostomy. Anaesthesia 1995;50:91.

124. Gazzaniga $\mathrm{AB}$. Surgical management of complications of respiratory failure. Surg Clin North Am 1980;60:1465-79.

125. Moore FA, Haenel JB, Moore EE, Read RA. Percutaneous tracheostomy/gastrostomy in brain-injured patients-a minimally invasive alternative. J Trauma 1992;33:435-9.

126. Siegel JH, Ivatury R, Stahl WM. Percutaneous dilational tracheostomy. Crit Care Med 1991;19:1219-20.

127. Jones JW, Reynolds M, Hewitt RL, Drapanas T. Tracheo-innominate artery erosion: successful surgical management of a devastating complication. Ann Surg 1976;184:194204.

128. Silen $W$, Spieker D. Fatal hemorrhage from the innominate artery after tracheostomy. Ann Surg 1965;162:1005-12.

129. Potondi A. Pathomechanism of haemorrhages following tracheotomy. J Laryngol Otol 1969;83:475-84.

130. Weissman BW. Tracheo-innominate artery tistula. Laryngoscope 1974;84:205-9.

131. Davis JB, Southwick HW. Hemorrhage as a postoperative complication of tracheotomy. Ann Surg 1956;144:893-6.

132. Cooper JD. Tracheo-innominate artery fistula: successful management of 3 consecutive patients. Ann Thorac Surg 1977;24:439-47.

133. Utley JR, Singer MM, Roe BB, Fraser DG, Dedo $\mathrm{HH}$ : Definitive management of innominate artery hemorrhage complicating tracheostomy. JAMA 1972;220:577-9.

134. Cooper JD, Grillo HC. Experimental production and prevention of injury due to cuffed tracheal tubes. Surg Gynecol Obstet 1969;129:1235-41.

135. Cooper JD, Grillo HC. The evolution of tracheal injury due to ventilatory assistance through cuffed tuhes: a pathologic study. Ann Surg 1969;169:334-48.

136. Grillo HC, Cooper JD, Geffin B, Pontoppidan H. A low-pressure cuff for tracheostomy tubes to minimize tracheal injury. A comparative clinical trial. J Thorac Cardiovasc Surg $1971 ; 62: 898-907$.

137. Thomas AN. The diagnosis and treatment of tracheoesophageal fistula caused by cuffed tracheal tubes. J Thorac Cardiovasc Surg 1973;65:612-9.

138. Wood DE, Mathisen DJ. Late complications of tracheotomy. Clin Chest Med $1991 ; 12: 597-609$.

139. Thomas AN. Management of tracheoesophageal fistula caused by cuffed tracheal tubes. Am J Surg 1972;124:181-7.

140. Grillo HC, Moncure AC, McEnany MT. Repair of inflammatory tracheoesophageal fistula. Ann Thorac Surg 1976;22:112-9.

141. Hilgenberg AD, Grillo HC. Acquired nonmalignant tracheoesophageal fistula. J Thorac Cardiovasc Surg 1983;85:492-8.

142. Bodenham A, Cohen A, Webster N. A clinical evaluation of the 'Rapitrach'. A bedside percutaneous tracheostomy technique. Anaesthesia 1992;47:332-4.

143. Glas WW, King OJ, Lui A. Complications of tracheostomy. Arch Surg 1962;85:56-63.

144. Delany S, Stokes J. Percutaneous dilational tracheostomy: one years experience. N Z Med J 1991;104:188-9.

145. Myers EN, Carrau MRL. Early complications of tracheotomy. Incidence and manage- 
ment. Clin Chest Med 1991;12:589-95.

146. Rigg CD, Edmondson L. Percutaneous dilational tracheostomy. Malposition leading to delayed weaning. Anaesthesia 1995;50:724-5.

147. Kenan PD. Complications associated with tracheostomy: prevention and treatment. Otolaryngol Clin North Am 1979;12:807-16.

148. Shapshay SM, Beamis JF, Hybels RL, Bohigian RK. Endoscopic treatment of subglottic and tracheal stenosis by radial laser incision and dilation. Ann Otol Rhinol Laryngol 1987;96:661-4.

149. Weber AL, Grillo HC. Tracheal stenosis: an analysis of 15 I cases. Radiol Clin North Am 1978;16:291-308.

150. Kirchner JA. Tracheotomy and its problems. Surg Clin North Am 1980;60:1093-1104.

151. Kirchner JA. Avoiding problems in tracheotomy. Laryngoscope 1986;96;55-7.

152. Pearson FG, Goldberg M, da Silva AJ. Tracheal stenosis complicating tracheostomy with cuffed tubes. Clinical experience and observations from a prospective study. Arch Surg 1968;97:380-94.

153. Pearson FG, Goldberg M, da Silva AJ. A prospective study of tracheal injury complicating tracheostomy with a cuffed tube. Ann Otol Rhinol Laryngol 1968;77:867-82.

154. Charters $P$, Mannar R, Jones AS. Laryngotracheal stenosis after percutaneous tracheostomy. Anaesthesia 1994;49:825-6.

155. Andrews MJ, Pearson FG. The incidence and pathogenesis of tracheal injury following cuffed tube tracheostomy with assisted ventilation: analysis of a two-year prospective study. Ann Surg 1971;173:249-63.

156. Ching NPH, Ayres SM, Spina RC, Nealon TF, Endotracheal damage during continuous ventilatory support. Ann Surg 1974;179:123-7.

157. Sun KO. Fracture and dislodgement of trached cartilage during percutaneous tracheostomy. Anaesthesia 1995;50:370.

158. Heurn LWE van, Theunissen PHMH, Ramsay G, Brink PRG. Pathologic changes of the trachea after percutaneous dilatational tracheotomy. Chest (in press)

159. Bhalla M. Grillo HC, McLoud TC, Shepard JO, Weber AL, Mark EJ. Idiopathic laryngotracheal stenosis: radiologic findings. AJR 1993;161:515-7.

160. Streitz JM, Shapshay SM. Airway injury after tracheotomy and endotracheal intubation. Surg Clin North Am 1991;71:1211-30.

161. Kwong JS, Adler BD, Padley SPG, Müller NL. Diagnosis of diseases of the trachea and main bronchi: Chest radiography vs CT. AJR 1993;161:519-22

162. Mansour KA, Lee RB, Miller JI. Tracheal resections: lessons learned. Ann Thorac Surg 1994;57:1120-5.

163. Grillo HC. The management of tracheal stenosis following assisted respiration. J Thorac Cardiovasc Surg 1969;57:52-71.

164. Grillo HC. Surgical treatment of postintubation tracheal injuries. J Thorac Cardiovasc Surg 1979;78:860-75.

165. Grillo HC. Primary reconstruction of airway after resection of subglottic laryngeal and upper tracheal stenosis. Ann Thorac Surg 1982;33:3-18.

166. Sasaki CT, Horiuchi M, Koss N. Tracheostomy-related subglottic stenosis: bacteriologic pathogenesis. Laryngoscope 1979;89:857-65.

167. Pearson FG, Cooper JD, Nelems JM, Van Nostrand AW. Primary tracheal anastomosis after resection of the cricoid cartilage with preservation of the recurrent laryngeal nerves. J Thorac Cardiovasc Surg 1975;70:806-16.

168. Bone RC. Subglottic stenosis. Otolaryngol Clin North Am 1979;12:869-75.

169. Kirchner JA, Sasaki CT. Fusion of the vocal cords following intubation and tracheoto- 
my. Trans Am Acad Ophtalmol Otolaryngol 1973;77:88-91.

170. Lawson DW, Grillo HC. Closure of persistent tracheal stomas. Surg Gynecol Obstet 1970; 130:995-6.

171. Jacksun C. Tracheotomy. Laryngoscope 1909;19:285-90.

172. Gilmore BB, Mickelson SA. Pediatric tracheotomy. Controversies in management. Otolaryngol Clin North Am 1986;19:141-51.

173. Björk VO. Partial resection of the only remaining lung with the aid of respirator treatment. J Thorac Cardiovasc Surg 1960;39:179-88.

174. Lynn HB, Heerden JA van. Tracheostomy in infants. Surg Clin North Am 1973;53:94552.

175. Friedberg J, Morrison MD. Paediatric tracheotomy. Can J Otolaryngol 1974;3:147-55.

176. Price DG. Techniques of tracheostomy for intensive care unit patients. Anaesthesia 1983;38:902-4.

177. Wenig BL, Applebaum EL. Indications for and techniques of tracheotomy. Clin Chest Med 1991;12:545-53.

178. Dukes HM. Tracheostomy. Thorax 1970;25:573-6.

179. Tommerup B, Borgeskov S. Endoscopic evaluation at follow-up after Björk tracheostoma. Scand J Thorac Cardiovasc Surg 1983;17:181-4.

180. Rogers LA. Complications of tracheostomy. South Med J 1969;62: 1496-1500.

181. Dugan DJ, Samson PC. Tracheostomy: present day indications and technics. Am J Surg 1963;106:290-306.

182. Mulder DS, Rubush JL. Complications of tracheostomy: relationship to long term ventilatory assistance. J Trauma 1969;9:389-402.

183. Yarington CT, Frazer JP. Complications of tracheotomy. Arch Surg 1965;91:652-5.

184. Meade JW. Tracheotomy: Its complications and their management. A study of 212 case. N Engl J Med 1961;265:519-23.

185. Watts JM. Tracheostomy in modern practice. Br J Surg 1963;50:954-75.

186. Goldstein SI, Breda SD, Schneider KL. Surgical complications of bedside tracheotomy in an otolaryngology residency program. Laryngoscope 1987;97:1407-9.

187. Chew JY, Cantrell RW. Tracheostomy: complications and their management. Arch Otolaryngol 1972;96:538-45.

188. Mathisen DJ. Percutaneous tracheostomy. A cautionary note. Chest 1990;98:1049.

189. Heffner JE. Percutaneous tracheotomy - novel technique or technical novelty? Intensive Care Med 1991;17:252-3.

190. Eiseman B, Spencer FC. Tracheostomy: an underrated surgical procedure. JAMA 1963;184:684-7.

191. Rodgers BM, Rooks JJ, Talbert JL. Pediatric tracheostomy: long-term evaluation. J Ped Surg 1979; 14:258-63.

192. Hawkins DB, Williams EH. Tracheostomy in infants and young children. Laryngoscope 1976;86:331-40.

193. Orlowski JP, Ellis NG, Amin NP, Crumrine RS. Complications of airway intrusion in 100 consecutive cases in a pediatric ICU. Crit Care Med 1980;8:324-31.

194. Line WS, Hawkins DB, Kablstrom EJ, MacLaughlin EF, Ensley JL. Tracheotomy in infants and young children: the changing perspective 1970-85. Laryngoscope 1986;96:510-5.

195. Crysdale WS, Feldman RI, Naito K. Tracheotomies: a 10-year experience in 319 chilơren. Ann Otol Rhinol Laryngol 1988;97:439-43.

196. Friedman Y, Fildes J, Samuel J, et al. Comparison of operative and percutaneous tracheostomies. Crit Care Med 1993;21:S251 
197. Sanctorius S. Commentaria in primam fen primi libri canonis Avicennac. Venetiis Iacobum Sarcinam, 1626.

198. Dekkers F. Exercitationes chirurgica. Ludugnum Batavorum: Luchtmans et Boutesteyn, 1695.

199. Heister L. Institutiones chirurgicae Amstelaedam: Janssonis-Waesherge, 1750.

200. Swieten $G$ van. Commentaria in Hermanni Boerhaave aphorismos de cognoscendis et curandis morbis. 3rd ed. Lugdunum Batavorum: Sam. et Joh. Luchtmans, 1785.

201. Goodall EW. The story of tracheotomy. Br J Child Dis 1934;31:253-72.

202. Ivatury R, Siegel JH, Stahl WM, Simon R, Scorpio R, Gens DR. Percutaneous tracheostomy after trauma and critical illness. J Trauma 1992;32;133-40.

203. Pelausa EO. Percutaneous tracheostomy: ready or not? J Otolaryngol 1991;20:88-92.

204. Fisher EW, Howard DJ. Percutaneous tracheostomy in a head and neck unit. J Laryngol Otol 1992;106:625-7.

205. Brathwaite CEM. Rapid percutaneous tracheostomy. Chest 1991;100:1475-6.

206. Griggs WM, Worthley LIG, Myburgh JA. Percutaneous tracheostomy. Anaesth Intensive Care 1991;19:131-2.

207. Griggs WM, Myburgh JA, Worthley LIG. Urgent airway access - an indication for percutaneous tracheostomy. Anaesth Intensive Care 1991;19:586-7.

208. Caldicott LD, Oldroyd GJ, Bodenham AR. An evaluation of a new percutaneous tracheostomy kit. Anaesthesia 1995;50:49-51.

209. Bodenham AR. Percutaneous dilational tracheostomy. Completing the anaesthetist's range of airway techniques. Anaesthesia 1993;48:101-2. 



\section{Chapter 2}

\section{The history of tracheotomy}

L.W.E. van Heurn, P.R.G. Brink, G. Kootstra

Het Nederlands Tijdschrift voor Geneeskunde 1995;139:2674-8 The Journal of Laryngology and Otology 1996;110:723-6 


\section{Introduction}

Tracheotomy is one of the oldest operations in surgery and was performed in ancient times. A good impression of its history can be obtained by a division in four periods, made with the help of available literature of the development of the technique and the indication for the operation.

In the roman era and before, medical writers discussed tracheotomy. A clear description of the technique was made and it was recommended for upper airway obstruction. After the collapse of the Roman Empire the operation was probably not or rarely performed, although it was found in the writings of mainly Arabic physicians.

In the Renaissance, tracheotomies were performed with certainty. They were done for upper airway obstruction due to trauma, corpus alienum and acute inflammatory conditions in which the larynx was involved.

During the third period, starting at the early part of the 19th century, tracheotomy was popularised because of the increased prevalence of diphtheria in France. The operation was considered the last cure for this lethal disease. Also in thyroid surgery tracheotomies were frequently performed.

A careful description of the indications and of the technique in the beginning of the 20th century preceded the fourth period. The indication for tracheotomy is widened with the aspiration of bronchial secretions and prolonged ventilation.

\section{Ancient times}

\section{ASCLEPIADES, GALEN, ARETAEUS AND ANTYLLUS}

It is uncertain when the first tracheotomy was done but is has been suggested that tracheotomy was practised by the Egyptians, 3,500 years ago [1]. About 500 years later the sacred Hindu Book, Rig Veda, referred to tracheotomy and also the Babylonian Talmud claimed the success of the operation: "In our village there was a sheep who suffered an injury to her windpipe. Hollow reeds were introduced into the windpipe and the sheep lived" [2]. Alexander the Great (356-323 B.C.) is mentioned to have done the operation: "He opened with the point of his dagger the trachea of a soldier given up for the dead" [3].

In the second century the operation was found in the writings of Aretaeus and Galen, two physicians in the ancient Rome [4]. The latter credited the Greek Asclepiades of Bethunia with being the originator of the procedure. Asclepiades practised in Rome about the end of the second century B.C. He performed the operation in patients with synanche, a group of inflammatory conditions of the floor of the mouth, larynx and throat. He was, like most other 
physicians on Rome, a Greek slave: medicine was held by the Romans to be an ignoble profession to which no free man could devote himself. Only in 46 B.C. Julius Caesar (100-44 B.C.) granted citizenship to physicians and by the time of the Roman Emperors Trajan (98 to 127 A.D.) and Hadrian (117 to 138 A.D.) physicians achieved considerable social stature.

The Roman Antyllus, a Greek physician, performed the operation in the 2nd century A.D.. His technique was described by Paulus of Aegina (625-690 A.D.), a famous Byzantine obstetrician and writer [5]. "In inflammations about the mouth and palate, and in cases of indurated tonsils which obstruct the mouth of the windpipe with the trachea unaffected, it will be proper to have recourse to pharyngotomy, in order to avoid the risk of suffocation. When, therefore, we engage in the operation, we slit open a part of the arteria aspera (for it is dangerous to divide the whole) below the top of the windpipe, about the third of fourth ring. This is a convenient location, being free of flesh, and because the vessels are placed at a distance from the part which is divided. Wherefore, bending the patient's head backwards, so as to bring the windpipe better into view, we are to make a transverse incision between two of the rings, so that it may not be cartilage which is divided, but the membrane connecting the cartilages.

In the fifth century, Caelius Aurelianus commented: "Laryngotomy is a futile and rash invention set forth by Asclepiades. After the collapse of the Roman Empire tracheotomies were not -or rarely- performed. Experienced Arabic physicians like Rhazes (850-932) and Avicenna (980-1037) based their comments on the operation on Paulus of Aegina's description of Antyllus' work. Avenzoar (1092?-1162), a moslem physician, wrote about it and successfully tried tracheotomy on a goat [6].

\section{The period 1500-1800}

\section{BRASAVOLA, FABRICIUS, CASSERIUS, AND HABICOT}

The Italian surgeon Antonio Musa Brasavola was the first to report the success of tracheotomy in 1546 (Figure 1)[7]. He saved a patient dying from suffocation caused by an abscess in the windpipe. Brasavola was a physician of note these days and among the patients he was in medical attendance upon were Emperor Charles $\mathrm{V}$ and several kings and popes. Despite his favourable report about tracheotomy, most surgeons were reluctant to use this procedure, known as "The Scandal of Surgery". 


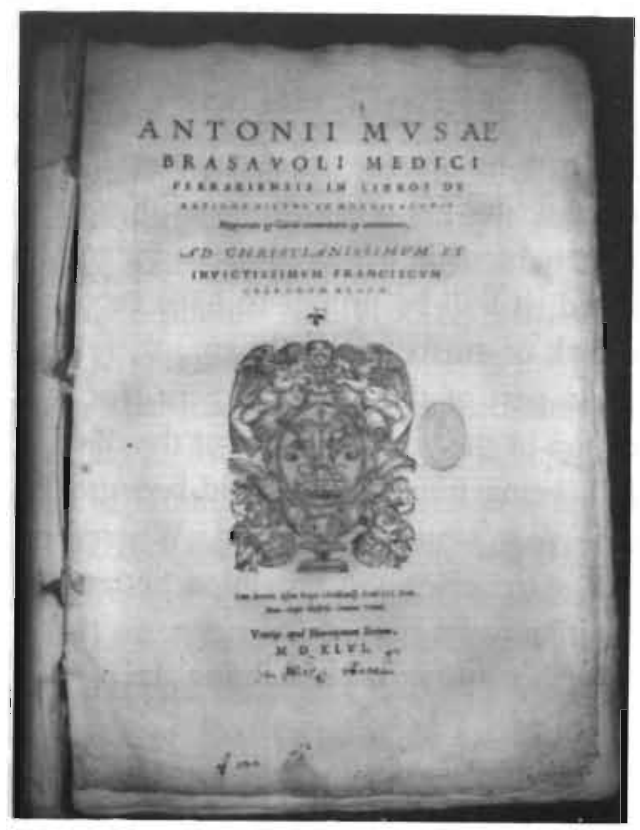

Figure 1. The title page of Brasavola's book 'Libris de ratione victus in morbis acutis, Hippocratis et Galenii commentaria et annotationes'. (University Library of Bologna, Italy)

The famous Italian anatomist and surgeon Fabricius ab Aquapendente (1537-1619), teacher of William Harvey (1578-1657), described in the chapter 'De perforatione asperae arteriae in angina' of his originally in 1617 published book 'Opera chirurgica' the details of the operation [8]. He advised tracheotomy in "diseases of the mouth and palate, of the tonsils and of the throat and of the larynx if the inflammation was serious and the uvula obstructed the trachea, but only if the bronchi were not affected". He recommended a vertical incision of the skin, access to the trachea between the third and fourth ring and, as the first, the use of a cannula. This cannula was small, straight and short preventing contact with the posterior wall of the trachea. It offered the surgeon to make smaller incisions than before. Fabricius, however, admitted that he had never performed a tracheotomy.

Julius Casserius (1545-1605), pupil of Fabricius, advised a longer, curved and fenestrated cannula [9]. He also does not seem to have done the operation. In his book 'De vocis auditusque organis historia anatomica' describing the anatomy of the head and neck region in humans and several other species, he illustrated the operation by some very nice figures (Figure 2 ). 


\section{I2 TAB. XXII. AE LARYNGOTOMIA.}

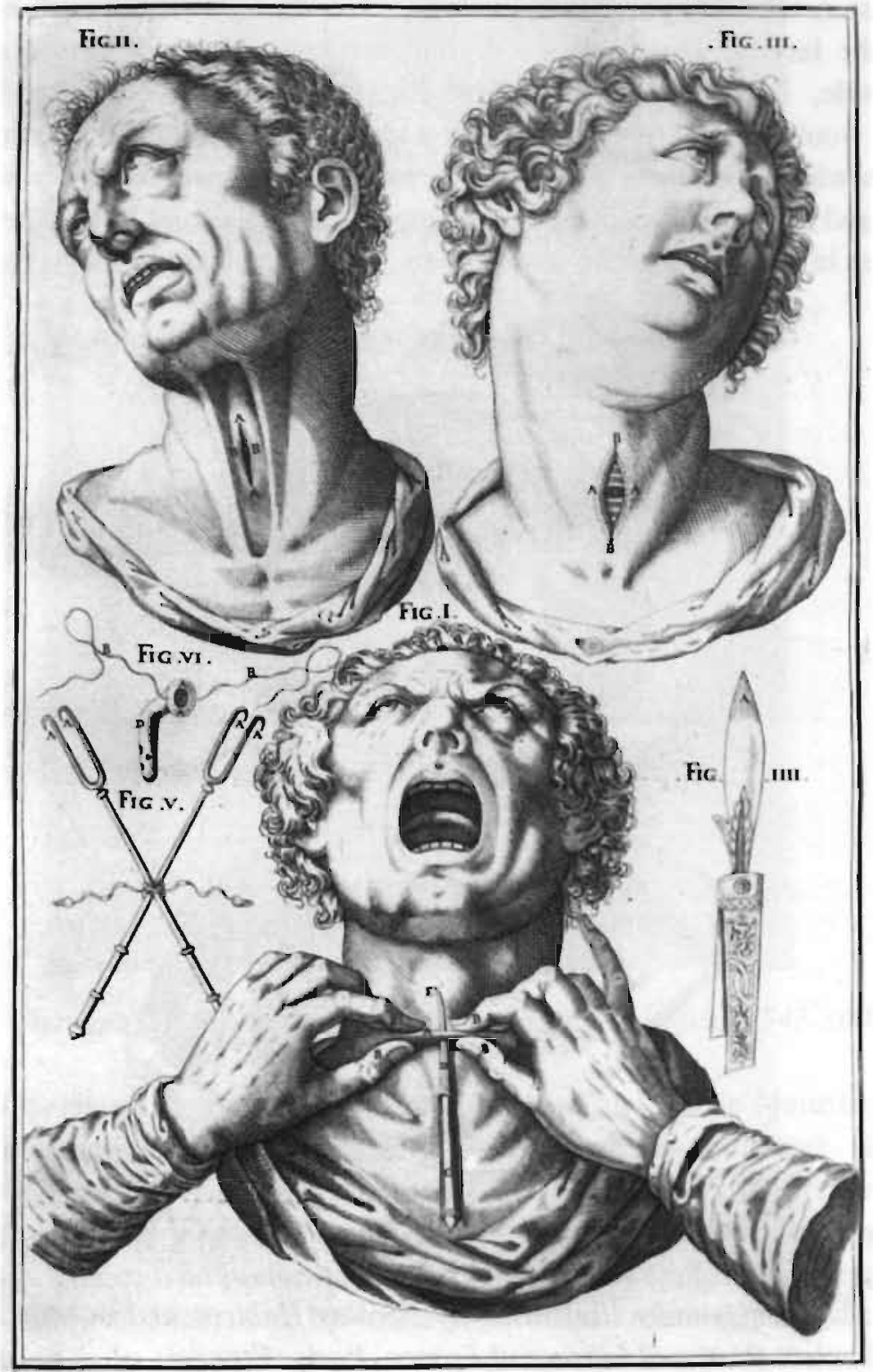

Figure 2. Tracheotomy in the Renaissance as illustrated by Julius Casserius in his book 'De vocis auditusque organis historia anatomica'. (University Library of Padova, Italy) 
The next successful cases of tracheotomy were reported by Nicolas Habicot (1550-1624) of Paris in 1620 [10]. He described a tracheotomy following a gunshot wound of the larynx. "A girl of about 25, stooping to open a door for her master, who was pursued by assassins, received a wound from a ball, which stuck the larynx, especially the thyroid cartilage. The ball passed across the other side, lodging under the skin. So much swelling supervened that the patient would have suffocated, but for a leaden tube introduced into the trachea, through which she might breathe". The cannula remained in situ for about three weeks and the patient recovered. Habicot describes this and three other successful cases in the first book on tracheotomy 'Question chirurgicale' (Figure 3).

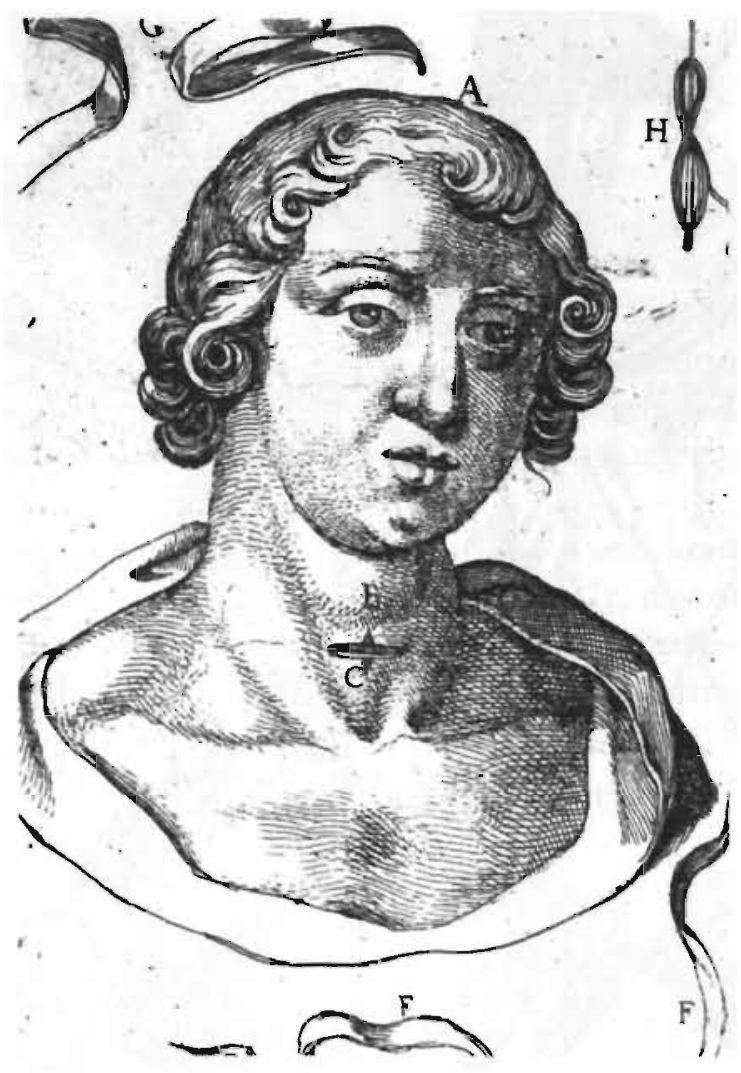

Figure 3. Tracheotomy illustrated by Nicolas Habicot in his book 'Question chirurgicale'. (National Library of France, Paris, France)

THE NETHERLANDS: HEURNIUS, FONTANUS, AND VAN SWIETEN Johannes Heurnius (1543-1601), professor at Leyden, gave his opinion about tracheotomy in his book 'De morbis pectoris liber' (Figure 4)[11]. 


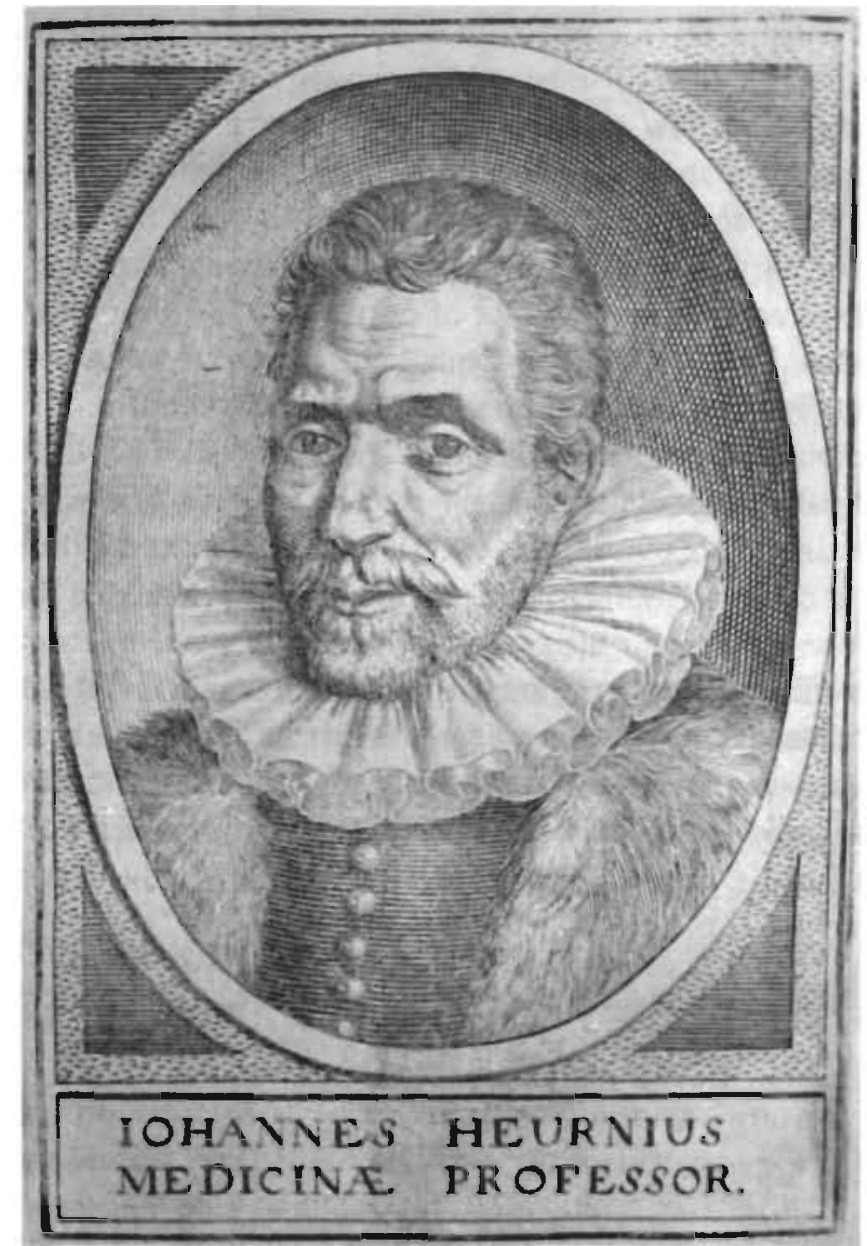

Figure 4. Portrait of Johannes Heurnius, professor at Leyden (1543-1601).

Heurnius, personal physician of William of Orange and Prince Maurits, studied at the University of Padua at the time of Fabricius ab Aquapendente. He based his comment on the writings of Aretaeus. "You wonder why the trachea is not incised directly and pierced if suffocation by angina is feared? Aretaeus gives the answer. Those, who perform this operation, do not appear to have approved the practicability of the thing by actual experiment. After all, the heat of the inflammation is increased by the wound and this contributes to the suffocation and cough. And, moreover, if by any means they should escape the danger, the edges of the wound do not heal and both pieces of cartilage do not unite again. If some physicians also claim that they can perform the operation without pain, we are fully satisfied". 
Nicolaas Fontanus (?-?), surgeon in Amsterdam, was the third to report the success of tracheotomy [12]. He attended a female patient who was feared to be strangled to death in a few hours. Although he had never seen a tracheotomy and never considered the procedure before, he decided to do the operation. "Using a sharp and short blade he made an incision over the outer part of the trachea over the cartilage rings which were carefully touched and divided, so that air was expired followed by a lot of purulent fluid in such an amount that the woman seemed breathless" The wound closed in five days and the woman fully recovered. Fontanus did not report of the use of a cannula.

More than one century later, Gerardus van Swieten (1700-1772), pupil of Herman Boerhaave (1668-1738) and physician of Maria Theresia Empress of Austria, gave in his 'Commentaria in Hermanni Boerhaave aphorismos de cognoscendis et curandis morbis' his opinion on a new technique for inserting a cannula with one stroke into the tracheal lumen, percutaneous tracheotomy: 'I have used this method on a large number of cadavers and living animals, but I consider the technique to be extremely difficult and not without danger, if the instruments used do not improve. Therefore I use the old method which is preferable and probably superior' [13]. We don't know whether van Swieten did tracheotomies on his patients, but there is evidence that he inserted tracheal cannulas in animals as mentioned above.

\section{PERCUTANEOUS TRACHEOTOMY: SANCTORIUS, DEKKERS, HEISTER, AND BAUCHOT}

The Italian surgeon Sanctorio Sanctorius (1561-1636) was probably the first surgeon to describe percutaneous tracheotomy [14]. Like Fabricius, Sanctorius was professor at the University of Padua, at that time the most prestigious university of Europe. Best known for his research into the physiology of metabolism (perspiratio insensibilis) and the development of the thermometer. He advised surgeons to use a 'ripping needle' (acus mucronata) -a small kind of dagger-, and a 'silver perforated cannula' (fistula argenta perforata). These were the same instruments as were used for tapping a hydrocele or an ascites (Figure 5). Using this needle, the operator introduced the cannula into the tracheal lumen and removed the needle. Sanctorius described the procedure in his book 'Commentaria in primam fen primi libri canonis Avicennae' but does not seem to have used this invention.

Frederik Dekkers (1648-1720), a professor at Leyden, told of a man who nearly suffocated as result of angina [15]. Dekkers intended to perform tracheotomy with the help of an 'unusual technique' (non vulgari methodo), one that he had never seen used before. He showed his instruments, a small straight cannula with little holes at the tip and a pointed trocar (Figure 6). 


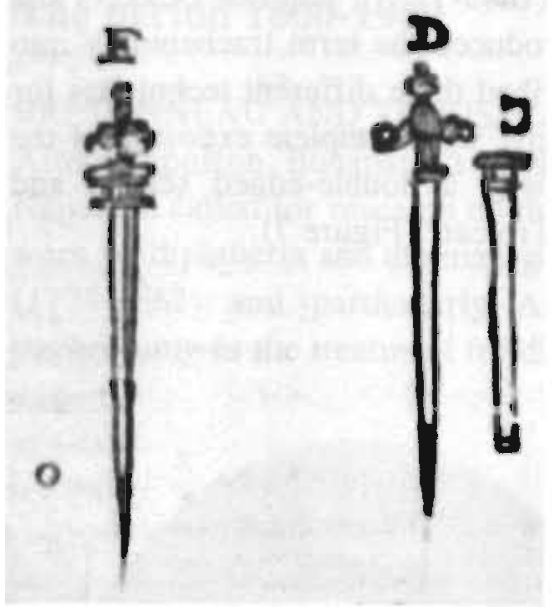

Figure 5. The instruments Sanctorius proposed to perform percutaneous tracheotomy in his book 'Commentaria in primam fen primi libri canonis Avicennae'. (Marciana Library, Venezia, Italy)

These instruments were similar to those of Sanctorius and without doubt Dekkers was on the point of performing the first percutaneous tracheotomy. However, the patients relatives were unenthusiastic and he successfully tried a method of oral intubation, abandoning his attempt to introduce a cannula percutaneously.

Figure 6. Dekkers instruments for tracheotomy and "oral intubation" in his book 'Exercitationes practicae'. (University Library of Leyden, The Netherlands)

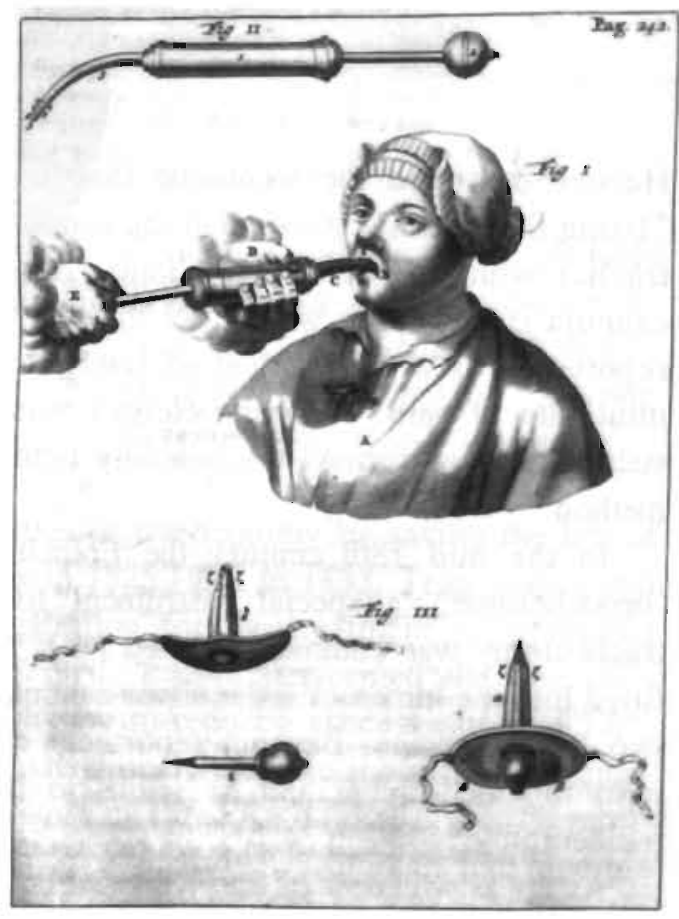


The German surgeon Laurentius Heister (1683-1758), pupil of Dekkers and a professor with a European reputation, introduced the term tracheotomy into the medical literature in 1718 [16]. He described three different techniques for inserting a tracheal cannula: open tracheotomy, with complete exposure of the trachea, tracheotomy done in one stroke with a double-edged scalpel and percutaneous tracheotomy with the use of a 'Troicar' (Figure 7).

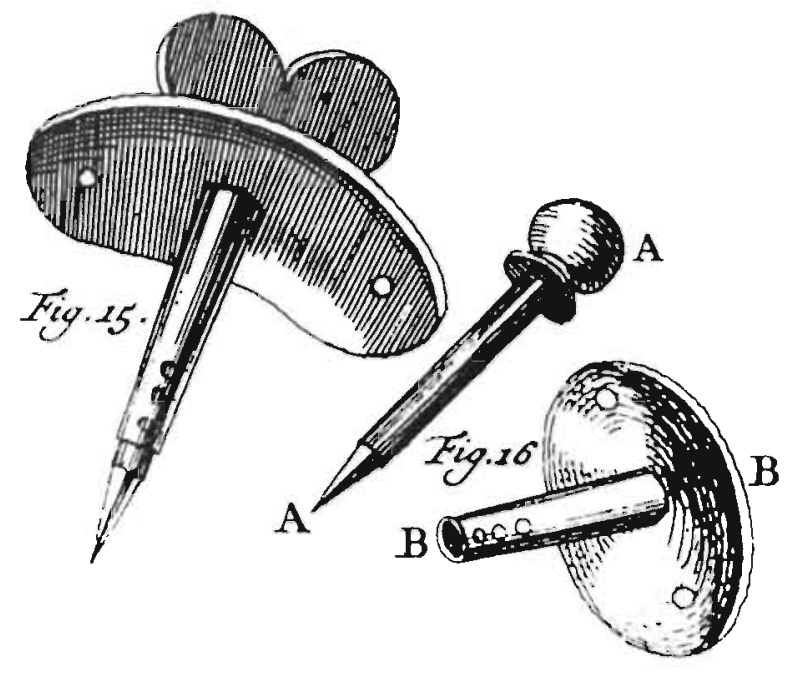

Figure 7. Percutaneous tracheotomy set illustrated by Heister in his book 'Institutiones chirurgicae'. (University Library of Leyden, The Netherlands)

Heister described the technique that he had learned from Dekkers clearly. "Using this peculiar instrument the cannula is introduced into the middle of the trachea with one stroke (uno ictu). After the troicar has been removed the cannula is left in the wound, so that the patient is able to breathe easily". He reported it as a fast method of tracheotomy that could be performed with a minimum of pain. Although Heister was one of the very few surgeons who successfully performed tracheotomy before 1800 , he probably used the open method.

In the mid 18th century the French physician Bauchot (?-?) invented a 'bronchotome', a special instrument for bronchotomy or laryngotomy, as tracheotomy was commonly called [17]. The cutting edge of the bronchotome fitted into the lumen of a flat silver cannula that was designed to be put between two tracheal rings. Bauchot reportedly operated successfully on two patients with this instrument and he seems to be the first to perform percutaneous tracheotomy.

As far as we know of only 28 successful cases of tracheotomy were reported from 1546 to 1825 [6]. 


\section{The period 1800-1900}

\section{BRETONNEAU AND TROUSSEAU}

After Napoleon Bonaparte's nephew died of diphtheria in France in 1807, Napoleon called for research on the disease, stimulating an enormous amount of work on diphtheria and the management of airway disorders. Pierre Bretonneau (1778-1862) and particularly Armand Trousseau (1801-1867) popularised tracheotomy as the treatment for diphtheria (Figure 8).

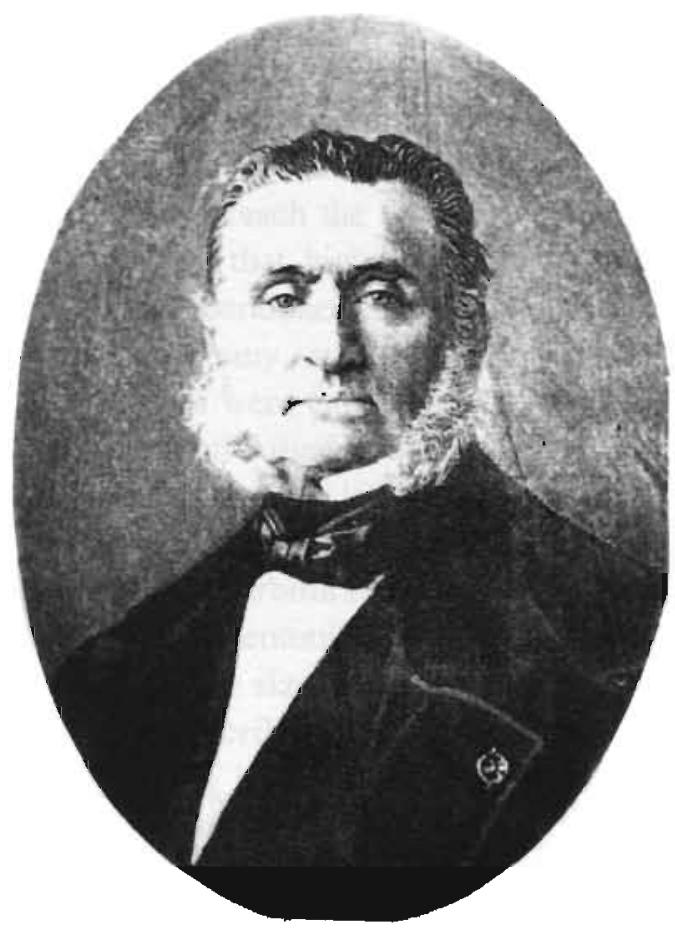

Figure 8. Portrait of Armand Trousseau in his 'Clinique médicale de l'Hotel-Dieu de Paris'. (University Library of Leuven, Belgium)

Bretonneau demonstrated the possibilities of tracheotomy by saving the life of the five-year old Elisabeth de Puységur in 1825 [18]. In 1833, Trousseau, pupil of Bretonneau, reported about the operation for the treatment of diphtheria (Figure 9) $[18,19]$. "Nowadays, gentlemen, I have performed the operation more than 200 times and I am rather happy to report a success rate of $25 \%$ ". He also designed a spreader for the tracheal opening while inserting the cannula, which is still in use today. For his work and treatise on the subject he received the coveted prize of the Académy de Médecine. Although the reported survival rate was only $25 \%$, it was a great advance over the previous results. 
Tracheotomy became the standard management of airway obstruction in severe diphtheria and became a widely accepted procedure in medical practice. It was used to guarantee an open airway for injuries of the larynx, foreign bodies, goitre and infections such as Ludwig's angina and diphtheria. Its frequent use is shown in the Netherlands by the experiences of 676 tracheotomies performed at the Wilhelmina Gasthuis in Amsterdam between 1899 and 1908 [20].

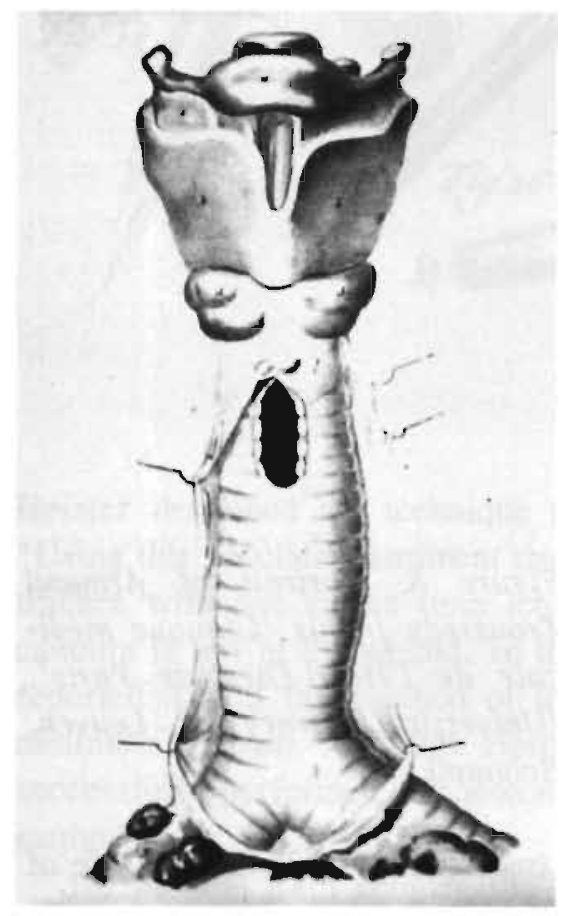

Figure 9. Illustration of the trachea after tracheotomy in Trousseau's en Belloc's book: 'Traité pratique de la phtisie laryngée, de la laryngite chronique et des maladies de la voix. (University Library of Leuven, Belgium)

Owing to increasing interest in tracheotomy the tracheal cannula was improved. Friedrich Trendelenburg (1844-1919) described a cannula covered by a rubber balloon wishing to seal the trachea from blood [21]. For the use in patients with a goitre the movable shield was invented [22]. The idea of a double cannula is older: In 1730, the British surgeon George Martin reported an inner cannula because "the innermost might be safely and easily taken out and cleaned without any molestation to the patient" [23]. 


\section{The period 1900-today}

\section{JACKSON}

After the turn of the century the number of tracheotomies done decreased because of the development of endotracheal tubes. The American paediatrician Joseph O'Dwyer (1841-1894) described the success of oral intubation which he believed was superior to tracheotomy in the management of airway obstruction in laryngeal diphtheria [24]. However, tracheotomy remained a common operation.

In 1909 Chevalier Jackson standardised the indications for tracheotomy, the technique itself and the instruments for the operation [25]. About the cannulas he reports: "The cannula must be of proper size and length. Nearly all cannulae in the shops are worthless, being both too short and of too short radius. Most of them will not reach the trachea after the neck has swelled in the reaction". He recommended that high tracheotomy, tracheotomy above the thyroid isthmus should be abandoned to prevent laryngeal stenosis [26]. He condemned cricothyroidotomy, an incision through the cricothyroid membrane, because its complications were excessive compared to tracheotomy. The technique Jackson proposed is still used today. The indications for tracheotomy, however, have widened. Wilson in 1932 and Galloway in 1943 suggested tracheotomy to facilitate aspiration of bronchial secretions in bulbar poliomyelitis, chest and head injury, Barbiturate intoxication and post surgical airway control [27]. Presently, tracheotomy is still used for the evacuation of bronchial secretions. The site and the size of the cannula are being discussed. In 1984, Matthews and coworkers described minitracheotomy, a small cannula in the tracheal lumen that interferes less with the normal glottic function like speaking, eating and coughing than the larger full sized tracheotomy [28]. It is generally introduced through the cricothyroid membrane although others advocate introduction between the first and second tracheal ring by a percutaneous Seldinger technique [29].

The latest application of tracheotomy began in Scandinavia during a poliomyelitis epidemic in 1952 and 1953 [30,31]. Tracheotomy enabled the most effective application of intermittent positive pressure ventilation. Although a translaryngeally introduced tube is normally used for artificial ventilation, nowadays tracheotomy is generally advocated in patients with prolonged ventilation and to facilitate weaning from ventilatory support [32]. It is a procedure which can be carried out with a low mortality and morbidity to secure an open airway in upper airway obstruction, to aspirate bronchial secretions and for prolonged ventilatory support. 


\section{AND CIAGLIA}

In 1955, Shelden reintroduced a method to introduce a tracheal cannula percutaneously $[33,34]$. He was the first to use the term percutaneous tracheotomy. To minimize the risk of damaging vital structures next to the trachea, Shelden first introduced a slot-needle into the tracheal lumen. He loaded the cannula onto a cutting trocar, slid it along the slot and then introduced it into the tracheal lumen.

Twelve years later, Toye and Weinstein used a Seldinger wire as a guide $[35,36]$. The wire was introduced into the tracheal lumen through a cannulated needle. The cannula, mounted on a bougie -apart from the shape, it was little different from Sanctorius' trocar-was advanced into the lumen over guide wire. The wire made safe introduction of a cannula possible and so was the vital step towards popularisation of the percutaneous technique.

In 1985, the American surgeon Ciaglia described his modification of percutaneous tracheotomy [37]. Like Sanctorius, who advocated the use of instruments for puncturing a hydrocele, he used a modified percutaneous nephrostomy set to perform the tracheotomy. After puncture of the tracheal lumen a guide wire was installed. The trachea was progressively dilated over the wire with tapered blunt dilatators, so that the cannula could be introduced over one of the dilatators. The early results of this technique were excellent comparing favourably with open tracheotomy. Percutaneous tracheotomy is now a generally accepted technique [38-40].

\section{Conclusion}

In more than 2000 years tracheotomy has become a procedure that is frequently used with a low mortality and morbidity. More than three hundred years ago Sanctorius invented percutaneous tracheotomy. Recent modifications of the instruments used made this old percutaneous technique suitable for modern surgery.

\section{References}

1. Wenig BL, Applebaum EL. Indications and techniques of tracheotomy. Clin Chest Med 1991;12:545-53.

2. Borman J, Davidson JT. A history of tracheostomy: si spiritum ducit vivit (Cicero). Brit J Anaesth 1963;35:388-90.

3. Alberti PW. Tracheotomy versus intubation. A 19th century controversy. Ann Otol Rhinol Laryngol 1984;93:333-7.

4. Guthrie D. Early records of tracheotomy. Bull Hist Med 1944;15:59-64. 
5. Grant RL. Antyllus, the elusive surgical genius of antiguity: an analysis of his writings. Surgery $1961 ; 50: 572-8$.

6. Goodall EW. The story of tracheotomy. Br J Child Dis 1934;31:167-76.

7. Brasavola AM. Libris de ratione victus in morbis acutis, Hippocratis et Galenii commentaria et annotationes. Venetiis: Scotum, 1546.

8. Fabricius H. Opera chirurgica, pars posterior operationes chirurgicas. Lugdunum Batavorum: Boutesteniana, 1617.

9. Casserius J. De vocis auditusque organis historia anatomica. Ferrara: Baldimus, 1601 .

10. Habicot N. Question chirurgicale. Paris: J. Corrozet, 1620.

11. Heurnius J. De morbis pectoris liber. Lugdunum Batavorum: Raphelengium, 1604.

12. Fontanus N. Observationum rariorum analecta. Amstelodam: Henricus Laurentius Bibliopolis, 1641.

13. Van Swieten G. Commentaria in Hermanni Boerhaave aphorismos de cognoscendis et curandis morbis. 3rd ed. Lugdugnum Batavorum: Sam. et Joh. Luchtmans, 1785.

14. Sanctorius $\mathrm{S}$. Commentaria in primam fen primi libri canonis Avicennae. Venetiis: lacobum Sarcinam, 1626.

15. Dekkers F. Exercitationes practicae. Lugdunum Batavorum: Luchtmans and Boutesteyn, 1695.

16. Heister L. Institutiones chirurgicae. Amstelaedam: Janssonis-Waesberge, 1750.

17. Goodall EW. The story of tracheotomy. Br J Child Dis $1934 ; 31: 253-72$.

18. Trousseau A. Clinique Médicale de l'Hotel-Dieu de Paris. 10th ed. Paris: Baillière, 1902.

19. Trousseau A, Belloc $\mathrm{H}$. Traité pratique de la phtisie laryngée, de la laryngite chronique et des maladies de la voix. Bruxelles: Société encyclographique des sciences médicales, 1837.

20. Schippers JC. Ervaringen bij 676 Tracheotomiën verricht gedurende de jaren 1899 tot 1908. Ned Tijdschr Geneeskd 1909;4:1969-76.

21. Trendelenburg F. Beiträge zu den operationen an den luftwegen. Archiv für Klinische Chirurgie $1871 ; 12: 112-33$.

22. Salzer F. Eine trachealcanüle für strumapatienten. Wiener Klinische Wochenschrift 1888; 1:591-2.

23. Martin G. Letter to William Graeme. Philosophical Transactions 1730;416:448.

24. O'Dwyer J. Two cases of croup treated by tubage of the glottis. New York Medical Journal $1885 ; 42: 146-51$.

25. Jackson C. Tracheotomy. Laryngoscope 1909;19:285-90.

26. Jackson C. High tracheotomy and other errors: The chief causes of chronic laryngeal stenosis. Surg Gynecol Obstet 1921;32:392-8.

27. Galloway TB. Tracheostomy in bulbar poliomyelitis. JAMA 1943;123:1096-8.

28. Matthews HR, Hopkinson RB. Treatment of sputum retention by minitracheotomy. Br J Surg 1984;71:147-50.

29. Van Heurn LWE, van Geffen GJ, Brink PRG. Percutaneous subcricoid minitracheostomy: Report of 50 cases. Ann Thorac Surg 1995;59:707-9.

30. Lassen HCA. Preliminary report on 1952 epidemic of poliomyelitis in Copenhagen with special reference to treatment of acute respiratory insufficiency. Lancet 1953;1:37-41.

31. Engström CG. Treatment of severe cases of respiratory paralysis by the Engström universal respirator. BMJ 1954;21:666-

32. Heffner JE, Miller KS, Sahn SA. Tracheostomy in the intensive care unit. Part 1:indications, technique, management. Chest 1986;90:269-74.

33. Shelden $\mathrm{CH}$, Pudenz RH, Freshwater DB, Crue BL. A new method for tracheostomy. J Neurosurg 1955;12:428-31. 
34. Shelden CH, Pudenz RH, Tichy FY. Percutaneous tracheotomy. JAMA 1957; 165:206870.

35. Toye FJ, Weinstein JD. A percutaneous tracheostomy device. Surgery 1969:65:384-9.

36. Toye FJ, Weinstein JD. Clinical experience with percutaneous tracheostomy and cricothyroidotomy in 100 patients. J Trauma 1986;26:1034-40.

37. Ciaglia P, Firsching R, Syniec. Elective percutaneous dilatational tracheostomy. Chest 1985;87:715-9.

38. Hazard P, Jones C, Benitone J. Comparative clinical trial of standard operative tracheostomy with percutaneous tracheostomy. Crit Care Med 1991;19:1018-1024.

39. Ciaglia P, Graniero KD. Percutaneous dilatational tracheostomy. Chest 1992;101:464-7.

40. Friedman $Y$, Mayer AD. Bedside percutaneous tracheostomy in critically ill patients. Chest; $1993 ; 104: 532-5$. 
Chapter 3

Clinical experience with percutaneous dilatational tracheotomy

Report of 150 cases

L.W.E. van Heurn, G.J. van Geffen, P.R.G. Brink

The European Journal of Surgery 1996;162:531-5 


\section{Introduction}

Tracheotomy is a procedure that is often used in patients who require prolonged mechanical ventilation, in patients who are unable to clear their bronchial secretions, and in patients with upper airway obstruction [1]. It is traditionally an open operation which is performed in the operation theatre.

Percutaneous dilatational tracheotomy is a relatively new technique that was introduced by Ciaglia et al. in 1985 [2]. Because it is done easily and quickly at the bedside with a low operative mortality and morbidity it has become increasingly popular $[3,4,5]$.

The excellent reported results of this technique made us introduce it in our hospital in 1990. We report here our experience with the first 150 operations and have compared it with the published reports emphasising the definition and prevention of complications.

\section{Patients and methods}

From July 1990 - July 1994 we did 150 consecutive percutaneous dilatational tracheotomies in 147 patients (95 male and 52 female). Their ages varied from 8 to 85 years, mean (SD) 58 (17). Their presenting diagnoses are listed in Table 1. Three patients had a second tracheotomy after elective decannulation because of recurrence of the original condition. During the study period three open surgical tracheotomies were done, because the surgeon on call had no experience of the percutaneous technique.

Table 1. Presenting condition of 147 patients who underwent percutaneous tracheotomy.

Condition

No. of patients

After abdominal operations

Neurological deficit

Multiple injuries

Internal or pulmonary disease

After other operations

Laryngeal disease

Total
71

27

20

18

8

3 
Percutaneous tracheotomies were done 95 tines because a longer period of ventilation was required or to facilitate weaning from the ventilator. The cannula was placed after a median of 11 days of endotracheal intubation. In 37 patients the cannula was introduced for pulmonary toilet and in 18 for airway control after facial injury or upper airway obstruction. After facial injuries the decision to do a tracheotomy was made by the surgeon. Otherwise the decision was always made by the intensive care specialist.

Exclusion criteria were oxygen requirements of greater than $10 \mathrm{~cm}$ PEEP (positive end expiratory pressure) or $0.8 \mathrm{FiO}_{2}$ (fraction of inspired oxygen) and evidence of infection of the soft tissues of the neck. Relative contraindications were severe bleeding disorders including thrombocytopenia (platelet count less than $25 \times 109$ ) or thrombocytopathy, and coagulopathy (Thrombotest less than $5 \%$ ). Anatomical difficulty (goitre or extreme obesity) was never a contraindication.

\section{TECHNIQUE}

The technique has been accurately described by others [2,6]. A commercially available kit is used (Cook, Medical Company, Son, The Netherlands). The patient's neck is hyperextended. If a laryngeal tube is in place it is withdrawn between the vocal cords. After a $2 \mathrm{~cm}$ longitudinal skin incision $0.5 \mathrm{~cm}$ below the cricoid cartilage the tracheal lumen is punctured with a cannulated needle. Its position is confirmed by the suction of air bubbles into a syringe. A guide wire is inserted through the plastic cover which is taken out (Figure 1).

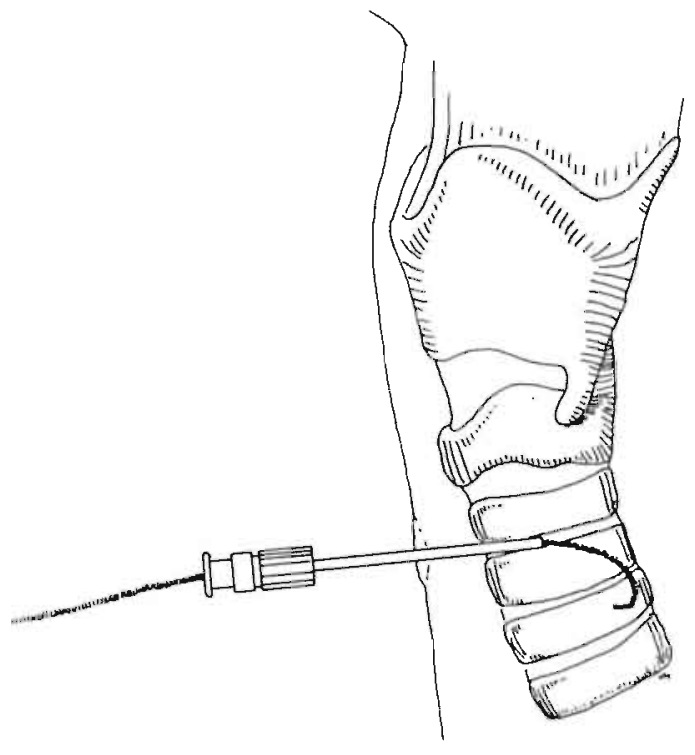

Figure 1. After the tracheal lumen has been punctured between the first and second tracheal rings the needle is taken out and a guide wire introduced through the plastic cover. 
The trachea is dilated once, a guiding catheter is placed over the wire and in several steps the opening is dilated with lubricated tapered dilatators. The cannula is placed over an appropriately sized dilatator and introduced into the tracheal lumen under firm pressure (Figure 2).

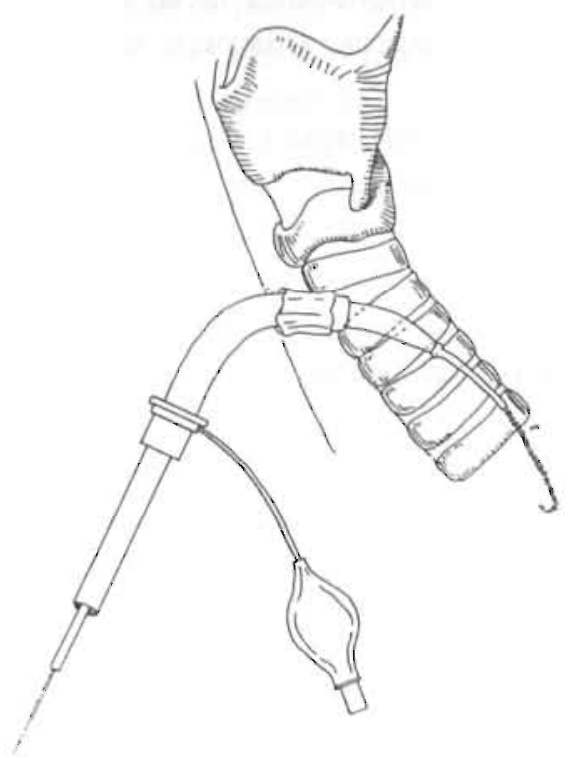

Figure 2. The cannula is mounted on an appropriately sized dilatator and inserted over the guide wire and guiding catheter.

Percutaneous tracheotomy was carried out by four experienced surgeons and five surgical trainees. An anaesthetist was responsible for withdrawing the laryngeal tube and for monitoring the patients' oxygen saturation and blood pressure. Trainees did their first five to 10 tracheotomies under close supervision by the surgeon who was most experienced at the procedure. Tracheotomies were generally done in the intensive care unit.

All patients had a cannula inserted with an inside diameter of $8.5 \mathrm{~mm}$ or 9 $\mathrm{mm}$. Two children were given smaller ones.

\section{FOLLOW-UP}

Operative complications were recorded at the time of the procedure. Complications during cannulation were recorded from retrospective review of the charts. Follow-up five to 53 months (median 21) after decannulation was complete.

\section{DEFINITIONS}

Operative complications: Complications during or directly attributed to the procedure.

Early complications: Operative complications and complications during cannu- 
lation.

Late complications: Complications after decannulation.

Minor haemorrhage: Bleeding that lengthened the procedure and was controlled by local compression.

Major haemorrhage: Bleeding that postponed the procedure, required suture ligation, surgical exploration, or blood transfusion.

False passage: Dilatation or insertion of the cannula outside the tracheal lumen. Stomal infection: Redness and swelling of the stomal edges of more than $1 \mathrm{~cm}$ with a swab from which grew pathogenic organisms.

\section{Results}

Forty-six patients died while they were cannulated after a median duration of 14 days (range 1 - 129 days). In one patient with serious disturbances of platelet function death was initially thought to be tracheotomy-related. This patient presented with a massive tracheal bleeding: at necropsy there was evidence of bleeding from almost every organ. A total of 101 patients survived after a median duration of cannulation of 24 days (range $2-418$ ). At the time of the study one patient still had the cannula in place.

The operative complications and the complications during cannulation are shown in Table 2.

Table 2. Operative complications, and complications during cannulation, in 147 patients with 150 percutaneous tracheotomies.

Complication

No. of patients

False passage 2

Haemorrhage

Minor ooze

9

Major bleeding

5

Subcutaneous emphysema

Pneumothorax

Hypergranulation tissue 
Operative haemorrhage was recorded in 12 patients, and considered major in three. On one occasion bleeding was controlled with a stitch, and on another the procedure was cancelled, the wound packed, and the next day after bleeding had stopped an uneventful percutaneous tracheotomy was done. Blood transfusion and surgical exploration was necessary in one patient. In two patients (major) tracheal or stomal bleeding was recorded during a total duration of cannulation of 5212 days.

Granulation tissue in two ventilated patients, 19 and 28 days after tracheotomy (at the site of the stoma and just below the tip of the cannula respectively) was removed endoscopically.

Late complications were recorded in six patients (6\%). One patient presented with a symptomatic tracheal stenosis at the cannulation site three months after decannulation which required repair. The cannula had been in situ for seven days after two weeks of endotracheal intubation. Tracheomalacia developed at the cuff site in two patients ventilated for 160 and 366 days with tracheotomies for 121 and 418 days, respectively. Disturbances of wound healing developed in three patients (3\%): an ugly retracted scar was corrected under local anaesthesia after a tracheotomy had been done through the recent operative wound to protect the airway after thyroid surgery, and two persistent tracheocutaneous fistulas after 111 and 152 days of cannulation, respectively, were closed. All other wounds healed fast and nicely after decannulation.

\section{Discussion}

Percutaneous tracheotomy was first described by Shelden in 1957. A needle was passed into the tracheal lumen, a hole was made with a special cutting blade, and a cannula was inserted into the trachea [7]. The second report about percutaneous tracheotomy dates from 1969: Toye and Weinstein dilated the trachea using a bougie with a cutting blade, and the cannula was introduced over a wire guide [8]. Further results of this technique were published in 1986 [9]. In 1985 Ciaglia described a technique which required no tracheal incision [2]. After direct puncture of the trachea the opening was bluntly dilated with disposable dilataturs over a guide wire. The cannula was inserted over one of the dilatators. This technique has become widely accepted $[3,4,5,10]$. Modifications of the dilatational technique have been reported by Griggs et al who dilated the trachea with a special forceps and by Schachner et al who enlarged the intercartilaginous space with a tracheal spreader [11-14].

Since we introduced percutaneous dilatational tracheotomy at our hospital in 1990 the number of tracheotomies has more than doubled. Because it could be done safely and rapidly at the bedside, the indications for tracheotomy widened 
and it was done earlier and in more severely ill patients. Comparison of the results with those of open tracheotomy at our own hospital before July 1990 was therefore considered inappropriate.

Our results do not differ from other studies of percutaneous dilatational tracheotomy and compare favourably with historical experience with conventional tracheotomy, which gave operative morbidity of $6 \%$ to as high as $51 \%$, although the general lack of definitions make studies difficult to compare [3,$4,5,15]$. Hazard et al. confirmed in a prospective randomised study that percutaneous tracheotomy is superior to conventional tracheotomy [16].

Operative haemorrhage is the most common complication and is usually controlled by local compression. When the cannula is in place the surrounding tissue is likely to tamponade any residual bleeding. If either minor or major haemorrhage is recorded as a complication, the distinction is arbitrary because exact measurements of blood loss were not made and suture ligation (which we defined as indicating major bleeding) is a normal part of the conventional procedure. The incidence of false passage is between $0.5 \%$ and $2 \%$. During the procedure it should be possible to move the guide wire without resistance. If there is doubt about the intraluminal position of the wire it must be checked; the plastic cover of the cannula needle should be reinserted over the wire, the wire removed, and air aspirated with the syringe. A common mistake that we made was to point the dilatator loaded with the cannula too far distally. The trachea does not run in a horizontal plane but, particularly when the neck is hyperextended, it recedes from the surface as it passes downwards. The cannula inserted with firm pressure may slide off on the front of the tracheal rings [17]. Puncturing the trachea in patients with a short fat neck or goitre is difficult, but even in patients with indistinct anatomy we found it possible to identify and puncture the trachea [6]. Endoscopic guidance or echography are helpful $[10,18]$. Multiple puncture sites are not the only cause of subcutaneous emphysema. Percutaneous dilatational tracheotomies that we have done in recently dead patients showed minor tearing of the intercartilaginous tissue next to the cannula, which permitted air to leak. The progression of subcutaneous emphysema is prevented by inflation of the cuff.

Complications during cannulation after percutaneous dilatational tracheotomy are rare $[3,4,5]$. Peristomal infection may be credited to extensive dissection during insertion of the cannula which explains the low infection rate after the procedure [5]. Secondary dislodgement of the cannula and bleeding from vascular erosion by continuous movements of the cannula are avoided by making sure that the cannula fits snugly in the surrounding tissue.

No prospective studies have been done to identify late complications. They usually occur a relatively long time after decannulation, so the late complica- 
tion rate is underestimated. Because the procedure is becoming increasingly popular, studies are needed to assess the incidence of late complications and to find out if complications such as tracheal stenosis depend on the peristomal infection rate, the duration of cannulation and previous oral intubation, or merely on the technique used. Because the cartilaginous rings remain intact with their blood supply preserved and because the infection rate is low, the percutaneous technique probably reduces the risk of tracheal stenosis $[5,19]$. Scars after percutaneous tracheotomy are small $[3,4]$. Only a small incision is necessary to insert the cannula and the infection rate is low. In our study one patient presented with an ugly retracted scar. The tracheotomy had been done five days after thyroid surgery and we were well aware of the risk of wound infection and wound healing problems.

The cost of percutaneous compared with open tracheotomy varies among hospitals and countries. The percutaneous procedure is easily done at the bedside, which saves valuable operating time, nursing staff, and equipment. It is substantially cheaper than conventional tracheotomy $[5,10]$.

There are differences of opinion about who should do the operation, and we think that a combined approach is advisable [3,20,21]. An anaesthetist should attend the procedure to take care of cardiopulmonary resuscitation and upper airway control. Surgeons have the advantage of their operating skill and are able to manage their own complications, but whoever does the operation should be properly trained. Many complications occur when unexperienced doctors use this simple technique. As with all operations training is the best way to avoid complications.

\section{References}

1. Heffner JE, Miller KS, Sahn SA. Tracheostomy in the intensive care unit. Part 1: indications, technique, management. Chest 1986;90:269-74.

2. Ciaglia P, Firsching R, Syniec C. Elective percutaneous dilatational tracheostomy. Chest 1985;87:715-9.

3. Ciaglia P, Graniero KD. Percutaneous dilatational tracheostomy. Chest 1992;101:464-7.

4. Friedman $Y$, Mayer AD. Bedside percutaneous trachenstomy in critically ill patients. Chest 1993; 104:532-5.

5. Toursarkissian B, Zweng TN, Kearney PA, Pofahl WE, Johnson SB, Barker DE. Percutaneous dilational tracheostomy: report of 141 cases. Ann Thorac Surg 1994;57:862-7.

6. Anderson HL, Bartlett RH. Elective tracheotomy for mechanical ventilation by the percutaneous technique. Clin Chest Med 1991;12:555-60.

7. Shelden CH, Pudenz RH, Tichy FY, Percutaneous tracheotomy. JAMA 1957;165:206870 .

8. Toye FJ, Weinstein JD. A percutaneous tracheostomy device. Surgery 1969;65:384-9.

9. Toye FJ, Weinstein JD. Clinical experience with percutaneous tracheostomy and cricothyroidotomy in 100 patients. J Trauma 1986;26:1034-40. 
10. Marelli D, Paul A, Manolidis S et al. Endoscopic guided percutaneous tracheostomy: early results of a consecutive trial. J Trauma 1990;30:433-5.

11. Griggs WM, Myburgh JA, Worthley LIG. A prospective comparison of a percutaneous tracheostomy technique with standard surgical tracheostomy. Intensive Care Med 1991; 17:261-3.

12. Griggs WM, Worthley LIG, Gilligan JE, Thomas PD, Myburg JA. A simple percutaneous tracheostomy technique. Surg Gynecol Ohstet 1990;170:543-5.

13. Schachner A, Ovil J, Sidi J, Avram A, Levy MJ. Rapid percutaneous tracheostomy. Chest 1990;98:1266-70.

14. Schachner A, Ovil Y, Sidi J, Rogev M, Heilbronn Y, Levi MJ. Percutaneous tracheostumy - a new method. Crit Care Med 1989;17:1052-6.

15. Stock MC, Woodward CG, Shapiro BA, Cane RD, Lewis V, Pecaro B. Periuperative complications of elective tracheostomy in critically ill patients. Crit Care Med 1986;14:861-3.

16. Hazard P, Jones C, Benitone J. Comparative clinical trial of standard operative tracheostomy with percutaneous tracheostomy. Crit Care Med 1991;19:1018-24.

17. Wang MB, Berke GS, Ward PH, Calcaterra TC, Watts D. Early experience with percutaneous tracheotomy. Laryngoscope 1992;102:157-62.

18. Paul A, Marelli D, Chiu RCJ, Vestweber KH, Mulder DS. Percutaneous endoscopic tracheostomy. Ann Thorac Surg 1989;47:314-5.

19. Hazard PB, Garrett HE, Adams JW, Robbins ET, Aguillard RN. Bedside percutaneous tracheostomy: experience with 55 elective procedures. Ann Thorac Surg 1988;46:63-7.

20. Bodenham AR. Percutaneous dilational tracheostomy. Completing the anaesthetist's range of airway techniques. Anaesthesia 1993;48:101-2.

21. Leinhardt DJ, Mughal M, Bowles B et al. Appraisál of percutaneous tracheostomy. Br J Surg 1992;79:255-8. 

Chapter 4

\section{Percutaneous subcricoid minitracheotomy}

Report of 50 procedures

L.W.E. van Heurn, G.J. van Geffen, P.R.G. Brínk

The Annals of Thoracic Surgery 1995;59:707-9 


\section{Introduction}

A minitracheotomy is a small cannula that has been placed in the trachea and that enables the frequent and efficient suction of bronchial secretions. It prevents sputum retention and has been shown to be an effective measure in patients with severe pulmonary disorders, in patients with neurologic deficits, and in patients who have undergone major surgical procedures [1-4].

Minitracheotomy was reported on for the first time by Matthews and Hopkinson in 1984 [1]. In their procedure, the cannula was introduced into the trachea through a small incision in the cricothyroid membrane using a guarded knife and an introducer. Later, other authors advocated a Seldinger dilatation technique to facilitate performance of the procedure. This involved passing a needle through the cricothyroid membrane and then, after insertion of a guide wire, the placement of the cannula with the help of a dilatator [5].

Because we were not completely satisfied with the position of the cannula through the cricothyroid membrane and because of our excellent experience with full sized percutaneous tracheotomy we started to use a percutaneous minitracheotomy in the subcricoid position. We describe here our experience in the first 50 patients who underwent this procedure at our institution.

\section{Patients and methods}

Between July 1990 and July 1993, 50 elective percutaneous minitracheotomies were carried out. These patients consisted of 36 men and 14 women with a mean age of 63 years (range, 22 to 88 years). Their underlying reasons necessitating minitracheotomy are listed in Table 1. Thirty-one of the patients had previously required endotracheal intubation for mechanical ventilation for a median time of 18 days. They were too weak to clear their superfluous bronchial secretions and, before extubation, a minitracheotomy cannula was inserted next to the translaryngeal tube. Thirteen patients received their cannula the end of a surgical procedure because they had difficulty coughing up bronchial secretions even before the operation. In six patients, the cannula was placed because they could not clear sputum, and this resulted in progressive pulmonary distress.

Minitracheotomy was carried out by four senior surgeons and four surgical trainees. Surgical trainees performed their first procedures under close supervision of the one surgeon who was most experienced with the procedure. If the procedure was carried out in an endotracheally intubated patient, the anaesthetist was responsible for withdrawing the endotracheal tube and monitoring the patient's oxygen saturation and blood pressure. 
Table' 1 . Underlying disease in 50 patients undergoing percutaneous subcricoid minitracheotomy

Condition

No. of patients

Thoracic and upper abdominal surgery

Neurological disease

Thoracic trauma

Chronic bronchitis

Upper airways obstruction

Total

The technique we use is similar to the percutaneous dilatational tracheotomy technique [6,7]. The patient is placed supine with his or her neck hyperextended. The cricoid cartilage is palpated, and, after local infiltration of $2 \%$ lidocaine hydrochloride, a small vertical skin incision is made. In the endotracheally intubated patient, the tube is withdrawn so that the tip is just below the vocal cord. The tracheal lumen is then punctured below the first tracheal ring with a (cannulated) needle attached to a syringe. The intratracheal position of the needle is confirmed by the aspiration of air into the syringe. A guide wire is placed inside the trachea. The minitracheotomy cannula with an inside diameter of $4 \mathrm{~mm}$, loaded over the dilatator, is then passed over the guide wire into the tracheal lumen using firm pressure.

Three types of commercially available kits have been used during the study period. From July 1990, a Cook minitracheotomy kit (No. C-CMTS-100; Cook, Son, the Netherlands) was used. Because of reported complications with this type of cannula, the set was not available from September 1991 to June 1993 and we switched to using the Minitrach II-Seldinger kit (Portex ${ }^{\star}$, Resprecare, The Hague, The Netherlands). Since June 1993 we have used the Cook ${ }^{*}$ minitracheotomy kit (No. C-TCCS-400-TT) containing a disposable scalpel, an 18-gauge cannulated needle, a J-tipped guidewire, a 12-French dilatator, and a reclosable flanged minitracheotomy cannula.

To facilitate the introduction of the cannula, we currently use a second larger dilatator that has been added to the set. Especially in young male patients, the force needed to insert the cannula is reduced substantially by this additional dilatational step. 


\section{Results}

The procedure was accomplished successfully in 48 patients. In two patients $(4 \%)$, the cannula was not inserted into the tracheal lumen but pretracheally in one and through the tracheal lumen into the paratracheal space the other. Both times the procedure was carried out by a senior surgeon unexperienced with either percutaneous tracheotomy or percutaneous minitracheotomy. Both cannulas were removed and a new cannula was inserted without problems or sequelae.

Minor complications occurred in three patients $(6 \%)$; and consisted of minor skin edge bleeding in one and subcutaneous emphysema in two. The bleeding was controlled by suture ligation, and the subcutaneous emphysema was minor and required no therapy. Secondary displacement of the cannula occurred in the first four endotracheally intubated patients. In all the cannula had been inserted next to the endotracheal tube at the end of their operation. When the tube was removed, the minitracheotomy cannula came out as well. Later this complication was simply avoided by holding the minitracheotomy cannula in place during extubation.

The mean duration of minitracheotomy was 11 days (range 1 to 50 days). Thirty-six patients were decannulated successfully, one of whom died in the hospital of congestive cardiac failure. In seven patients, the minitracheotomy was converted to a larger tracheotomy cannula using the percutaneous dilatational technique. In two, bronchial secretions proved to be too viscid to be aspirated through a cannula with a 4-mm lumen, and a cannula with an inside diameter of $7 \mathrm{~mm}$ was inserted. Mechanical ventilatory support was required in five, who suffered respiratory failure despite their minitracheotomy, and their cannula was converted to one with an inside diameter of $8.5 \mathrm{~mm}$. Seven patients died during the time the minitracheotomy cannula was in place. They were judged to be unsuitable candidates for ventilation, in two because of a disseminated malignancy and in five because of old age with severe chronic obstructive pulmonary disease. Of the 50 patients receiving a minitracheotomy, 11 died in the hospital. Their cause of death was never tracheotomy related, but was due to respiratory insufficiency in five, sepsis in four, pulmonary embolus in one, and congestive heart failure in one. Two of the patients with sepsis and the one with pulmonary embolus were mechanically ventilated after conversion to a full sized tracheotomy cannula.

Decannulation was easy in all patients. Their wounds healed nicely without signs of infection within three days of decannulation with only minimal scarring.

Outpatient follow-up was complete. No late complications were seen one to 
four years after the procedure. In particular, no clinical signs of tracheal stenosis or voice changes were found.

\section{Discussion}

Minitracheotomy gives permanent access to the trachea and makes frequent aspiration of bronchial secretions possible. It is considered superior to both translaryngeal intubation and full sized tracheotomy. Translaryngeal intubation is uncomfortable for the patient, often requires sedation and makes eating, speaking and coughing impossible [1]. The mortality and the complication rates associated with tracheotomy are relatively high; the complication rate varies from $6 \%$ to $51 \%$, although it may decrease substantially to rates of $3 \%$ to $25 \%$ if the percutaneous technique is used [8-10]. A normal sized tracheotomy cannula with an outside diameter of 12 or $13 \mathrm{~mm}$ abolishes the ability to eat and to generate a normal explosive cough. A minitracheotomy is much smaller and remains the better choice if the patient is not able to evacuate his or her own superfluous bronchial secretions. The best position for the minitracheotomy cannula may be questionable.

The minitracheotomy cannula is commonly inserted through the cricothyroid membrane $[1,4,5,11,12]$. Minicricothyroidotomy would be a more accurate name for a cannula in this position, however [12]. Minitracheotomy in the subcricoid position has several advantages over a cannula placed through the cricothyroid membrane. First, the procedure can be performed percutaneously in the endotracheally intubated patient. The oral tube is then withdrawn between the vocal cords. After the minitracheotomy cannula has been inserted, the endotracheal tube can be placed in its former position. If a minicricothyroidotomy is performed in the intubated patient, the cannula has to be introduced between the tube and the cricothyroid membrane using an open procedure, and this carries a higher risk of misplacement of the cannula [13]. Second, many clinicians are reluctant to use a cannula placed through the cricothyroid membrane because of the risk of subglottic stenosis and voice changes. In some reports, this risk in adults is described as being only minimal if a small-bore minitracheotomy cannula is used for a short time [11,14]. However, it remains a devastating complication, and its incidence is increased in the setting of predisposing conditions such as an injured larynx caused by prolonged intubation [15]. Third, it is possible to convert a minitracheotomy to a larger subcricoid cannula if bronchial secretions prove to be too viscid to be aspirated through a small minitracheotomy cannula or if a patient with progressive respiratory failure has to be ventilated. In this event, a guidewire is passed through the minitracheotomy and the cannula is removed. After a few dilatational steps, a cannula with an inside 
diameter of $8 \mathrm{~mm}$ or more is then easily introduced into the trachea. In our series, conversion to a full sized tracheotomy was carried out in seven patients (14\%). Fourth, the upper airways are wider below the cricoid cartilage than they are at the level of the larynx and the false vocal cords. Cannulas with an inside diameter of $4 \mathrm{~mm}$ and larger can be used in the subcricoid position with little obstruction of the trachea and good preservation of normal glottic function. They only minimally interfere with speaking and eating.

Access to the trachea below the cricoid cartilage appears to be more difficult than that through the cricothyroid membrane. As a result, there may be more operative complications in association with the subcricoid procedure. However, the complication rate of minicricothyroidotomy is comparable with or even higher than our operative complication rate of $10 \%[3,16,17]$. Twice the cannula was misplaced during introduction. Both times the procedure was carried out by a senior surgeon who was not experienced with percutaneous dilatational tracheotomy, and who was performing a minitracheotomy for the first time. To prevent malplacement of the cannula, one should take care to confirm that air can be aspirated into the syringe after the tracheal lumen is punctured. After removal of the needle and before insertion of the guidewire, the intraluminal position of the introducer catheter must be checked again. The minitracheotomy cannula has to be introduced more or less upward. In a patient with a hyperextended neck, the distal trachea runs slightly toward the back. If forced downward, the cannula may slide off on the anterior aspect of the trachea as the guidewire is kinked, resulting in a pretracheal insertion of the cannula [18].

The most common complications of percutaneous dilatational tracheotomy also include haemorrhage and subcutaneous emphysema. In reports on this technique, the incidence of these usually minor complications is low $[9,10]$. Secondary displacement of the cannula occurred in the first four endotracheally intubated patients who underwent this procedure. As mentioned earlier, it was simply avoided by holding the cannula in place during extubation, and never occurred again. We do not believe that percutaneous subcricoid minitracheotomy carries a higher complication rate than the technically more difficult percutaneous dilatational tracheotomy, and our results confirm this. However, to compare percutaneous subcricoid minitracheotomy with percutaneous minicricothyroidotomy a prospective randomised trial is necessary.

In conclusion, we found that percutaneous subcricoid minitracheotomy is an easy procedure to perform and is associated with a low complication rate. Because of the advantages of the subcricoid position, we prefer percutaneous subcricoid minitracheotomy in patients who require frequent suctioning of bronchial secretions. 


\section{References}

1. Matthews HR, Hopkinson RB. Treatment of sputum retention by minitracheotomy. Br J Surg 1984;71:147-50.

2. Gupta A, McClelland MR, Evans A, el Masri WS. Minitracheotomy in the early respiratory management of patients with spinal injuries. Paraplegia 1989;27:269-77.

3. Pedersen J, Schurizek BA, Melsen NC, Juhl B. Is minitracheotomy a simple and safe procedure? A prospective investigation in the intensive care unit. Intensive Care Med 1991;17:333-5.

4. Issa MM, Healy DM, Maghur HA, Luke DA. Prophylactic minitracheotomy in lung resections. A randomized controlled study. J Thorac Cardiovasc Surg 1991;101:895-900.

5. Corke C, Cranswick P. A Seldinger technique for minitracheostomy insertion. Anaesth Intensive Care 1988; 16:206-7.

6. Ciaglia P, Firsching R, Syniec C. Elective percutaneous dilatational tracheostomy. Chest 1985;87:715-9

7. Anderson $\mathrm{HL}$, Bartlett RH. Elective tracheotomy for mechanical ventilation by the percutaneous technique. Clin Chest Med 1991;12:55.5-60.

8. Stock MC, Woodward CG, Shapiro BA, Cane RD, Lewis V, Pecaro B. Perioperative complications of elective tracheostomy in critically ill patients. Crit Care Med 1986;14:861-3.

9. Hazard P, Jones C, Benitone J. Comparative clinical trial of standard operative tracheostomy with percutaneous tracheostomy. Crit Care Med 1991;19:1018-24.

10. Ciaglia P, Graniero KD. Percutaneous dilatational tracheostomy. Chest 1992;101:464-7.

11. Ophir D, Konichezky S. Minicricothyrotomy for tracheobronchial toilet. Ann Otol Rhinol Laryngol 1990;99:337-9.

12. Au J, Walker WS, Inglis D, Cameron EWJ. Percutaneous cricothyroidostomy (minitracheostomy) for bronchial toilet: results of therapeutic and prophylactic use. Ann Thorac Surg 1989;48:850-2.

13. Mastboom WJB, Wobbes T, van den Dries A, Goris RJA. Bronchial suction by minitracheotomy as an effective measure against sputum retention. Surg Gynecol Obstet 1991:173:187-92.

14. Campbell JB, Watson MG, Povey L, Shenoi PM. Minitracheotomy and laryngeal function. A prospective study. J Laryngol Otol 1988; 102:49-52.

15. Brantigan CO, Grow JB. Subglottic stenosis after cricothyroidotomy. Surgery $1982 ; 91: 217-21$.

16. Randell T, Kalli I, Lindgren L. Minitracheotomy: complications and follow-up with fibreoptic tracheoscopy. Anaesthesia 1990;45:875-9.

17. Wain JC, Wilson DJ, Mathisen DJ. Clinical experience with minitracheostomy. Ann Thorac Surg 1990;49:881-6.

18. Wang MB, Berke GS, Ward PH, Calcaterra TC, Watts D. Early experience with percutaneous tracheotomy. Laryngoscope 1992;102:157-62. 

Chapter 5

Late complications of percutaneous dilatational tracheotomy

L.W.E. van Heurn, R. Goei, I. de Ploeg, G. Ramsay, P.R.G. Brink

Chest 1996;110:1572-6 


\section{Introduction}

Percutaneous dilatational tracheotomy (PDT) is a relatively new technique to introduce a cannula into the trachea [1]. The trachea is entered by direct needle puncture and the opening into the trachea is dilated over a guide wire with Teflon dilatators so that a tracheal cannula can be introduced. This method is easier and faster than the conventional open technique with significantly less early complications [2-4]. Some surgeons are reluctant to use the percutaneous technique because the incidence of tracheal stenosis is unknown [5]. Only few prospective studies with a limited number of patients have been performed to assess tracheal stenosis after PDT $[2,6]$.

In this study we evaluate tracheal stenosis and other late complications of PDT prospectively. The incidence of tracheal stenosis is accurately analysed by tomography of the trachea [7-10].

\section{Patients and methods}

A prospective review was undertaken to assess the late complications of PDT. All adult patients who were successfully decannulated after PDT between January 1, 1992, and January 1, 1995, were studied. In this period 123 consecutive patients underwent PDT. Thirty-nine patients died after a median duration of cannulation of 20 days (range 1-130) and one patient was still cannulated at the time of the study. Excluded from analysis were three patients with a previous tracheotomy. Eighty patients entered analysis. Their characteristics are shown in Table 1.

PDT was performed by three surgeons and four surgical trainees under close supervision. A commercially available kit (Cook ${ }^{\circledR}$ Company, Son The $\mathrm{Ne}$ therlands) was used. The technique has been described previously by Ciaglia et al. and Anderson et al. [1,11]. All patients received a Shiley 8 tracheal cannula with an outside diameter of $12 \mathrm{~mm}$ (Laméris, Veenendaal, The Netherlands).

Operative complications and complications during cannulation had been registered in a separate study [12]. Late complications were assessed prospectively with complete follow-up. Patients alive at the time of the study were examined as outpatients in the hospital or at home. Dyspnea and voice changes were assessed by a detailed interview. Voice changes were registered only in patients without a history of neck- or left thoracic surgery, because of the possibility of surgical recurrent nerve damage. The tracheotomy scar was measured. Plain anteroposterior and lateral tomograms of the trachea with a $3 \mathrm{~mm}$ scanning distance were performed and reviewed by an experienced 
radiologist. The dimensions and topography of the tracheal lesions were measured. Using the tomograms in two directions, a reduction in the cross sectional area of the trachea greater than $10 \%$ was defined as tracheal stenosis.

Table 1. The patients characteristics of 80 patients successfully decannulated after percutaneous dilatational tracheotomy

Characteristics

No.

Male/female

$47 / 33$

Age, yr, median (range)

$61.5(18-83)$

Duration of oral intubation, day,

median (range)

Duration of cannulation, day, median (range)

Indication for tracheotomy

Prolonged ventilation

Bronchial toilet

Airway protection

The primary outcome measures voice change, scar level and tracheal stenosis were statistically analysed. Univariate and multivariate relative risk analysis was carried out for factors measurable at the time of decannulation with the use of logistic regression. Risk factors investigated were as follows: sex (male, female), age (60 years or younger, older than 60 years), surgeon (most experienced, others), duration of previous oral intubation (14 days or less, more than 14 days) and the duration of cannulation (28 days or less, more than 28 days). Age, surgeon, duration of translaryngeal intubation and duration of cannulation were used in all multivariate analyses. Proportions are presented with $95 \%$ confidence intervals. A p-value of 0.05 or less was considered evidence of a significant difference between groups.

\section{Results}

Fourteen patients died between decannulation and the moment of the study. Their cause of death, listed in Table 2, was never tracheotomy related. Operative complications and complications during cannulation included minor haemorrhage in two and granulation tissue at the tip of the cannula in one, which was removed endoscopically. Sixty-six patients, alive 3 to 39 months (mean 16 
months) after decannulation, were reviewed for late complications.

Table 2. Cause of death of 14 patients who died after decannulation

Cause of death

No. of patients

\begin{tabular}{lc}
\hline Malignancy & 8 \\
Cerebrovascular accident & 2 \\
Renal failure & 1 \\
Gastrointestinal hemorrhage & 1 \\
Myocardial infarction & 1 \\
Pulmonary embolus & 1 \\
Total & $\overline{14}$ \\
\hline
\end{tabular}

Tomography of the trachea was performed in 54 patients. Ten patients refused the procedure and two were unable to undergo the investigation due to a neurological deficit. Of 54 patients with a tomogram of the trachea, 14 (26\%) had developed a tracheal stenosis of more than $10 \%$. None had symptoms of dyspnea. The estimated diameter reduction of the trachea was between $10 \%$ and $25 \%$ in eleven, between $25 \%$ and $50 \%$ in two, and between $50 \%$ and $75 \%$ in one patient. The site of the stenosis varied from 25 to $70 \mathrm{~mm}$ below the vocal cords, without preference for a certain distance. Twelve of the stenoses were situated anteriorly or anterolaterally. Once the stenosis was at the posterior aspect of the trachea and once it was circumferential.

Table 3 shows that in a univariate analysis the operating surgeon was the only risk factor for the development of tracheal stenosis. One of the surgeons had a large experience with the technique and he had a significantly lower incidence of tracheal stenosis, which remained significant after other factors were taken into account.

In 64 patients the tracheotomy scar was less than $2 \mathrm{~cm}$ in length. In two patients in whom PDT was performed through the recent operative wound to protect the airway after thyroid surgery, the scar was longer and required correction under local anaesthesia in one. Thirteen patients had a retracted scar, of whom two had a persistent tracheocutaneous fistula after 111 and 152 days of cannulation, respectively. Both fistulas were surgically closed. 
Table 3. Relative risk estimation for tracheal stenosis by logistic regression models.

\begin{tabular}{|c|c|c|c|c|c|}
\hline & \multirow[b]{2}{*}{ Level } & \multirow[b]{2}{*}{ Rate } & \multicolumn{2}{|c|}{ Odds ratio (95\% CL) } & \multirow[b]{2}{*}{$p$-value } \\
\hline & & & $\begin{array}{l}\text { Univariate } \\
\text { analysis }\end{array}$ & $\begin{array}{l}\text { Multivariate } \\
\text { analysis }\end{array}$ & \\
\hline \multirow[t]{2}{*}{ Surgeon } & Most experienced & $1 / 19$ & 1 & 1 & \\
\hline & Others & $13 / 35$ & $10.62(1.27-89.04)$ & $30.87(2.87-332.0)$ & $\mathrm{p}=0.03$ \\
\hline \multirow{2}{*}{$\begin{array}{l}\text { Duration of intubation } \\
\text { (day) }\end{array}$} & 215 & $3 / 22$ & 1 & 1 & \\
\hline & $=14$ & $11 / 32$ & $3.31(0.80-13.70)$ & $9.50(1.75-51.75)$ & $\mathrm{p}=0.10$ \\
\hline Duration of cannulation & $=29$ & $5 / 19$ & 1 & 1 & \\
\hline (day) & $\leq 28$ & $9 / 35$ & $1.03(0.29-3.68)$ & $1.28(0.27-6.16)$ & $p=0.96$ \\
\hline \multirow[t]{2}{*}{ Age (year) } & $\leq 60$ & $5 / 24$ & 1 & 1 & \\
\hline & $=61$ & $9 / 30$ & $1.63(0.46-5.72)$ & $3.17(0.64-15.62)$ & $p=0.45$ \\
\hline
\end{tabular}

As shown in Table 4, patients cannulated for more than four weeks were at increased risk for a retracted, sunken, scar, also when the statistical analysis is adjusted for other factors $(p=0.002)$. Both patients with a duration of cannulation of more than three months developed a tracheocutaneous fistula.

Table 4. Relative risk estimation for scar retraction by logistic regression models.

\begin{tabular}{|c|c|c|c|c|c|}
\hline & \multirow[b]{2}{*}{ Level } & \multirow[b]{2}{*}{ Rate } & \multicolumn{2}{|c|}{ Odds ratio (95\% CL) } & \multirow[b]{2}{*}{ p-value } \\
\hline & & & $\begin{array}{l}\text { Univariate } \\
\text { analysis }\end{array}$ & $\begin{array}{l}\text { Multivariate } \\
\text { analysis }\end{array}$ & \\
\hline Duration of cannulation & $\div 28$ & $3 / 42$ & 1 & 1 & \\
\hline (day) & 229 & $10 / 24$ & $9.28(2.23-38.70)$ & $18.41(3.42-99.10)$ & $p=0.002$ \\
\hline Duration of intubation & $\geq 15$ & $3 / 28$ & 1 & 1 & \\
\hline (day) & $=14$ & $10 / 38$ & $2.98(0.73-12.05)$ & $7.15(1.34-41.35)$ & $p=0.13$ \\
\hline \multirow[t]{2}{*}{ Surgeon } & Others & $8 / 43$ & 1 & 1 & \\
\hline & Most experienced & $5 / 23$ & $1.22(0.35-4.26)$ & $1.04(0.21-5.33)$ & $p=0.76$ \\
\hline \multirow[t]{2}{*}{ Age (year) } & $\geq 61$ & $7 / 37$ & 1 & 1 & \\
\hline & .60 & $6 / 29$ & $1.12(0.33-3.78)$ & $1.57(0.34-7.25)$ & $p=0.86$ \\
\hline
\end{tabular}

Of 61 patients analysed, $13(21 \%)$ had the subjective feeling that their voice had changed. Subjective assessment by the patient included severe hoarseness in one, slight intermittent hoarseness provoked by prolonged speech in six, difficulty reaching high notes with singing in four, and a loss of power of the voice in two patients. Positive associations between voice changes and sex, age, surgeon, duration of translaryngeal intubation, duration of tracheal cannulation and the site of tracheal stenosis was not found. Although none of the six patients without intubation prior to PDT had a changed voice, this finding failed to reach significance. 


\section{Discussion}

There are no generally accepted criteria to quantify tracheal damage after tracheotomy. Clinical symptoms and physical examination are not sensitive in the detection of tracheal stenosis [7,8]. Dyspnea and stridor at rest appear only if there is a stenosis of $50 \%$ or more. Pulmonary function tests are diagnostic only when the airway is $8 \mathrm{~mm}$ or less in diameter $[7,8]$. Routine chest roentgenograms are not useful [9]. Plain linear tomography shows excellent detail of the airway in coronal and sagittal views and may be the only radio-graphic procedure performed in benign stenosis [7-10]. Computed tomography (CT) is useful but the axial views make it difficult to visualise the contour and the extent of airway injury and adds little or no information over plain tomography $[8,10]$. Tracheoscopy is a good diagnostic technique but it is an invasive procedure that can fully occlude the airway if there is a severe stenosis. It is frightening for the patient, and is not advisable for screening the airway if a large follow-up is required, but it should be performed in all patients undergoing resection of a tracheal stenosis [9].

Examination of the patients was carried out at least three months after decannulation, because tracheal stenoses usually develop two to 12 weeks after decannulation [13]. Tomography of the trachea was performed in $82 \%$ of the patients at risk for tracheal stenosis, which makes an accurate analysis of the long-term sequelae of PDT possible. It is unlikely that the selection of patients undergoing radiologic examination has influenced the results. If there is a bias, it will rather give an overestimation of the incidence of tracheal stenosis than an underestimation. Only one patient, known with congestive cardiac failure, in the group who refused tomography was breathless on exertion. The others were asymptomatic. The most important reason not to take part in the study was the absence of complaints.

Our incidence of tracheal stenosis of $26 \%$ compares well with historical experiences of conventional tracheotomy. Using tomography of the trachea Stauffer et al. reported tracheal stenosis of more than $10 \%$ in nine of 15 patients after conventional tracheotomy and Davidson et al. described tracheal narrowing varying between $34 \%$ and $86 \%$ in 48 out of 50 patients $[7,14]$. In both studies the most common site of the stenosis was at the level of the stoma and tracheal lesions due to the cannula cuff were rare. After PDT, there is a small stoma and the cannula is snugged between pretracheal tissue avoiding movements of the cannula, one of the considered risk factors for tracheal damage and tracheal stenosis $[15,16]$.

It is difficult to assess if the lowe- areas of narrowing of the trachea correspond to the stoma itself, to the cuff or to the tip of the cannula. PDT is a blind 
technique and there is a large variation in the level at which the trachea is punctured [17].

The only significant risk factor for the development of tracheal stenosis was the operating surgeon. A tracheal cannula that is inserted obliquely may fracture its proximal ring giving protrusion of the anterior tracheal wall into the lumen [17]. Therefore, oblique puncture of the trachea and extreme hyperextension of the neck at insertion of the cannula, which may result in an oblique position of the cannula when the head is brought forward to its normal position, should be avoided. Other possible risk factors such as sex, age, tracheal diameter, duration of prior translaryngeal intubation and duration of cannulation were not significant.

One of the limitations of the study is that the incidence of voice changes was assessed with the subjective feelings of the patient and his or her relatives. Laryngoscopy to register laryngeal damage was not performed. Voice changes after PDT are considered to be rare [3,6]. Mild voice changes have been reported before by Ciaglia et al. and paralysis of one of the vocal cords was described by Delany et al. [3,18]. Our median duration of translaryngeal intubation of 13 days preceding tracheotomy is relatively long [19-22]. Laryngeal damage is a common complication of prolonged intubation $[23,24]$. In this study the duration of translaryngeal intubation was not an accurate predictor of the development of voice changes. However, there were no voice changes in six patients without previous intubation. Others have shown that the duration of intubation is the most important variable related to the severity of laryngeal damage and even vocal cord paralysis has been reported as a complication of intubation [19,23]. It is difficult to assess if PDT is responsible for the voice changes in this study. It has been suggested that tracheotomy related superinfection of the larynx may determine the severity of laryngeal damage in patients with an injured larynx by oral intubation [19]. Scarring of the damaged vocal cords, which lie in apposition if a patient ventilates through a tracheotomy cannula, can lead to fusion and voice changes [25]. Also, a high tracheotomy between the cricoid cartilage and the first tracheal ring can cause damage of the cricoid and laryngitis, which may result in voice changes.

Scars after PDT are generally small and cosmetically acceptable. Retraction of the scar was related to the duration of cannulation and was not seen in patients cannulated less than ten days. Epithelialisation of the cannula tract may cause a pit and even a tracheocutaneous fistula after a duration of cannulation of more than months $[10,26]$. Tracheocutaneous fistulas also occur after conventional tracheotomy and it is unlikely that this complication is related to the percutaneous procedure [27].

We conclude that the incidence of tracheal stenosis after PDT is low. In 
addition, prospective studies comparing the early complications of conventional tracheotomy and PDT are favourable to the latter. Thus fear of excess complications should not cause a surgeon to avoid using the percutaneous dilatational technique $[2,28]$. However, experience with the technique is important to avoid late tracheal stenosis.

\section{References}

1. Ciaglia P, Firsching R, Syniec C. Elective percutaneous dilatational tracheostomy. Chest 1985;87:715-9.

2. Hazard $\mathrm{P}$, Jones $\mathrm{C}$, Benitone J. Comparative clinical trial of standard operative tracheostomy with percutaneous tracheostomy. Crit Care Med 1991;19:1018-24.

3. Ciaglia P, Graniero KD. Percutaneous dilatational tracheostomy. Chest 1992;101:464-7.

4. Friedman $Y$, Mayer AD. Bedside percutaneous tracheostomy in critically ill patients. Chest 1993;104:532-35.

5. Heffner JE. Percutaneous tracheostomy - novel technique or technical novelty? Intensive Care Med 1991;17:252-3.

6. Fischler MP, Kuhn M, Cantieni R, Frutiger A. Late outcome of percutaneous dilatational tracheostomy in intensive care patients. Intensive Care Med 1995;21:475-81.

7. Stauffer $几$, Olson DE, Petty TL. Complications and consequences of endotracheal intubation and tracheostomy. Am J Med 1981;70:65-76.

8. Streitz JM, Shapshay SM. Airway injury after tracheotomy and endotracheal intubation. Surg Clin North Am 1991;71:1211-30.

9. Mansour KA, Lee RB, Miller JI. Tracheal resections: lessons learned. Ann Thorac Surg 1994;57:1120-5.

10. Wood DE, Mathisen DJ. Late complications of tracheotomy. Clin Chest Med $1991 ; 12: 597-609$.

11. Anderson HL, Bartlett RH. Elective tracheotomy for mechanical ventilation by the percutaneous technique. Clin Chest Med 1991;12:555-60.

12. Van Heurn LWE, van Geffen GJ, Brink PRG. Clinical experience with percutaneous dilatational tracheostomy: report of 150 cases. Eur J Surg 1996; 162:53 l-5.

13. Weber AL, Grillo HC. Tracheal stenosis: an analysis of 151 cases. Radiol Clin North Am 1978; 16:291-308.

14. Davidson IA, Cruikshank AN, Duthie WH, Bargh W, Duncan JG. Lesions of the trachea following tracheostomy and endotracheal intuhation. Proc Royal Soc Med 1971;64:88692.

15. Andrews MJ, Pearson FG. The incidence and pathogenesis of tracheal injury following cuffed tube tracheostomy with assisted ventilation: analysis of a two-year prospective study. Ann Surg 1971;173:249-63.

16. El-Naggar M, Sadapogan S, Levine H, Kantor H, Collins VJ. Factors influencing choice between tracheostomy and prolonged translaryngeal intubation in acute respiratory failure: a prospective study. Anesth Analg 1976;55:195-201.

17. Van Heurn LWE, Theunissen PHMH, Ramsay G, Brink PRG. Patholngic changes of the trachea after percutaneous dilatational tracheotomy. Chest 1996;109:1466-9.

18. Delany S, Stokes J. Percutaneous dilational tracheostomy: one years experience. N Z Med J 1991;104:188-9.

19. Whited RE. A prospective study of laryngotracheal sequelae in long term intubation. 
Laryngoscope 1984;94:367-77.

20. Heffner JE, Miller KS, Sahn SA. Tracheostomy in the intensive care unit. Part 1: indications, technique, management. Chest 1986;90:269-74.

21. Griggs WM, Myburgh JA, Worthley LI. A prospective comparison of a percutaneous tracheostomy technique with standard surgical tracheostomy. Intensive Care Med 1991;$17: 261-3$.

22. Toursarkissian B, Zweng TN, Kearney PA, Pofahl WE, Johnson SB, Barker DE. Percutaneous dilational tracheostomy: report of 141 cases. Ann Thorac Surg 1994;57:862-7.

23. Kastanos N, Miro RE, Perez AM, Mir AX, Agusti-Vidal A. Laryngotracheal injury due to endotracheal intubation: incidence, evolution, and predisposing factors. A prospective long-term study. Crit Care Med 1983;11:362-7.

24. Colice GL, Stukel TA, Dain B. Laryngeal complications of prolonged intubation. Chest 1989;96:877-84.

25. Kirchner JA. Tracheotomy and its problems. Surg Clin North Am 1980;60:1093-1104.

26. Winkler WB, Karnik R, Seelmann O, Havlicek J, Slany J. Bedside percutaneous dilational tracheostomy with endoscopic guidance: experience with 71 ICU patients. Intensive Care Med 1994;20:476-9.

27. Lawson DW, Grillo HC. Closure of persistent tracheal stomas. Surg Gynecol Obstet 1970;130:995-6.

28. Leinhardt DJ, Mughal M, Bowles B, et al. Appraisal of percutaneous tracheostomy. Br J Surg 1992;79:255-8. 


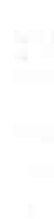


Chapter 6

\section{Pathologic changes of the trachea after percutaneous dilatational tracheotomy}

L.W.E. van Heurn, P.H.M.H. Theunissen, G. Ramsay, P.R.G. Brink

Chest 1996;109:1466-9 


\section{Introduction}

Injury of the trachea is a well-known late complication of both translaryngeal intubation and tracheotomy [1,2]. After tracheotomy lesions of the trachea are found distally, at the site of the tip of the cannula or at the cuff site, and more proximally at the level of the stoma itself. The incidence of distal lesions due to pressure necrosis has been greatly reduced by the use of low-pressure cuffs [3]. Tracheal damage at the stoma site is related to a large stoma with a mobile cannula and to infection [4].

Percutaneous dilatational tracheotomy (PDT) is a relatively new technique to introduce a cannula into the trachea $[5,6]$. No surgical wound is made and the cannula is snugged between the surrounding tissue reducing movements of the cannula. An incision into the tracheal rings is not necessary and the rings remain theoretically intact. The parastomal infection rate is considerably lower than after conventional open tracheotomy [7,8]. A preliminary study of the effects of percutaneous tracheotomy on the trachea in dogs showed only minor microscopic changes of the trachea, and animals with tracheal stenosis were not found three months after tracheotomy [9].

We examined macroscopic and histopathologic changes of the trachea in patients who underwent PDT to assess the effects of PDT on the trachea.

\section{Patients and methods}

PDT was performed by four surgeons and surgical residents with a commercially available kit (Cook ${ }^{\star}$, Son, The Netherlands). The technique described by Ciaglia was followed [5]. After hyperextension of the neck and a small incision through the skin the first tracheal interspace was identified. The trachea was punctured with a cannulated needle on a syringe. The intraluminal position of the needle was checked, the syringe and the needle removed, and through the sheath a guidewire was introduced into the lumen. Over the guidewire, the tract was progressively dilated with tapered dilatators so that a Shiley size-8 tracheal cannula with an outside diameter of $12 \mathrm{~mm}$ (Laméris, Veenendaal, The Netherlands) could be introduced mounted on an appropriately sized dilatator.

In the 15 month period between November 1, 1993 and February 1, 1995, the tracheas of 12 consecutive patients who died after PDT were removed at autopsy. The cause of death was never tracheotomy related. The specimens were removed en bloc and were opened along the membraneous portion. The location of the tracheotomy and macroscopic damage were noted. The tracheas were photographed. The specimens were fixed in $10 \%$ formalin and embedded in paraffin. Hematoxylin-eosin-stained transverse sections were microscopically 
analysed.

The patient characteristics, the duration of cannulation and the duration of previous orotracheally intubation are listed in Table 1.

Table 1. The patient characteristics of 12 autopsies.

Characteristics

No. of patients

Male

7

Age (year), median (range)

$73.5(69-84)$

Duration of cannulation (days), median (range)

$16(2-122)$

Prior oral intubation (days), median (range)

$6(0-13)$

Nine patients were orotracheally intubated and received their cannula for prolonged ventilation. The other three received a cannula for bronchial toilet. Operative complications of the procedure and complications during cannulation, assessed by retrospective chart review, included bleeding in two patients. Suture ligation was necessary in one. In one patient cannulated for 122 days granulation tissue at the stomal site was removed by laser therapy.

Comparison of group characteristics was performed by the Fisher's exact test for categorical measures. A p-value of 0.05 or less was considered evidence of a significant difference between groups.

\section{Results}

The tracheotomy site in this group of patients varied greatly: Twice between the cricoid cartilage and the first ring, six times between the first and second ring, once through the thyroid isthmus between the second and third ring, and three times between the third and fourth ring.

Broken cartilaginous rings, the cricoid cartilage included, were registered in 11 patients, of whom six had more than one broken ring (Table 2). In all eight patients with a tracheotomy for more than 10 days, destruction and necrosis of one or more rings was found. This was significant compared with the group with a shorter duration of cannulation, in whom no destruction of rings was found $(p<0.005)$. In one patient cannulated for 122 days, two tracheal rings next to the cannula were almost completely devoid of cartilage with extensive ossification next to the rings. Necrosis of the cartilaginous rings with ossification at the outer side of the rings was always present if a patient had been cannulated for more than three weeks (Fig 1). It was found only in one patient with 
a shorter duration of cannulation $(p<0.01)$. There was no relation between damage of the cartilaginous rings and the position of the tracheal cannula.

Table 2. Damage of the trachea after percutaneous dilatational tracheotomy in 12 patients at autopsy.

Damage

No. of patients

Cartilaginous ring fracture 11

Destruction of one of more rings

Deep mucosal ulceration

Damage of the cricoid cartilage

Protrusion of the tracheal wall into the lumen

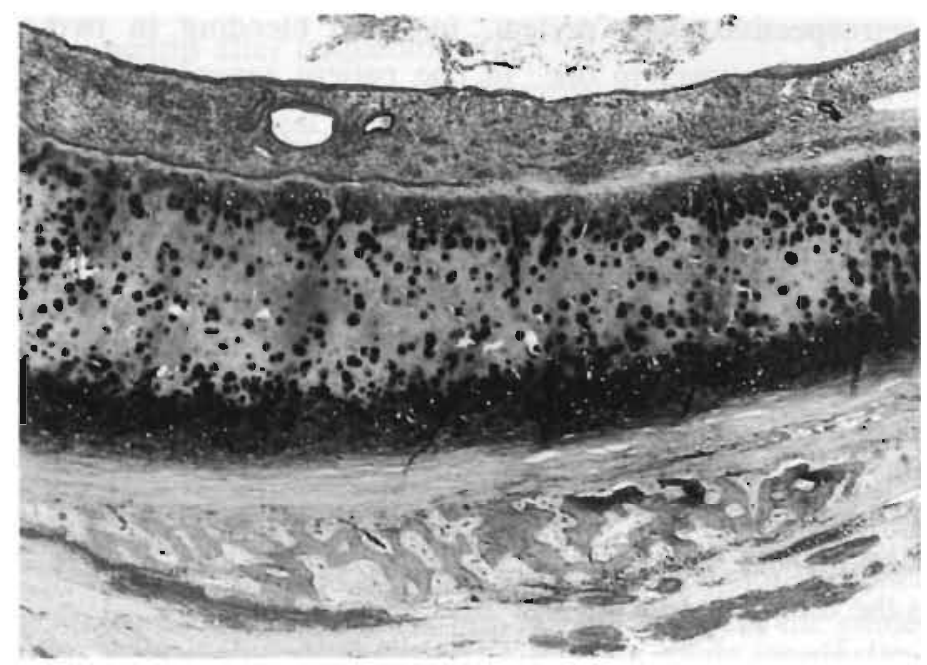

Figure 1. Reactive ossification on the outer side of a cartilaginous ring (hematoxylin-eosin, original $x 40$ ).

Both patients with their cannula just below the cricoid cartilage had a fracture of their cricoid. At the time of death they had been cannulated for two and five days. Necrosis of the cricoid was seen once at the outer side of the cartilage caused by a cannula that was inserted very obliquely into the tracheal lumen. 
Tracheal stenosis of $20 \%$ and $30 \%$ was registered in two patients cannulated for 20 and 12 days respectively. In both there was a broken tracheal ring just proximal to the tracheotomy site causing protrusion into the tracheal lumen. It was the result of a cannula tract that very obliquely entered the tracheal lumen.

Deep ulceration of the mucosa with exposure of the cartilaginous rings was present at the stomal site in 11 patients. In one patient cannulated for two days there was no mucosal ulceration. Only in those with a duration of cannulation of more than three weeks it did exceed more than two segments or more than half of the circumference of the trachea. In all others, ulcers were smaller. As on the inner side, there was damage on the outer side of the trachea. In six patients, one or more rings proximal to the cannula were bared on the outer side by continuous pressure from the cannula.

Ulceration of the distal trachea was usually shallow, although there was deeper ulceration with exposure of tracheal rings in four patients. It was located anteriorly and never exceeded more than three segments. Fractures or necrosis of the cartilage was never found. In one of three patients with a cannula for sputum retention, a deep anterior ulcer was found despite a deflated cuff. Ulceration of the compliant membraneous portion of the trachea was never seen.

Damage to the mucosa varied from incomplete to complete erosion, acute inflammatory reaction with submucosal oedema, and haemorrhage, which was especially present in both patients with operative bleeding. Metaplasia with flattening of the epithelium was identified in most patients. One had a cannula tract that was completely covered with stratified squamous epithelium.

\section{Discussion}

PDT is a relatively easy technique for the insertion of a tracheal cannula. The operative complications are low and in a prospective randomised study this technique was superior to the conventional open procedure [7]. However, few studies assess the late complications of this technique and involve only limited numbers of patients [10]. To our knowledge, pathologic studies have never been done. Although the number of tracheas in this study is relatively small and there is no comparison with tracheas after orotracheal intubation or conventional open tracheotomy, the results of the study may improve the percutaneous dilatational technique and prevent complications.

PDT is carried out by direct needle puncture of the trachea after a small skin incision. There are surgeons who dissect bluntly the pretracheal tissue with a mosquito clamp before they puncture the trachea. This enables clear palpation of the cricoid cartilage and the tracheal rings. Because we believed that this 
enlarged the risk of procedural bleeding, we have not generally used this technique. Others show good results of endoscopic guided PDT, which may be helpful to confirm the exact puncture site [11]. The puncture sites in this small group of patients show a large variation and show cricoid damage with the risk of laryngotracheal stenosis [12].

PDT is generally used at the subcricoid level or between the first and second tracheal rings [6]. Many surgeons are reluctant to use lower levels because of fear of haemorrhage from the isthmus of the thyroid. We found a fractured cricoid ring in both patients who underwent tracheotomy at the subcricoid level. Necrosis and destruction of cartilage was present in all patients with a duration of cannulation of more than 10 days. To prevent destruction of the cricoid cartilage and subglottic stenosis, we prefer insertion of the cannula below the first or preferably below the second tracheal ring.

Fractured rings were seen after both short and long duration of cannulation. Since the cannula used does not always fit tightly on the appropriate dilatator, it requires firm pressure to push the dilatator-cannula complex into the tracheal lumen. This can fracture the cartilaginous rings. After prolonged cannulation necrosis and softening of the rings make them vulnerable for fragmentation and damage from the cannula [13]. Similar to cartilaginous changes due to high pressure cuffs, necrosis and destruction of cartilaginous rings is present after 10 days to two weeks of cannulation [1]. It is caused by high pressure from the cannula. Destruction of rings can lead to loss of rigidity of the tracheal wall and to tracheal collapse. Reactive ossification, which was always present after three weeks of cannulation, may be able to prevent tracheal collapse.

Tracheal stenosis at the stomal site is generally seen anteriorly. It is caused by fibrosis of the trachea, granulation tissue next to the stoma, and a posterior displaced anterior tracheal wall [14]. A tracheal cannula that is inserted obliquely may fracture its proximal ring and result in protrusion of the tracheal wall into the lumen (Figure 2). Extreme hypertension of the neck for adequate exposure pulls the trachea upward. If in this position a skin incision is made over the first tracheal ring, the trachea is punctured, and a cannula inserted, the tract of the cannula becomes oblique when the head is brought forward to its normal position at the end of the procedure. Also, the trachea recedes from the surface as it passes down from the level of the cricoid cartilage to the carina. Puncture at a right angle to the skin means an oblique puncture of the trachea. Installation of the cannula may fracture the ring above the site of the entry and indentation of the anterior tracheal wall. 


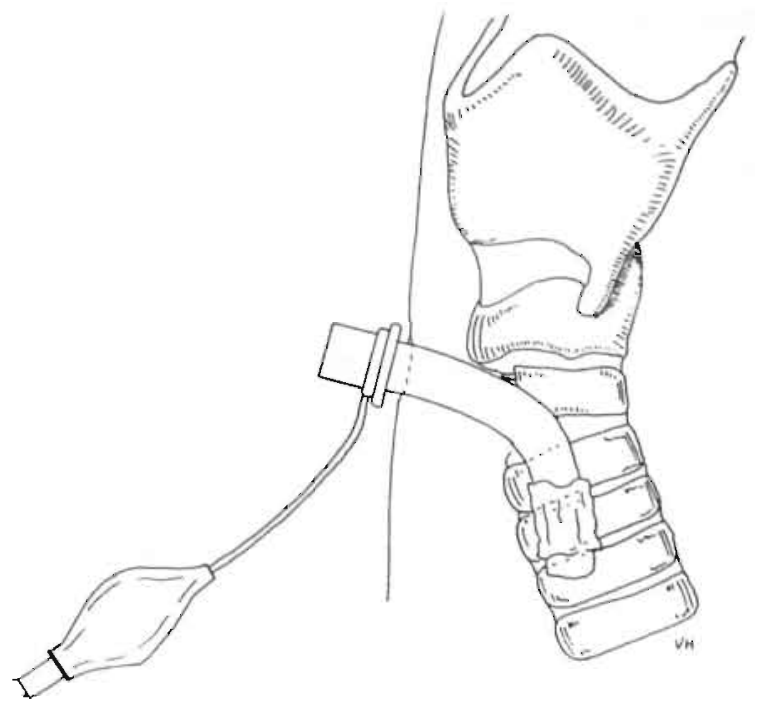

Figure 2. A cunnula inserted obliquely into the tracheal lumen with protrusion of the tracheal wall.

Since 1990, we have performed more than 200 PDTs at De Wever Hospital with excellent early results [15]. Since details are of importance to avoid longterm complications, this pathologic study may be helplul in improving the technique used. After clear identification of the tracheal rings, the trachea is punctured below the first or preferably the second tracheal ring. An oblique position of the cannula to the trachea should be avoided.

\section{References}

1. Cooper JD, Grillo HC. The evolution of tracheal injury due to ventilatory assistance through cuffed tubes: a pathologic study. Ann Surg 1969;169:334-48.

2. Donnelly WH. Histopathology of endotracheal intubation: an autopsy study of 99 cases. Arch Pathol 1969;88:511-20.

3. Grillo HC, Cooper JD, Geffin B, Pontoppidan H. A low-pressure cuff for tracheostomy tubes to minimize tracheal injury: a comparative clinical trial. J Thorac Cardiovdse Surg 1971;62:898-907.

4. Streitz JM, Shapshay SM. Airway injury after tracheotomy and endotracheal intubation. Surg Clin North Am 1991;71:1211-30.

5. Ciaglia P, Firsching R, Syniec C. Elective percutaneous dilatational tracheostomy: a simple bedside procedure: preliminary report. Chest $1985 ; 87: 715-9$.

6. Ciaglia P, Graniero KD. Percutaneous dilatational tracheostomy: results and long-term follow-up. Chest 1992;101:464-7.

7. Hazard $P$, Jones $C$, Benitone J. Comparative clinical trial of standard operative tracheostomy with percutaneous tracheostomy. Crit Care Med 1991;19:1018-24. 
8. Griggs WM, Myburgh JA, Worthiey LIG. A prospective comparison of a percutaneous tracheostomy technique with standard surgical tracheostomy. Intensive Care Med 1991;17:261-3.

9. Schachner A, Ovil J, Sidi J, Avram A, Levy MJ. Rapid percutaneous tracheostomy. Chest 1990;98:1266-70.

10. Fischler MP, Kuhn M, Cantieni R, Frutiger A. Late outcome of percutaneous dilatational tracheostomy in intensive care patients. Intensive Care Med 1995;21:475-81.

11. Paul A, Marelli D, Chiu RCJ, Vestweber KH, Mulder DS. Percutaneous endoscopic tracheostomy. Ann Thorac Surg 1989;47:314-5.

12. McFarlane C, Denholm SW, Sudlow CLM, Moralee SJ, Grant IS, Lee A. Laryngotracheal stenosis: a serious complication of percutaneous tracheostomy. Anaesthesia 1994;49:38-40.

13. Wood DE, Mathisen DJ. Late complications of tracheotomy. Clin Chest Med 1991;12:597-609.

14. Kirchner JA. Avoiding problems in tracheotomy. Laryngoscope 1986;96:55-7.

15. Van Heurn LWE, van Geffen GJ, Brink PRG. Clinical experience with percutaneous dilatational tracheotomy. Eur J Surg 1996;162:531-5. 
Chapter 7

Percutaneous dilatational versus conventional open tracheotomy in a growing animal: a study in goats

L.W.E. van Heurn, A.E.J.M. van den Bogaard, G. Kootstra, P.R.G. Brink

The Journal of Pediatric Surgery 1996;31:1512-5. 


\section{Introduction}

Percutaneous dilatational tracheotomy (PDT) is a relatively new technique for the intruduction of a tracheal cannula into the tracheal lumen [1]. The trachea is punctured with a needle, and the opening dilated over a guide wire so that a cannula can be installed. The early results of this technique were good, with a low complication rate during operation and cannulation. The complication rates of this technique are comparable to or lower than those associated with conventional open tracheotomy [2-5]. It can be performed at the bedside under either general or local anaesthesia without having to transfer critically ill patients to an operating theatre $[2,4,5,6]$. Moreover, it is relatively inexpensive $[4,6]$.

Most surgeons are reluctant to use this technique in children under 16 years of age because of technical limitations, the fear of tracheal stenosis and the possibility of adverse effects on tracheal growth [7]. A recent report suggests that PDT can be used safely in teenagers [6]. This confirms our own experience, in which PDT was used successfully in three children, aged 8, 10 and 14 years [4].

To compare trachea growth after PDT and after conventional open tracheotomy we performed both procedures in goat kids and analysed the results.

\section{Materials and methods}

Fourteen male goat kids (approximate age, 10 days) were divided randomly in two groups of seven; the animals underwent either conventional open tracheotomy or PDT. They were anaesthetised with a subcutaneous injection of xylazine $0,04 \mathrm{mg} / \mathrm{kg}$, ketamine $10 \mathrm{mg} / \mathrm{kg}$ and atropine $0,1 \mathrm{mg} / \mathrm{kg}$.

In seven animals, the open conventional technique was used. A $1.5-\mathrm{cm}$ longitudinal incision through the skin was made $1 \mathrm{~cm}$ below the cricoid cartilage. The strap muscles were separated by blunt dissection. Two cartilaginous rings were incised longitudinally without removal of cartilage, and a size-2 Shiley cannula (Laméris, Veenendaal, The Netherlands) with an outer diameter of $6 \mathrm{~mm}$ was introduced into the tracheal lumen.

In seven other animals the technique described by Ciaglia was followed using a commercially available kit ( $\mathrm{Cook}^{\star}$, Son, The Netherlands) [1]. After a longitudinal skin incision of $1 \mathrm{~cm}$ the tracheal lumen was punctured between two tracheal rings with a $17-$ Gauge cannulated needle. The intraluminal position of the needle was confirmed by the suction of air into a syringe. The needle was removed and a J-tip guide wire was introduced into the tracheal lumen through the sheath. The opening in the trachea was dilated once, with an introducer catheter, so that a guiding catheter could be introduced to prevent 
kinking of the wire. The opening in the ventral wall of the trachea was dilated with 12- and 18-French lubricated tapered dilatators, and the Shiley ${ }^{\otimes}$ size-2 tracheal cannula was introduced loaded over the 12-French dilatator, which was removed afterwards. The cannulas remained in place for 7 days.

Immediately before the operation and during the duration of cannulation, all animals received daily antibiotic prophylaxis to prevent pulmonary infection (enrofloxacin $5 \%, 0.5 \mathrm{ml}$, intramuscularly, once daily), were suctioned six times per day and the air was humidified. One week after the procedure the tracheal cannulas were removed and spontaneous closure of the opening was awaited. The moment of stomal closure was noted at 8 -hourly intervals.

Three months after decannulation, the animals were killed with an intravenous injection of $4 \mathrm{ml}$ pentobarbital. Immediately after dissection the internal sagittal (AP) and internal coronal (lateral) diameters of the trachea were measured with a calibrated $0.1 \mathrm{~mm}$ accurate measuring rod at three different levels: the level of the stoma, two rings proximal to the stoma, and six rings distal to the stoma. The tracheal cross-sectional areas were calculated assuming the trachea was an ellipse. The tracheas were fixed in $3.4 \%$ formalin and were embedded in paraffin. Hematoxylin-eosin stained transverse sections were analysed microscopically.

Descriptive statistics are expressed as mean (SEM). Comparison of group characteristics was performed using the Student's $t$ and Fisher's Exact tests for continuous and categorical measures, respectively. Probability values of 0.05 or less were considered evidence a significant difference between groups.

\section{Results}

There was no significant difference between the two groups with respect to mean weight at the time of operation: $4.1(0.16) \mathrm{kg}$ for the PDT group versus $4.2(0.21) \mathrm{kg}$ for the open group $(\mathrm{p}=0.75)$. Introduction of the tracheal cannula was accomplished successfully within 10 minutes for each animal in both groups. There were no intraoperative complications.

Two animals in the PDT group died on postoperative day 1 and 2 of a plugged cannula, and one died animal on day 6 of pneumonia. One animal in the open group died of a plugged cannula on day 1. Early post-operative death did not correlate significantly with the type of surgical procedure $(p=0.56)$, but animals with a low weight at the time of surgery had a significantly higher mortality rate. Three of the four animals that weighed $3.8 \mathrm{~kg}$ or less died, compared with only one in the group that weighed more than $3.8 \mathrm{~kg}(\mathrm{p}=-$ $0.031)$.

There was no leakage of air through the previous stoma in three out of the 
four animals in the PDT group 8 hours after decannulation. In the fourth animal stomal closure was registered after 16 hours. In the open group, air leakage through the stoma stopped after 16 hours (5 animals) and 32 hours (1 ani$\mathrm{mal})(\mathrm{p}=0.038)$.

At the time of killing, the PDT and the open group were comparable with respect to weight and percentage of weight-increase : $23.0(0.4) \mathrm{kg}$ versus 21.5 $(0.9) \mathrm{kg}(\mathrm{p}=0.17)$ and $433 \%(34 \%)$ versus $422 \%(15 \%)(\mathrm{p}=0.78)$, respectively. Comparing the PDT and the open groups, the mean internal sagittal diameter, $9.1(0.8) \mathrm{mm}$ versus $8.8(0.6) \mathrm{mm}(\mathrm{p}=0.73)$, the mean internal coronal diameter, $8.1(0.1) \mathrm{mm}$ versus $8.5(0.4) \mathrm{mm}(\mathrm{p}=0.31)$, and the mean crosssectional area, $58(5) \mathrm{mm}^{2}$ vs. $59(6) \mathrm{mm}^{2}$, of the remainder of the trachea did not differ.

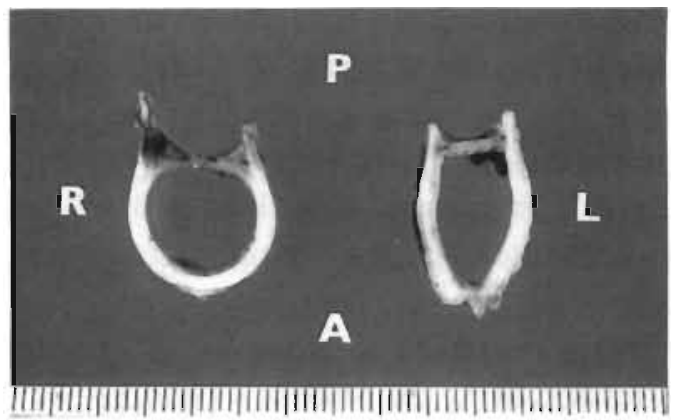

Figure 1. Macroscopical specimen of the distal trachea and the trachea at the stomal site from an animal after conventional open tracheotomy, showing distortion of the tracheal ring at the level of the stoma. a: anterior, p: posterior, r: right, l: left.

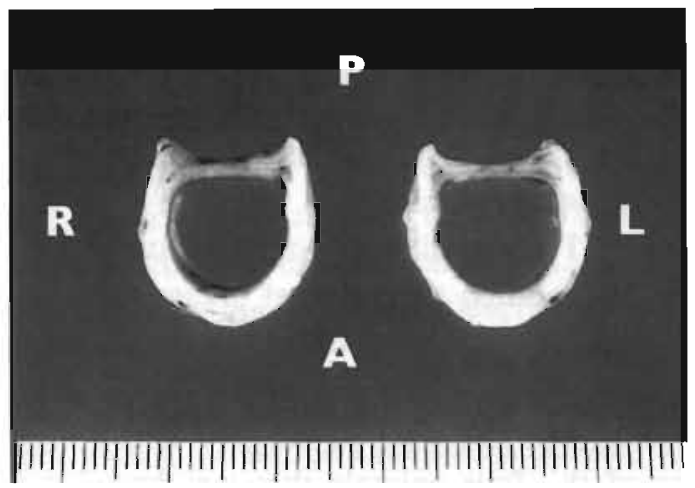

Figure 2. Macroscopical specimen of the distal trachea and the trachea at the stomal site after percutaneous dilatational tracheotomy (PDT), without macroscopical changes of the cartilage. a: anterior, $p$ : posterior, $r$ : right, l: left. 
In the open group, the sagittal diameter at the level of the stoma was increased compared to the remainder of the trachea, with a reduction of the coronal diameter and a loss of the anterior concavity. The cross-sectional area at the level of the stoma was reduced in all six animals ranging from 24 to $40 \%$. In the PDT group, no changes in tracheal measurements were found at the level of the stoma compared to the remainder of the trachea. Differences between the open group and the PDT group are shown in Figures 1 and 2 and listed in Table 1.

Table 1. The mean (SEM) sagittal diameter, coronal (lateral) diameter and cross-sectional area of the trachea at the level of the tracheotomy and the reduction of the cross-sectional area compared with the distal trachea in goats after percutaneous dilatational tracheotomy (PDT) and conventional open tracheotomy, respectively.

$$
\text { PDT }(n=4) \quad \text { Open }(n=6) \quad \text { P-value }
$$

\begin{tabular}{lccr}
\hline Sagittal diameter $(\mathrm{mm})$ & $9.1(0.8)$ & $11.2(0.6)$ & 0.078 \\
Coronal diameter $(\mathrm{mm})$ & $8.1(0.1)$ & $4.7(0.2)$ & $<0.001$ \\
Cross-sectional area $\left(\mathrm{mm}^{2}\right)$ & $58(4.6)$ & $41(3.0)$ & 0.023 \\
Reduction cross-sect. area $(\%)$ & 0 & $30(2.6)$ & $<0.001$ \\
\hline
\end{tabular}

Histological analysis showed a reactive deformity of the tracheal cartilage with proliferation and rounding off of the edges at the level of the stoma in the open group. Both anterior ends of the incised cartilage were connected by fibrous tissue; the epithelium was normal (Figure 3). In the PDT group there were no epithelial, stromal, or cartilaginous changes.

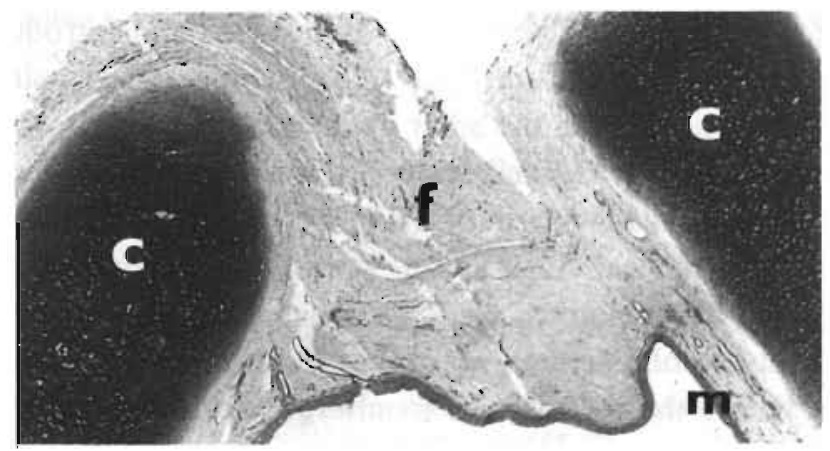

Figure 3. Microscopical section of the trachea after conventional open tracheotomy showing nonunion of cartilage (hematoxylin-eosin, original $x 40$ ).

c: cartilage, f: fibrous tissue, $m$ : mucosa. 


\section{Discussion}

Sanctorius was the first to describe percutaneous tracheotomy in the Renaissance period [8]. He used a trocar for the introduction of a tracheal cannula. One century later, Gerard van Swieten of Leyden, personal physician of Empress Maria Theresia of Austria, used this technique in living animals, but he considered it to be too dangerous for usage in humans as long as the instruments available were not improved [9]. Only a decade ago Ciaglia introduced percutaneous dilatational tracheotomy, and since then percutaneous tracheotomy gained increased popularity [1].

A wide variety of conventional techniques of tracheotomy are used. For the pediatric age group most investigators advocate a longitudinal incision of the trachea [10-13]. Others prefer a Björk or modified Björk flap, but the vascularisation of the flap may become compromised with subsequent risk of tracheal stenosis [14-16]. PDT does not require a tracheal incision, and the cannula is introduced between two tracheal rings. Mendez-Picon et al. used longitudinal and horizontal incisions of the trachea in puppies and showed that horizontal incisions healed with less scarring and less narrowing of the tracheal lumen [17].

In the present study, it was easy to perform PDT in all animals. The superficial position of the trachea and the long neck in goats facilitate the procedure. The 17-Gauge cannulated needle on the $\left(\mathrm{Cook}^{(}\right)$set is relatively large for $4 \mathrm{~kg}$ animals. Puncturing the deeper lying trachea in neonates and infants with the same sized needle may prove difficult. In these patients a smaller needle and thus a smaller guide wire should be used. Endoscopic guided PDT may prove helpful to confirm the intraluminal position of the needle and may prevent damage to the posterior tracheal wall and creation of a false tract [18]. In our study dilatation of the trachea and introduction of the cannula were carried out without difficulty. The young and growing trachea is more compliant and pliable than the adult trachea and dilatation was easier than in most adult patients in whom firm pressure is often required.

Relatively large cannulas with an outer diameter of $6 \mathrm{~mm}$ were used to exert firm pressure on the tracheal rings and to prevent the animals from breathing around the cannula. Although they were suctioned six times per day and the air was humidified, three animals died of a plugged cannula. This complication is hardly to avoid unless the animals are monitored continuously. In infants and children, this is also one of the most frequent and lethal complications of tracheotomy [19-21].

The incidence of functional tracheal stenosis in paediatric tracheotomy varies from $0 \%$ to $12 \%[13,16,22]$. A decrease of the cross-sectional area of 
the trachea up to $50 \%$ usually is symptomless, but an abnormal and narrowed trachea might play a role in the incidence of respiratory infection $[17,23]$. The effect of a tracheotomy incision is subject to considerable discussion, but data on the growing trachea are scanty [16]. In the present study, there was a consistent reduction of the cross-sectional area at the level of the stoma after open tracheotomy. The sagittal diameter was increased, there was narrowing of the coronal diameter, and loss of the anterior concavity of the trachea. Similar findings have been reported by others, after a longitudinal incision into the trachea in puppy dogs and after incision of the cricoid cartilage in rabbits $[14,17,24,25]$. Interruption of cartilage with release of interlocked stresses in the cartilage may contribute to the development of deformities of the tracheal rings $[24,25]$. The anterior parts of the incised cartilaginous rings were separated by fibrous tissue. This may result in a functional type of obstruction in which the trachea narrows and collapses, particularly at maximum respiratory effort. After PDT, no damage of cartilaginous rings was found and the inner contour of the tracheal lumen was smooth.

In our experimental work in goats, PDT performed compared favourably with open conventional tracheotomy with respect to the development of tracheal stenosis. Therefore, we conclude that it is unlikely that PDT in children would be associated with an increased risk of tracheal stenosis and adverse effects on tracheal growth. Further studies in children are necessary to determine whether there is a lowest age for safe performance.

\section{References}

1. Ciaglia P, Firsching R, Syniec C. Elective percutaneous dilatational tracheostomy: a new simple bedside procedure; preliminary report. Chest 1985;87:715-9.

2. Hazard $\mathbf{P}$, Jones $\mathbf{C}$, Benitone J. Comparative clinical trial of standard operative tracheostomy with percutaneous tracheostomy. Crit Care Med 1991;19:1018-24.

3. Ciaglia P, Graniero KD. Percutaneous dilatational tracheostomy. Results and long-term follow-up. Chest 1992;101:464-7.

4. Van Heurn LWE, van Geffen GJ, Brink PRG. Clinical experience with percutaneous dilational tracheostomy. Eur J Surg (in press).

5. Friedman Y, Mayer AD. Bedside percutaneous tracheostomy in critically ill patients. Chest $1993 ; 104: 352-5$.

6. Toursarkissian B, Fowler CL, Zweng TN, et al. Percutaneous dilational tracheostomy in children and teenagers. J Pediatr Surg 1994;29:1421-4.

7. Anderson HL, Bartlett RH. Elective tracheotomy for mechanical ventilation by the percutaneous technique. Clin Chest Med 1991;12:555-60.

8. Sanctorius $\mathrm{S}$. Commentaria in primam ten primi libri canonis Avicennae. Venetiis: Iacobum Sarcinam, 1626.

9. Van Swieten G. Commentaria in Hermanni Boerhaave aphorismos de cognoscendis et curandis morbis 3rd ed. Lugdunum Batavorum: Sam. et Joh. Luchtmans, 1785. 
10. Aberdeen E, Downes JJ. Artificial airways in children. Surg Clin North Am 1974;54:1155-70.

11. Johnson DG, Jones R. Surgical aspects of airway management in infants and children. Surg Clin North Am 1976;56:263-79.

12. Perotta RJ, Schley WS. Pediatric tracheotomy. A five-year comparison study. Arch Otolaryngol 1978;104:318-21.

13. Rodgers BM, Rooks JJ, Talbert JL. Pediatric tracheostomy: long-term evaluation. J Pediatr Surg 1979;14:258-63.

14. Lulenski GC, Batsakis JG. Tracheal incision as a contributing factor to tracheal stenosis. An experimental study. Ann Otol 1975;84:781-6.

15. Salassa JR, Pearson BW, Payne WS. Gross and microscopical blood supply of the trachea. Ann Thorac Surg 1977;24:100-7.

I6. Gilmore BB, Mickelson SA. Pediatric tracheotomy. Controversies in management. Otolaryngol Clin North Am 1986;19:141-51.

17. Mendez-Picon G, Ehrlich FE, Salzberg AM. The effect of tracheostomy incisions on tracheal growth. J Pediatr Surg 1976;11:681-5.

18. Paul A, Marelli D, Chiu RCJ, et al. Percutaneous endoscopic tracheostomy. Ann Thorac Surg 1989;47:314-5.

19. Tucker JA, Silberman HD. Tracheotomy in pediatrics. Ann Otol 1972;81:818-24.

20. Hawkins DB, Williams EH. Tracheostomy in infants and young children. Laryngoscope 1976;86:331-40.

21. Crysdale WS, Feldman RI, Naito K. Tracheotomies: a 10-year experience in 319 children. Ann Otol Rhinol Laryngol 1988;97:439-43.

22. Westgate HD, Roux KL. Tracheal stenosis following tracheostomy: incidence and predisposing factors. Anesth Analg 1970;49:393-401.

23. Tommerup B, Borgeskov S. Endoscopic evaluation at follow-up after Björk tracheostoma. Scand J Thorac Cardiovasc Surg 1983;17:181-4.

24. Verwoerd CDA, Bean JK, Adriaansen FCPM, Verwoerd-Verhoef HL. Trauma of the cricoid and interlocked stress. Acta Otolaryngol (Stockh) 1991;111:403-9.

25. Bean JK, Verwoerd-Verhoef HL, Verwoerd CDA. Intrinsic and extrinsic factors relevant to the morphology of the growing cricnid ring after a combined anterior and posterior cricoid split: an experimental study in rahhits. Int J Pediatr Otorhinolaryngol 1994;29:12937. 
Chapter 8

\section{A complication of percutaneous dilatational tracheotomy: mediastinal emphysema}

L.W.E. van Heurn, R.J.T.J. Welten, P.R.G. Brink

Anaesthesia 1996;51:605 
We wish to report a previously unreported complication of percutaneous dilatational tracheotomy (PDT). A 24-year-old, $53 \mathrm{~kg}$ and $151 \mathrm{~cm}$, mentally retarded woman developed severe adult respiratory distress syndrome (ARDS) after a car accident and required mechanical ventilation for which her trachea was orotracheally intubated. After six days a tracheotomy was performed. Ventilation was continued with $14 \mathrm{~cm}$ PEEP and an $\mathrm{FiO}_{2}$ of 0.65 .

PDT was performed using Ciaglia's technique and a Shiley ${ }^{\star}-8$ tracheal cannula was inserted without obvious intraoperative complications [1]. The trachea was punctured once and there were no signs of posterior wall damage.

Immediately after PDT mediastinal emphysema was seen on the chest $\mathrm{X}$-ray (Figure 1). Fibreoptic tracheo-bronchoscopy excluded lesions of the trachea and the bronchi. The mediastinal emphysema resolved spontaneously in three days.

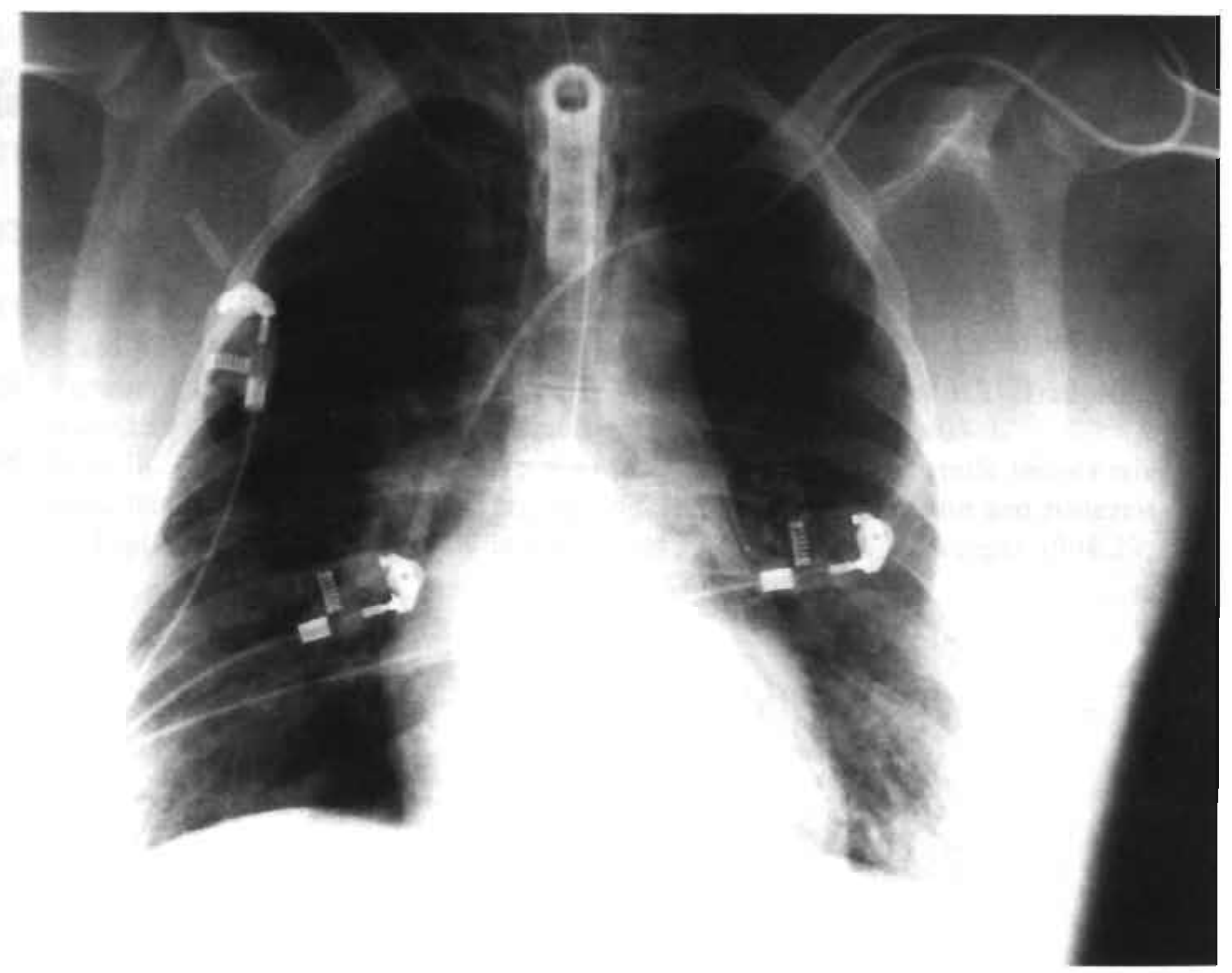

Figure 1. A chest X-ray showing a large cannula in comparison with the tracheal diameter and mediastinal emphysema after percutaneous dilatational tracheotomy. 
A small risk of mediastinal emphysema exists following PDT. It is a blind technique and it is not possible to estimate the tracheal diameter during operation. An adult sized cannula may be too large for small adults and may tear the intercartilaginous tissue, causing mediastinal emphysema. Progression of lesions of the proximal trachea is prevented by inflating the cannula cuff.

Mediastinal emphysema has been described after percutaneous tracheotomy with a Rapitrac ${ }^{\infty}$ dilatator when the sharp-tipped dilatator lacerated the posterior tracheal wall [2].

Lesions of the distal trachea and bronchi can be avoided by the use of a J-tip guide wire and blunt tapered dilatators.

In this case, mediastinal emphysema developed during the cannulation procedure. After completing the dilatational steps, we leave the largest dilatator in situ when we load the cannula over the appropriate dilatator to minimise stomal blood loss into the trachea and to prevent loss of ventilation. Any air leak around the tapered end of the dilatator, which does not fully occlude the opening in the tracheal wall itself but which is snugged between pretracheal tissue, may dissect into the mediastinum due to high ventilatory pressures. Together with torn intercartilaginous tissue due to the large cannula, this may be responsible for the mediastinal emphysema in this patient.

High ventilatory pressure is one of the risk factors for the development of mediastinal emphysema. Other complications of PDT, such as stomal haemorrhage into the airways, loss of ventilatory pressure with pulmonary atclectasis and pneumothorax are easily controlled in a normal situation, but may cause severe hypoxia and even death in patients with maximum ventilatory support. Therefore, we think that PDT should not be done in patients requiring ventilation with a high $\mathrm{FiO}_{2}$ or high PEEP.

\section{References}

1. Ciaglia P, Firsching R, Syniec C. Elective percutaneous tracheostomy: a new simple bedside procedure; preliminary report. Chest 1985;87:715-9.

2. Hutchinson R, Mitchell RD. Life threatening complications from percutaneous dilatational tracheostomy. Intensive Care Med 1991;19:118-20. 


\section{Summary and conclusions}

Percutaneous dilatational tracheotomy (PDT) is a procedure for inserting a cannula into the tracheal lumen without a large incision, without extensive dissection of pretracheal tissue and without exposure of the trachea. It was introduced in 1985 with excellent preliminary results.

The objective of the thesis was to analyse the early and late results of PDT and the smaller minitracheotomy.

Chapter 1 gives a short review of the anatomy of the trachea. The PDT technique is described with the indications for tracheotomy. The early and late complications of the technique are discussed with the emphasis on how these complications should be avoided. The results of PDT are compared to open conventional tracheotomy as well as a short comparison with other percutaneous tracheotomy techniques is made.

Chapter 2 gives an overview of the history of tracheotomy. The procedure was probably used by the Romans, although the first actual case report dates from 1546, when Brasavola inserted a tracheal cannula in a patient who nearly suffocated. Almost one century later, Sanctorius described percutaneous tracheotomy. Only in the 19th century tracheotomy did become a common surgical procedure after it had been popularised by Trousseau. Nowadays, the indications for tracheotomy have widened and it is still an operation that is performed frequently.

Chapter 3 reports on the early results of PDT in 147 consecutive patients. The success rate of the procedure was $99 \%$. Operative complications occurred in $11 \%$ and were usually minor. During a total duration of cannulation of 5212 days four complications were recorded. Haemorrhage was the most frequent early complication (14 patients).

Chapter 4 describes the results of percutaneous subcricoid minitracheotomy in 50 patients. This technique proved to be easy both with local anaesthesia and under general anaesthesia in translaryngeally intubated patients. Operative complications occurred in five patients $(10 \%)$, which all were minor. The pros and cons of minitracheotomy in the subcricoid position are discussed.

Chapter 5 gives an estimation of the incidence of late complications of PDT. Sixty-six consecutive patients were followed-up three to 39 months after decannulation. Tracheal narrowing of more than $10 \%$, assessed with tomo- 
graphy of the trachea, was present in $14(26 \%)$ of 54 patients. It was related to the operating surgeon $(p=0.03)$. Voice changes, found in $13(21 \%)$ of 61 patients, were minor in 12. Retraction of the tracheotomy scar, seen in $13(19 \%)$ of 66 patients, was related to the duration of cannulation $(p=0.002)$. A tracheocutaneous fistula was present in two patients.

Chapter 6 shows in a pathological study that the cannulation site of the trachea varied from just below the cricoid cartilage to below the third ring. At autopsy, a fracture of one or more tracheal rings was present in $11(92 \%)$ of 12 patients, of whom 2 had a fractured cricoid. Destruction of one or more tracheal rings was present in all 8 patients cannulated for more than 10 days and was related to duration of cannulation $(p<0.005)$. Protrusion of the anterior wall into the tracheal lumen with tracheal stenosis was seen in two patients.

Chapter 7 discusses growth of the trachea in goat kids after PDT and conventional tracheotomy, respectively. The tracheas of animals, who had been cannulated for 7 days, were analysed three months after decannulation. The coronal (lateral) diameter and the cross-sectional area at the level of the stoma were significantly smaller in the conventional group $(p<0.001$ and $p=0.023$, respectively). The quotient of the stomal cross-sectional area and the normal cross-sectional area showed a reduction of $24 \%$ to $40 \%$ after conventional tracheotomy without any reduction after PDT $(\mathrm{p}<0.001)$.

Chapter 8 describes a patient with mediastinal emphysema as a complication of PDT. The genesis of this complication is discussed.

PDT proves to be a valuable technique for inserting a cannula into the tracheal lumen. It is relatively easy to learn and can be carried out at the patient's bedside. The mortality of the procedure is below $0,5 \%$ and the early complication rate is low with significantly less early complications than with the conventional technique.

The late complications of the technique are usually minor. The incidence of tracheal stenosis of PDT compares favourably to historical experiences with open conventional tracheotomy. Avoiding oblique introduction of the cannula may decrease the incidence of this complication even further. The clinical relevance of fractures of the cartilaginous rings, as seen in most patients after PDT, is probably minimal, unless an oblique position of the cannula fractures the ring above the site of entry with indentation of the anterior tracheal wall. Also, high insertion of the cannula between the cricoid and the first tracheal ring with the risk of cricoid damage should be avoided. Further studies are 
necessary to make a more reliable comparison with the late complications of conventional tracheotomy.

Generally accepted contraindications for PDT include bleeding disorders and coagulopathy, goitre and extreme obesity, age below 16 years, and cardiopulmonary instability. Bleeding and clotting disorders can usually be corrected before the procedure. Endoscopic or ultrasound guidance makes percutaneous introduction of a tracheal cannula possible in patients with anatomical difficulty. In goat kids, PDT compares favourably with conventional open tracheotomy and therefore it is unlikely that PDT forms an increased risk of tracheal stenosis and adverse effects on tracheal growth. However, clinical studies are necessary to determine whether there is a lowest age for safe performance. Cardiopulmonary instability remains a contraindication for PDT. Minor complications may cause severe hypoxia and death in patients with maximum ventilatory support. Further clinical experience with the technique will make clear in which patients PDT can be used safely.

Percutaneous subcricoid minitracheotomy shows a similar early complication rate as PDT. The smaller minitracheotomy cannula can be introduced safely below the cricoid cartilage. This position of the cannula has advantages over a cannula through the cricothyroid membrane with good preservation of the normal glottic function and a minimal risk of subglottic stenosis. Also, it is possible to convert a minitracheotomy to a larger subcricoid cannula, if required. However, to compare percutaneous subcricoid minitracheotomy with a cannula through the cricoid membrane, a prospective randomised trial is necessary. 


\section{Samenvatting en conclusies}

Percutane dilatatie tracheotomie (PDT) is een operatie om een canule in de trachea te brengen, zonder grote incisie, zonder uitgebreide dissectie van pretracheaal weefsel en zonder dat de trachea in het zicht komt. Deze techniek werd in 1985 geïntroduceerd met zeer goede voorlopige resultaten.

Het doel van de dissertatie is om de vroege en late resultaten te analyseren van PDT en de kleinere percutane minitracheotomie.

Hoofdstuk 1 geeft een kort overzicht van de anatomie van de trachea. De PDT techniek wordt beschreven met de indicatie voor tracheotomie. De vroege en late complicaties van de techniek worden besproken, met name hoe deze complicaties kunnen worden vermeden. De resultaten van PDT worden vergeleken met conventionele open tracheotomie en ook met andere percutane tracheotomie technieken.

Hoofdstuk 2 geeft een overzicht van de geschiedenis van de tracheotomie. De operatie werd waarschijnlijk reeds gedaan door de Romeinen. De eerste feitelijke beschrijving dateert van 1546, toen Brasavola een trachea canule inbracht bij een patiënt die bijna stikte. Een eeuw later beschreef Sanctorius de percutane tracheotomie. Pas in de $19 \mathrm{e}$ eeuw werd de tracheotomie een algemeen uitgevoerde operatie, nadat ze was ingevoerd door Trousseau. Tegenwoordig zijn de indicaties voor tracheotomie uitgebreid en is de tracheotomie nog steeds een frequent verrichte operatie.

Hoofdstuk 3 beschrijft de vroege resultaten van PDT bij 147 achtereenvolgende patiënten. De operatie was succesvol bij $99 \%$. Operatieve complicaties waren er bij $11 \%$ van de patiënten en waren in het algemeen gering. Gedurende een totale canulatie duur van 5212 dagen werden vier complicaties geregistreerd. Bloeding was de meest algemene vroege complicatie (14 patiënten).

Hoofdstuk 4 is gewijd aan de resultaten van de minitracheotomie onder het cricoid bij 50 patiënten. Deze techniek was gemakkelijk uitvoerbaar zowel met lokale anesthesie als onder algehele anesthesie bij oraal geïntubeerde patiënten. Operatieve complicaties bij vijf patiënten (10\%) waren gering. De voor- en nadelen van de minitracheotomie onder het cricoid worden behandeld.

Hoofdstuk 5 geeft een schatting van de incidentie van de late complicaties van PDT. Zesenzestig opeenvolgende patiënten werden onderzocht, drie tot 39 maanden na decanulatie. Vernauwing van de trachea van meer dan $10 \%$, 
vastgesteld met planigrafie van de trachea, was aanwezig bij $14(26 \%)$ van 54 patiënten. Deze complicatie was gerelateerd aan de operateur $(p=0,03)$. Stem veranderingen, aanwezig bij $13(21 \%)$ van 61 patiënten, waren gering bij 12 patiënten. Retractie van het tracheotomie litteken, gezien bij $13(19 \%)$ van 66 patiënten, had een relatie met de canulatie duur $(p=0,002)$. Een tracheocutane fistel werd bij twee patiënten gevonden.

Hoofdstuk 6 laat in een pathologisch onderzoek zien dat de canulatie plaats bij PDT varieert van juist onder het cricoid tot onder de derde trachea ring. Bij obductie was er een fractuur van een of meer kraakbeen ringen bij 11 (92\%) van de 12 patiënten, waarbij twee een fractuur van het cricoid hadden. Destructie van één of meer ringen werd gevonden bij acht patiënten met een canulatie duur van meer dan tien dagen en was gerelateerd aan de canulatie duur $(\mathrm{p}<0,005)$. Protrusie van de voorste tracheawand in het lumen met trachea stenose werd gezien bij twee patiënten.

Hoofdstuk 7 beschouwt de groei van de trachea bij jonge geiten na respectievelijk PDT en conventionele tracheotomie. De tracheas van de dieren, die 7 dagen gecanuleerd waren geweest, werden drie maanden na decanulatie bekeken. De laterale diameter en het oppervlak van de dwarsdoorsnede ter hoogte van het stoma waren significant kleiner in de conventionele groep $(p<0,001$, respectievelijk $\mathrm{p}=0,023$ ). Het quotiënt van de dwarsdoorsnede ter hoogte van het stoma en de dwarsdoorsnede van de rest van de trachea gaf een reductie van $24 \%$ tot $40 \%$ in de conventionele groep, terwijl er geen reductie werd gezien na PDT $(\mathrm{p}<0,001)$.

Hoofdstuk 8 beschrijft een patiënt met mediastinaal emfyseem na PDT. De genese van deze complicatie wordt beschreven.

PDT heeft bewezen een waardevolle techniek te zijn om een canule in de trachea te brengen. Het is relatief eenvoudig om te leren en kan gedaan worden aan het bed van de patiënt. De mortaliteit van de operatie is minder dan $0,5 \%$ en de vroege complicatie ratio is laag met significant minder complicaties dan bij de conventionele open techniek.

De late complicaties van de techniek zijn meestal gering. De late complicatie ratio van PDT is gunstig vergeleken met vroegere studies naar de conventionele open tracheotomie. Het vermijden van schuine introductie van de trachea canule vermindert de incidentie van deze complicatie mogelijk nog verder. De klinische relevantie van gebroken kraakbeenringen, welke bij de meeste patiënten na PDT wordt gezien, is waarschijnlijk gering, tenzij een 
schuin ingebrachte canule de ring boven de introductie plats breckt met indeuking van de voorste tracheawand. Ook moet het houg inbrengen van een trachea canule tussen het cricoid en de eerste trachea ring met het risico op schade van het cricoid vermeden worden. Verdere studies zijn noodzakelijk om een betrouwbaarder vergelijking met de late complicaties van de conventionele tracheotomie te kunnen maken.

Algemeen geaccepteerde contraïndicaties voor PDT zijn bloedings- en stollingsstoornissen, struma en extreme adipositas, leeftijd lager dan 16 jaar en cardiopulmonale instabiliteit. Bloedings- en stollingsstoornissen, welke een grotere kans op operatieve bloeding geven, kunnen veelal voor de ingreep worden gecorrigeerd. Endoscopie en echografie maken percutane introductie van een tracheacanule mogelijk bij patiënten met een ongunstige anatonie. Bij jonge geiten heeft PDT voordelen ten opzichte van de conventionele techniek en daardoor is het onwaarschijnlijk dat PDT een hogere kans geeft op tracheastenose en op groeistoornissen van de trachea. Er zijn echter klinische studies nodig om vast te stellen of er een leeftijdsgrens is waarbij PDT veilig kan worden gebruikt. Cardiopulmonale instabiliteit blijft tot nu toe een contraindicatie voor PDT. Geringe complicaties kunnen bij patiënten met maximale ventilatoire ondersteuning ernstige hypoxie en zelfs de dood veroorzaken. Verdere ervaringen met deze techniek zullen in de toekomst duidelijk maken bij welke patiënten PDT veilig kan worden gebruikt.

Percutane minitracheotomie onder het cricoid heeft een vergelijkbare complicatie ratio als PDT. De kleinere minicanule kan veilig onder het cricoid worden ingebracht. Deze positie heeft voordelen boven een canule door de membrana cricothyreoidea met een goed preservatie van de functie van de glottis en een geringe kans op subglottis stenose. Verder is het mogelijk een minitracheotomie te vervangen door een grotere canule, wanneer dit nodig is. Om percutane minitracheotomie onder het cricoid te vergelijken met een canule door de membrana cricothyreoidea is echter een prospectief gerandomiseerd onderzoek nodig. 


\section{Acknowledgements}

Luck is one of the most important factors for finishing a thesis: being at the right place at the right time and working with the right people.

A large number of patients required a tracheotomy at the 'De Wever Hospital' during the study period. Many of these patients were willing to come back to the hospital for further examination and investigation, although they knew they would not benefit from it. "Maybe it will help other people:" was their motivation. I am very grateful to them.

Frans Slangen, Joyce Suyk, and Ton van den Bogaard helped me to care for the baby-goats and I am certain that many more of them had died without their help.

Henk Blezer preparated the trachea's of those people who died with a tracheal cannula and Harry Houben made excellent microscopical sections.

Geert-Jan van Geffen was a pit-bull doing donkey-work and he is credited for the complete follow-up of the retrospective studies.

Paul Theunissen and Reginald Goei assisted with the pathological and radiological studies. Their advise and enthusiasm is highly appreciated.

Gauke Kootstra is greatly appreciated for the various improvements on the thesis, not only on the animal study. His remark at the beginning of my surgical training that you can not write a thesis and do a full time surgical training job at the same time was particularly stimulating.

The combination of an intensive care specialist and a surgeon makes Graham Ramsay the ideal co-promotor. I have enjoyed the sharp and polite British way he has commented on several parts of the studies.

I am very grateful to Peter Brink. He gave me the opportunity to study this technique that he had introduced into the Netherlands. Despite is enthusiasm for this thesis, he allowed me to prepare it my way. His optimism and confidence that I would finish this thesis, made him spend much of his time on my surgical training to make me a better doctor and surgeon.

Now this thesis has been finished, I am happy that Lonneke and 'baby' will show me that there are more important things than writing a thesis. 


\section{Curriculum vitae}

Ernest van Heurn was born in Haarlem on May 30, 1961. He graduated from grammar school (Stedelijk Gymnasium, Haarlem) in 1979 and took the propaedeuse degree in biology in 1980. From 1980 to 1988 he attended medical school in Leiden. During his medical training he was student assistant at the departments of anatomy and physiology and he worked at the surgical and transplantation unit of Papworth Hospital, Cambridge, England (Sir Terence English).

After graduation from medical school he was surgical resident (the St. Antoniushove Hospital, Leidschendam, Dr. H. Wamsteker and the Bergweg Hospital, Rotterdam, Dr. J.W. Merkelbach), and resident in cardiothoracic surgery at the Antonius Hospital in Nieuwegein (F.E.E. Vermeulen) and at the Hospital for Sick Children, Great Ormond Street, London, England (Mr. J. Stark, Mr. M.R. de Leval, Mr. M. Elliott).

In 1992 he started his surgical training at the Wever Hospital in Heerlen (Dr. P.R.G. Brink). Presently he is performing the second part of his training at the surgical unit of the University Hospital of Maastricht (Prof. Dr. G. Kootstra). 


\section{List of publications}

1. Gooszen HG, Schmidt JM, van Heurn LWE, Jansen JBMJ, Lamers CBHW, Terpstra JL. Surgical treatment for pain relief in chronic pancreatitis. Scand J Gastroenterol $1988 ; 23$ (suppl 154):98-102

2. Van Heurn LWE, Varekamp AP. A rare case of iliac vein obstruction: pelvic lipomatosis. Neth J Surg 1990;42:58-60

3. Van Heurn LWE, English TAH. Medium-term durability of porcine bioprosthetic valves. Thorac Cardiovasc Surg 1991;39:32-5.

4. Van Heurn LWE, Hamerlijnck RPHM, Brutel de la Rivière A, Suttorp MJ, Ernst JMPG, Vermeulen FEE. Combined traumatic avulsion of the aortic valve and rupture of the left common carotid artery. Ann Thorac Surg 1992;53:187-8.

5. Van Heurn LWE, Hamerlijnck RPHM, Brutel de la Rivière A, Vermeulen FEE. Stomp thoraxtrauma met letsel van hart en grote vaten. Ned Tijdschr Geneeskd 1992;136:10289.

6. Van Heurn LWE, Martin IR, Elliott MJ, Wallwork J, de Leval MR. Gecombineerde hartlongtransplantatie bij kinderen: 4 jaar ervaring in Londen. Ned Tijdschr Geneeskd 1993;137:547-9.

7. Van Heurn LWE, Wong CM, Spiegelhalter DJ, Sorensen K, de Leval MR, Stark J, Elliott MJ. Surgical treatment of aortic coarctation in infants younger than three months: 1985 to 1990. Success of extended end-to-end aortoplasty. J Thorac Cardiovase Surg 1994; 107:74-86.

8. Van Heurn LWE, van Geffen GJ, Brink PRG. Percutaneous subcricoid minitracheostomy. Ann Thurac Surg 1995;59:707-9.

9. Van Heura LWE, Brink PRG. Prospective randomized trial of high versus low vacuum drainage after axillary lymphadenectomy. Br J Surg 1995;82:931-2.

10. Brink PRG, van Heurn LWE, van Geffen GJ. De percutane punctie en dilatatie techniek als vervanging van de tracheotomie. Ned Tijdschr Geneeskd 1995;139:837-40.

11. Van Heurn LWE, Brink PRG, Kootstra G. De geschiedenis van de tracheotomie. Ned Tijdschr Geneeskd 1995;139:2674-8.

12. Van Heurn LWE, van Geffen GJ, Brink PRG. Clinical experience with percutaneous dilatational tracheotomy. Eur J Surg 1996;162:531-5.

13. Van Heurn LWE, Theunissen PHMH, Ramsay G, Brink PRG. Pathologic changes of the trachea after percutaneous dilatational tracheotomy. Chest 1996;109:1466-9.

14. Van Heurn LWE, van den Bogaard AEJM, Kootstra G, Brink PRG. Percutaneous dilatational versus open tracheotomy in a growing animal: a study in goats. J Ped Surg $1996 ; 31: 1512-5$.

15. Van Heurn LWE, Welten RJTJ, Brink PRG. A complication of percutaneous dilatational tracheostomy: mediastinal emphysema. Anaesthesia 1996;51:605.

16. Van Heurn LWE, Brink PRG. The history of percutaneous tracheotomy. J Laryngol Otol 1996;110:732-6.

17. Van Heurn LWE, Goei R, de Ploeg 1, Ramsay G, Brink PRG. Late complications of percutaneous dilatational tracheotomy. Chest 1996;110:1572-6.

18. Van Heurn L,WE, Brink PRG, Ramsay G. Percutaneous dilatational tracheotomy. In Vincent JL (ed). Yearbook of intensive care and emergency medicine. Springer. 1997. (in press).

19. Van Heurn LWE, Theunissen PHMH, Ramsay G, Brink PRG. Pathologic changes of the trachea after percutaneous dilatational tracheotomy (letter to the editor). Chest (in press). 
